\title{
Methane Adsorption on Heteroatom-Modified Maquettes of Porous Carbon Surfaces
}

\author{
Rylan Rowsey, ${ }^{1}$ Erin E. Taylor, ${ }^{1}$ Stephan Irle, ${ }^{2}$ Nicholas P. Stadie, ${ }^{1 *}$ and Robert K. Szilagyi ${ }^{1 *}$ \\ 1Department of Chemistry \& Biochemistry, Montana State University, Bozeman, Montana, 59717, \\ United States
}

${ }^{2}$ Computational Sciences \& Engineering Division, Oak Ridge National Laboratory, Oak Ridge, Tennessee, 37831, United States

*Corresponding authors: nstadie@montana.edu and szilagyi@montana.edu

\begin{abstract}
Experimental studies and theoretical models presently disagree on methane adsorption energetics on carbon materials that include crystalline graphene-like structures to amorphous materials with or without significant edge structure. However, this information is critical for the rational design and optimization of the structure and composition of adsorbents for natural gas storage. The delicate nature of the interactions inherent to methane physisorption, such as dispersion interactions, polarization of both the adsorbent and the adsorbate, interplay between $\mathrm{H}$ bonding and tetrel bonding, and induced dipole/Coulomb interactions, requires computational treatment at the highest possible level of theory while remaining non-prohibitive in terms of computational cost. In this study, we employ the smallest reasonable computational model, a maquette, of porous carbon surfaces with a central atomic binding site for substitution. The most accurate predictions of the methane adsorption energetics were achieved by electron-correlated molecular orbital theory (CCSD(T)) and hybrid density functional theory (MN15) calculations, both employing a saturated all-electron basis set. The characteristic geometry of methane adsorption on a carbon surface was likened to a "lander" position over the ring centers of the adsorbent. This adsorbate/adsorbent arrangement arises due to bonding interactions of the adsorbent $\pi$-system with the proximal $\mathrm{H}-\mathrm{C}$ bonds of methane, in addition to tetrel bonding between the antibonding orbital of the distal $\mathrm{C}-\mathrm{H}$ bond and the central atom of the maquette $(\mathrm{C}, \mathrm{B}, \mathrm{or} \mathrm{N})$. The polarization of the electron density as well as structural deformations in both the adsorbate and adsorbent molecules clearly indicate a $\sim 3 \mathrm{~kJ} \mathrm{~mol}^{-1}$ preference for methane binding on the N-substituted maquette. In this study, the B-substituted maquette showed a comparable or lower binding energy than the unsubstituted, pure $\mathrm{C}$ model, depending on the level of theory employed. The calculated thermodynamic results indicate an unambiguous guiding strategy toward incorporating electronenriched substitutions (e.g., N) in carbon materials as a way to increase methane storage capacity over electron deficient (e.g., B) modifications. The thermochemical calculation methodologies were critically evaluated in order to establish a conceptual agreement between the experimental isosteric heat of adsorption and the binding enthalpies/free energies from statistical thermodynamics principles.
\end{abstract}

\footnotetext{
${ }^{+}$This manuscript has been co-authored by UT-Battelle, LLC under Contract No. DE- AC05-000R22725 with the U.S. Department of Energy. The United States Government retains and the publisher, by accepting the article for publication, acknowledges that the United States Government retains a non-exclusive, paid- up, irrevocable, world-wide license to publish or reproduce the published form of this manuscript, or allow others to do so, for United States Government purposes. The Department of Energy will provide public access to these results of federally sponsored research in accordance with the DOE Public Access Plan (http://energy.gov/downloads/doe-public-access-plan).
} 


\section{Graphical Table of Contents Figure:}

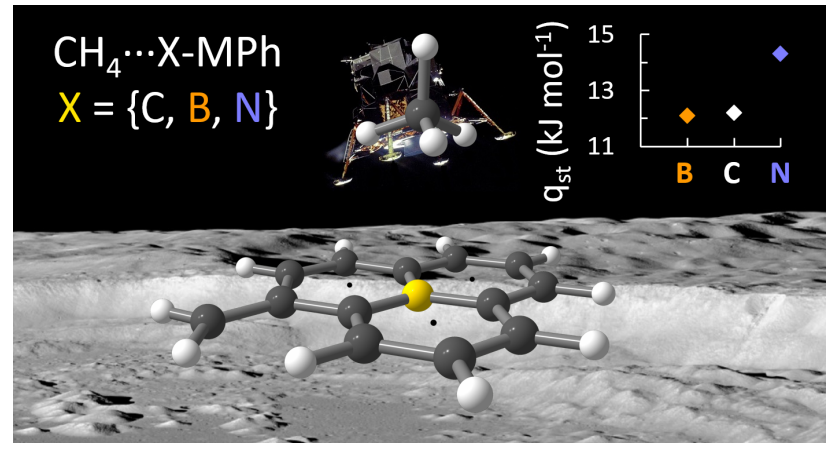

Keywords: physisorption, binding energy, zeolite-templated carbon, boron-doping, nitrogendoping, correlated MO theory, density functional theory

\section{Introduction}

Adsorption is a ubiquitous phenomenon in nature, relevant to every catalytic and enzymatic function among many other engineering and environmental processes. Adsorption of small molecules on a carbon-based surface is one of the simplest systems for study with graphene being the archetypical surface. ${ }^{1}$ Graphene- or graphite-like adsorbing environments are relevant to applications ranging from natural gas resource estimation in deep subterranean reservoirs ${ }^{2-5}$ to single-molecule sensors ${ }^{6-8}$ and high-power ion mobility devices for next-generation electrochemical energy storage.9-12 Porous carbon-based adsorbents have attracted particular attention for the compact storage of light molecular fuels, especially hydrogen and methane.13-19 Carbon is a promising building block for adsorbent materials owing to its natural abundance, light weight, and versatile bonding and therefore variety of structural motifs (i.e., "bonding chutzpah"20). Porous carbon materials are especially desirable as a storage medium for methane owing to their nearoptimal binding energy that permits its robust, reversible storage at near ambient temperatures. ${ }^{15}$ Several attributes of the ideal adsorbent surface structure must be simultaneously achieved in order to maximize deliverable methane capacity at modest pressures (e.g., below 100 bar). These include high surface area (per mass of adsorbent), high surface density (per volume of adsorbent), and surface homogeneity (with respect to chemistry and structure). An exemplary material that meets these criteria is zeolite-templated carbon (ZTC), ${ }^{21}$ exhibiting a dense, regular network of atomically thin carbon ribbons separated by the near-optimal pore width of $\sim 1.2 \mathrm{~nm} .{ }^{22-24}$ Hence, zeolite-templated carbon serves as an archetypical representation of a periodic carbon structure composed of free-standing graphene-like fragments. Despite the amorphous nature of these materials, their periodic bulk-structure and finely controlled, bottom-up synthesis allow for rigorous theoretical studies. ${ }^{25}$

Strategies abound for designing adsorbent materials to achieve high density, reversible methane storage at near room temperature.26-27 The surfaces need to be effectively arranged in order to optimize the overall density of the adsorbate/adsorbent system, and thus minimize the "dead volume" unavailable for adsorption interactions. Likewise, the methane binding energy should neither be too weak nor too strong to enable maximum storage and delivery of the adsorbate for its 
intended application. Adsorption at or near coordinatively unsaturated structural metal sites ${ }^{28-29}$ within the lattice (e.g., as exemplified by metal-organic frameworks, MOFs) has been suggested as a method to tune the binding energy within a wide range between $5-30 \mathrm{~kJ} \mathrm{~mol}^{-1}$. An often cited target binding strength for reversible methane delivery is $\sim 19 \mathrm{~kJ} \mathrm{~mol}^{-1,30}$ although pore structure and entropic contributions may increase this value to up to $23 \mathrm{~kJ} \mathrm{~mol}^{-1} .{ }^{27}$ However, differing conditions considerations place the optimal binding energy for isothermal delivery at 10-15 kJ mol-1, which is well within the range accessible to porous carbons without metals. ${ }^{26}$ Indeed, the copper-based HKUST-1 exhibits perhaps the most promising uptake among MOF adsorbents is characterized by a binding energy of 16-17 kJ mol-1 without the consideration of methane-methane interactions. ${ }^{31} \mathrm{An}$ alternative strategy to the incorporation of metals, far less explored, would be to modify a pure carbon surface by heteroatom substitution. ${ }^{32-33}$

Past work to computationally estimate methane binding energy and isosteric heat of adsorption on pure carbon-based surfaces has been carried out on model systems ranging from flat, graphene-like open surfaces ${ }^{34-36}$ to curved buckybowls, ${ }^{35}$, 37-38 amorphous porous carbons, ${ }^{39}$ and slit pores between stacked graphitic sheets of varying widths. ${ }^{22-23,30}$ The influence of pore size, temperature, and pressure on the isosteric heat of adsorption was studied by grand-canonical Monte Carlo (GCMC) simulations that showed a maximum in binding energy at intermediate pore width roughly equal to two monolayers of adsorbed methane. ${ }^{22}$ Similar studies comparing GCMC simulations have shown that the binding energy of pure carbon surfaces (11-13 $\mathrm{kJ} \mathrm{mol}^{-1}$ ), even in ideal pore width structures, are still below the ideal values for maximum methane delivery at $300 \mathrm{~K} .{ }^{23}$ These GCMC calculations have since been followed by numerous studies using first-principle DFT and MO theory in an effort to better understand methane storage limits on carbon-based materials. The varying methods employed for estimating methane binding on pure-carbon models (Table S1) yielded interaction energies ranging widely from 5 to $43 \mathrm{~kJ} \mathrm{~mol}^{-1}$.

While acknowledging the popularity of modern density functional theory, it is crucial to critically evaluate the chemical accuracy of these calculations by comparison to a fundamentally converging series of explicitly correlated $a b$ initio molecular orbital (MO) theory, ${ }^{40}$ especially when investigating the importance of non-covalent interactions. Furthermore, our fundamental understanding of $\mathrm{C}-\mathrm{H} \cdots \pi$ interactions between aliphatic adsorbate and aromatic adsorbent models is based on the seminal $a b$ initio correlated MO study of gas-phase clusters of aromatics with methane. ${ }^{41}$ It has since been acknowledged ${ }^{42}$ that this single-ring focused bonding picture must be extended to cover double and triple H-bonded adsorbate arrangements over multiple adjacent rings of a polyaromatic hydrocarbon moiety. The energy range for methane binding narrows to 14$19 \mathrm{~kJ} \mathrm{~mol}^{-1}$ in a systematic study using electron-correlated molecular orbital (MO) theory employing a series of polyaromatic hydrocarbon models, as a function of the model size. ${ }^{42}$ This work establishes a chemical accuracy of less than $1 \mathrm{~kJ} \mathrm{~mol}^{-1}$ that is achievable by correlated MO theory.

Heteroatom substitution (i.e., doping) of carbon-based surfaces is a well-explored technique for applications ranging from electrocatalysis to carbon capture. 43 The most common candidate dopant species are boron and nitrogen, owing to their proximity to carbon in size, effective nuclear charge, and electronic structure. Boron substitution for carbon effectively imparts an electron "hole" in the overall conjugated $\pi$-network that renders the $\pi$-electron cloud electron deficient. Due to the presence of unpaired electrons, spin polarization emerges, which is among the more complex (often overlooked) magnetic quantum chemical effects imparted by doping. Nitrogen substitution, 
conversely, introduces an additional electron into the conjugated $\pi$-network and thus corresponds to an electron-enriched environment, in addition to generating spin polarization in the $\pi$-electrons as well. In this way, boron and nitrogen substitution both represent a simple, elegant method for tuning the electronic structure (and hence surface chemistry) of carbon-based adsorbents. Numerous theoretical studies and a single experimental study have exploited this quintessential approach for methane adsorption, as summarized in Table S1.

The adsorption of methane on B- and N-doped carbon-based models has, to date, only been investigated on the open surface of graphene-like systems, across a variety of doping concentrations and functional groups. It was first reported that the methane interaction energy increases with increasing electronegativity of the dopant from B-doped graphene $\left(14.5 \mathrm{~kJ} \mathrm{~mol}^{-1}\right)$ to pure carbon (14.9 kJ mol-1), NB-doped (16.4 $\left.\mathrm{kJ} \mathrm{mol}^{-1}\right)$, and finally $\mathrm{N}$-doped (17.3 kJ mol-1) graphene. ${ }^{36}$ In subsequent studies, the opposite trend was observed, as the B-doped surfaces exhibited the highest binding energy $\left(49 \mathrm{~kJ} \mathrm{~mol}^{-1}\right)$ followed by pure carbon $\left(43 \mathrm{~kJ} \mathrm{~mol}^{-1}\right)$ and finally by $\mathrm{N}$-doped (41 kJ mol-1) surfaces. ${ }^{34}$ Studies based on a large $(1.8 \times 2.3 \mathrm{~nm})$ graphene sheet adsorbent model comprising three distinct ways of doping boron and nitrogen predicted an increase in the methane binding energy for both B- and N-doped surfaces compared to the pure carbon case. ${ }^{44}$ The estimated methane binding energies varied widely as a function of the location and type of substitution: between 7.1-17.5 kJ mol-1 and 5.4-13.4 kJ mol-1 for B- and N-doped surfaces, respectively. ${ }^{44}$ Determining the role of heteroatom dopants on binding energy toward gas adsorbates is inherently challenging due to the need for mapping networks of "weak interactions" that are dominated by electron density polarizability and London dispersion forces. ${ }^{45}$

Experimental studies of the role of heteroatom substitution on adsorption energetics face significant challenges due to complexities that inherently arise upon chemical doping, such as the omnipresence of oxygen in porous carbon materials (often increased upon doping), varying chemical speciation of the desired heteroatom (including as oxide derivatives, such as $\mathrm{NO}_{\mathrm{x}}$ or $\mathrm{BO}_{\mathrm{x}}$ ), and concomitant effects on composition and structure (e.g., changes in pore size). To date, only nitrogen-doping was investigated with respect to methane adsorption, and is reported to increase binding affinity; 46 boron remains unexplored experimentally.

All in all, across experiment and theory, there seems to be evidence that heteroatom doping by either boron or nitrogen can lead to an increase in binding energy toward methane. This is consistent with the thesis of a recent protestation that all modifications of graphene seem to lead to an improvement in its properties toward electrocatalytic applications. ${ }^{47}$ However, the fundamental electronic structure differences among $\mathrm{B}, \mathrm{C}$, and $\mathrm{N}$ sites in carbon materials motivate further scrutiny of the experimental and theoretical observations toward methane binding. Universal guiding principles that are based on comparative quantum calculations are needed to facilitate the rational design and optimization of adsorbent materials for methane storage. In this study, a complementary series of high-level quantum chemical calculations are used to determine whether B- or N-doped carbon surfaces should be considered as advantageous for methane storage in comparison to pure carbon surfaces.

Our approach is founded on using a conceptually converging series of quantum chemical calculations to assess methane interactions with carbon-based surfaces in order to determine the influence of heteroatom substitutions (i.e., planar $\mathrm{BC}_{3}$ and $\mathrm{NC}_{3}$ type sites) to the highest chemical accuracy that is computationally feasible. The desired accuracy in binding energy ( $1 \mathrm{~kJ} \mathrm{~mol}^{-1}$ ) necessitates the use of electron-correlated, post-HF MO-based $a b$ initio correlated MO theory. ${ }^{42}$ The 
single-reference, coupled-cluster method with single, double, and perturbative triple substitutions $(\operatorname{CCSD}(\mathrm{T}))$ was chosen as the highest level of theory. Basis set effects were also evaluated using a modified version of the complete basis set extrapolation method, CBS-QB3, and counter-poise calculations were performed to determine the basis set superposition error (BSSE). These desired levels of theory guided the construction of an appropriate model system that can capture the physical chemistry of methane adsorption on carbon surfaces. Among the candidates considered, including such well-studied systems as open crystalline graphite/graphene surfaces, amorphous carbonaceous surfaces with variable composition $\mathrm{C}_{\mathrm{x}} \mathrm{H}_{\mathrm{y}} \mathrm{O}_{\mathrm{z}}$, and graphitic slit pores or cylindrical nanotube environments, a fragment of zeolite-templated carbon (ZTC) was selected (see Figure 1). Among porous carbon materials, ZTC was chosen as the system of focus in this work since it is a synthetically accessible material of particular interest for comparison of theory and experiment 25 and has been the subject of several high precision methane adsorption studies. ${ }^{48-49}$

A model of minimal size, methylidene phenalene $(\mathrm{MPh})$, that retains key relevant chemical features of a representative portion of the surface of zeolite-templated carbon with a closed-shell, diamagnetic electronic ground state was chosen (inset in Figure 1). This molecular maquette (an atomic-scale representative model) was created by considering inorganic coordination chemistry principles: inner, outer, and peripheral spheres around the site of substitution for capturing covalent, ionic, and steric interactions, respectively. A molecule comprising three six-membered rings centered at the site of heteroatom substitution (i.e., phenalene) was first chosen as an ideal minimalist maquette for a site of heteroatom substitution in porous carbon surfaces such as those found in ZTC. The phenalene frame was augmented by a peripheral methylidene group $\left(=\mathrm{CH}_{2}\right)$ to ensure extended $\pi$-conjugation. This model system is smaller than coronene (24 versus 36 atoms), which allows for structural optimizations at high levels of theory, such as CCSD(T). This MPh maquette is also favorable over coronene due to the existence of a central site of substitution with a balanced distribution of atoms from inner, outer, and peripheral spheres. MPh allows for a systematic study of the effect of substitution at the center of the model, including spin polarization effects due to heteroatom substitution with an odd number of electrons. Furthermore, MPh is especially suited for comparison to actual porous carbon materials like ZTC. For example, the surface structure of ZTC distinctly contrasts that of a perfect graphene sheet; it contains functional groups, very significant edge character, and defects (e.g., vacancies, different ring sizes, etc.) that disrupt the long-range delocalization displayed by graphene and graphene-like molecular models

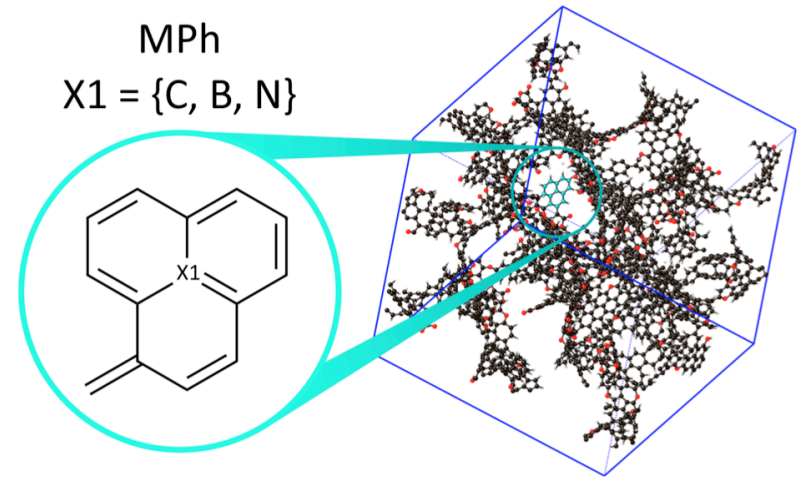

Figure 1. Methylidene phenalene (MPh), a molecular maquette of porous carbon surfaces such as zeolitetemplated carbon (ZTC). The central atom (X1 = C, B, or $\mathrm{N}$ ) is chosen as the site of heteroatom substitution. such as coronene. 50 The presence of the methylidene group introduces asymmetry to the tricyclic MPh frame that lead to deviation from the perfect co-planarity expected for a conjugated $\pi$-system. ${ }^{38}$ Ultimately, the MPh maquette is an ideal model for the theoretical treatment ${ }^{41}$ of polyaromatic cyclic systems to high chemical accuracy, ${ }^{42}$ as inspired by Pople's model chemistries, 51 Peterson's Complete Basis Set extrapolation method, ${ }^{110}$ and Schaefer's focal point analysis. ${ }^{111}$

Heteroatom doping is represented herein by direct replacement of the central atom of MPh (X1 in Figure 1), leading to the formation of two 
radical variants: $\mathrm{B}-\mathrm{MPh}$ and $\mathrm{N}-\mathrm{MPh}$, both in $\mathrm{S}=1 / 2$ ground state. This strategy departs from investigations where a hydrogen is added to the carbon atom neighboring the site of substitution to ensure a closed-shell, diamagnetic electron configuration. 52 The present strategy is instead a compositionally uncompromised, materials science approach, with less concern for the computational cost and challenges due to complexities of the employed model composition and/or electronic structure. We also note that if a hydrogen atom is used to ensure a diamagnetic state, there are many energetically competitive positional isomers that would also need to be considered, including hydrogen addition on inner, outer, and peripheral carbons, methylidene to methyl conversion (in the case of MPh), and numerous possible zwitterionic forms. Herein, we simply embrace the need to address spin polarization, despite that it is computationally more challenging than performing spin-restricted, closed-shell calculations. This is not an experimentally unreasonable approach, as supported by several reports describing the possible paramagnetic nature of porous carbon materials. ${ }^{53-54}$

In addition to aiming for the highest level of theory, computational productivity with minimal compromise to chemical accuracy was also considered. The reference level of theory chosen for high-throughput calculations, such as potential energy surface mapping, evaluating combinatorial possibilities for adsorbent/adsorbate orientations, etc., is BSSE-corrected density functional theory (DFT) with the MN15 functional and the sizeable 6-311++ $\mathrm{G}^{* *}$ basis set. This particular choice of level of theory is based on a recent study of a structurally and compositionally relevant 0substituted polyaromatic molecule $55-56$ and recent theoretical investigations of acetone adsorption on graphene. ${ }^{57}$ The reference MN15 structures and energetics were compared to a systematic series of correlated MO theory calculations represented by MP2, MP4, and CCSD(T) methods. Nevertheless, fortuitous error cancellations observed in the calculations at the CCSD(T)/6$311++G^{* *}$ level of theory, owing to basis set incompleteness and the truncation of higher order terms at the non-explicit triples level. These observations suggest the need for even higher levels of theory,57 multi-reference active-space treatment, ${ }^{58-60}$ or consideration of density-matrix renormalization group theory. ${ }^{61-62}$ Advantageously, the achievement of close to $1 \mathrm{~kJ} \mathrm{~mol}^{-1}$ chemical accuracy ${ }^{42}$ renders single-reference correlated MO methods as sufficiently accurate for the present study. The structural and energetic differences reported in this study are significant enough to establish nitrogen doping, over both boron doping and pure carbon surfaces, as a definitive strategy for increasing methane adsorption interactions on carbon-based adsorbents. Contrary to the claim that any substitution improves desired properties in carbon materials, ${ }^{47}$ in this work we find that more electron enriched substitution sites lead to an increase in the strength of methane affinity, a significant guiding result for practical applications of porous carbon adsorbents designed for mobile natural gas storage and delivery.

\section{Computational Models and Methods}

\subsection{Nomenclature}

The three models considered in this study as maquettes of single binding sites on a porous carbon surface are 5-methylidene-phenalene (MPh), 1-boro-5-methylidene-phenalene (B-MPh), and 1-azo5-methylidene-phenalene (N-MPh), where the central position of the model is occupied by a C, B, or $\mathrm{N}$ atom, respectively. All of the models are of neutral charge. While the parent compound $\mathrm{MPh}$ has a closed shell, diamagnetic $\mathrm{S}=0$ ground state, the substituted $\mathrm{B}-\mathrm{MPh}$ and $\mathrm{N}-\mathrm{MPh}$ molecules were 
treated as $S=1 / 2$ radicals. The trefoil-shaped tricyclic ring system's symmetry is broken by the additional methylidene group, which is needed for the seven orbital $\pi$-system that is occupied by 13,14 , or 15 electrons for $\mathrm{B}-\mathrm{MPh}, \mathrm{MPh}$, and $\mathrm{N}-\mathrm{MPh}$, respectively. The electron count defines the $\pi_{7}$ orbital to be the HOMO and $\pi_{8}$ as the LUMO, the redox active orbitals relevant to the compositional change from $\mathrm{MPh}$ to $\mathrm{B}-\mathrm{MPh}$ and $\mathrm{N}-\mathrm{MPh}$, respectively. The reference orientation and atom numbering convention used herein for MPh and its variants are shown in Figure S1. The internal coordinates used to describe the adsorbent geometry and the adsorption model (adsorbent + methane) are shown in Figures $\mathbf{S} \mathbf{2}$ and $\mathbf{S 3}$, respectively.

\subsection{Methods: Selection of Levels of Theory}

The primary level of theory employed in this work is based on density functional theory (DFT); however given the approximate nature of the treatment of electron exchange and correlation in DFT, the main results were compared to additional calculations made using ab initio correlated MO theory. By focusing on valence-only basis sets, we briefly ventured into the domain of semiempirical quantum theory, a desirable direction for extending this work toward larger and more realistic maquettes of porous carbon materials.

\subsubsection{Density Functional Theory}

Spurred on by future considerations of larger, periodic systems (such as the porous ZTC framework ${ }^{50}$ ) and owing to the direct relationship with density-functional tight-binding (DFTB) calculations, ${ }^{63-65} \mathrm{PBE}$ exchange and correlation functionals ${ }^{66-67}$ with the $6-311++\mathrm{G}^{* *}$ basis set ${ }^{68-70}$ were initially used for mapping the potential energy surface of methane adsorption on MPh and its heteroatom-substituted variants (Figure S4a). While this is not our preferred level of theory for describing extended $\pi$-conjugated systems involved in non-covalent interactions, ${ }^{71}$ the significantly varied stationary structures obtained by this approach (Figure S4b) were leveraged as starting structures for higher level optimizations. Permutation of the methane approach geometry and the adsorbent composition $(\mathrm{X} 1=\mathrm{C}, \mathrm{B}$, or $\mathrm{N}$ ) defines a $3 \times 3$ matrix of starting geometries for calculations at more adequate levels of theory. This approach provided a modest sampling of the potential energy surface with respect to methane interaction geometry with the MPh adsorbent.

The starting geometries for structural optimizations were taken from the potential energy surface described by the adsorbate distance and orientation relative to the site of substitution (X1). Four different approaches of the methane molecule to the adsorbent surface were considered: single $\left(\kappa^{1}\right)$, double $\left(\mu_{2}\right)$, and triple $\left(\mu_{3}\right)$ end-on $\mathrm{C}-\mathrm{H} \cdots \mathrm{X} 1$ geometries, and side-on $\left(\eta^{2}\right) \mathrm{C}-\mathrm{H} \cdots \mathrm{X} 1$ geometry. Control of the internal coordinates for each approach was achieved by utilizing dedicated Z-matrix coordinate systems specific to each adsorption model, as summarized in Table S2. The resulting potential energy surface maps are shown in Figure S4a. The three initial structures (at positions indicated in Figure S4a) for further optimizations were selected from approximately the middle of the surface $\left(\sim 2.0 \AA \mathrm{X} 1-\mathrm{H}\right.$ distance and $\sim 130^{\circ} \mathrm{X} 1 \cdots \mathrm{H}-\mathrm{C}$ angle), one for each variant of MPh. It is important to note that the overall shape of the methane adsorption potential energy surface calculated at the PBE/6-311++G** level is practically identical to that obtained by superior calculations at the reference level of DFT (Figure S4c).

A recent systematic study55 focusing on tricyclic aromatic compounds with keto, phenol, and phenolate functional groups served as a benchmark for the work carried out herein, comparing the most commonly used functionals across each rung of Jacob's Ladder. ${ }^{72}$ Out of the nearly 100 functionals considered, a clear structural and energetic advantage to using the MN15 functional ${ }^{73}$ 
was reported, ${ }^{56}$ over both PBE and B3LYP.74-75 Therefore, the reference level of DFT chosen herein is $\mathrm{MN} 15 / 6-311++\mathrm{G}^{* *}$, referred to simply as "MN15" by omitting the reference basis set specification. All structures reported in this work were confirmed to be equilibrium structures without exhibiting any imaginary normal modes. A striking difference between the PBE and MN15 functionals was the collapse of the $3 \times 3$ starting structures for the adsorption model at the MN15 level into just three unique structures irrespective of central site substitution, while different equilibrium structures were obtained at the PBE level.

For scientific rigor and to broaden the impact of the work reported herein, a limited evaluation of the basis set effect on structure, energetics, and chemical bonding was carried out at the MN15 level. Calculations carried out with the $6-31 \mathrm{G}^{*}$ basis ${ }^{76-78}$ (a smaller, double- $\zeta$ quality basis set with polarization functions) and the def2-QZVPP79-80 basis (a larger, quadruple- $\zeta$ quality basis set with polarization functions) are referred to as "MN15-" and "MN15+," respectively. The comparison of results achieved using MN15-, MN15, and MN15+ provide clear trends with respect to the BSSE and basis set saturation behavior. In addition, calculations carried out with the minimal basis set STO3G 81-82 $^{8 n d}$ the valence-electron-only "SDDAll" basis set ${ }^{83}$ (a high-quality valence shell basis set with effective core potentials for the 1s orbitals) are referred to as "\{MN15\}" and "[MN15]," respectively. Unexpectedly, these considerably less computationally expensive levels of theory $(\{\mathrm{MN} 15\}$ and [MN15]) provided results with reasonable chemical accuracy. These results lay the theoretical foundation for our future modeling of molecular adsorption on larger maquettes of porous carbon materials, where the application of the reference $M N 15 / 6-311++G^{* *}$ level of theory would be prohibitively expensive.

\subsubsection{Ab initio Correlated MO Methods}

Owing to the approximate nature of exchange and correlation functionals, as well as to the computationally challenging weak binding interactions typical of physisorption, the MN15 structural optimizations and energy calculations were extended by performing a series of $a b$ initio correlated MO calculations. The reference level Hartree-Fock (HF) ${ }^{84-85}$ calculations behaved similarly to the PBE/6-311++G** DFT calculations, as both methods led to more than three unique structure types within the $3 \times 3$ combinatorial possibilities of starting geometries and compositions (as described above). However, already at a modest level of treatment of electron correlation (MP2/6-311++G**), the calculations resulted in a single unique structure type for all starting geometries and compositions, similar to the reference level of DFT theory used in this work (MN15). A conceptually converging series of $a b$ initio correlated MO methods ${ }^{51}$ were was carried out with increasingly accurate treatment of electron correlation (MP2,86-87 MP3,88-89 MP4, ${ }^{90-91}$ $\operatorname{CCSD},{ }^{92-94}$ and $\operatorname{CCSD}(\mathrm{T})^{93,95}$ methods with all 1s orbitals of heavy atoms (15) frozen and without any virtual orbital excluded from the correlation calculations) for direct comparison to the results obtained by DFT methods. Due to the prohibitive computational cost of full MP4 and CCSD(T), the structural optimization was only carried out at the truncated MP4SDQ and CCSD levels, followed by single-point potential energy calculations at the true MP4 and CCSD(T) levels. Hence, these calculations are referred to as MP4SDQ|MP4 and $\operatorname{CCSD} \mid \operatorname{CCSD}(\mathrm{T})$, respectively. All correlated MO methods were carried out using the $6-311++\mathrm{G}^{* *}$ basis set (as used for the reference level DFT calculations) and are thus omitted for brevity when referencing the level of MO theory. Given the fortuitous error cancellations between this specific basis set and the highest degree of electron correlation $(\operatorname{CSSD}(\mathrm{T}))$, the energetic analysis was completed using a modified complete basis set extrapolation method (CBS-QB3),96-97 where the standard DFT level (B3LYP) used to generate the 
equilibrium structure was replaced by the more suitable MN15 level, referred to herein as mCBSQB3.

\subsubsection{Electronic Structure Analysis}

The molecular electron densities for the adsorption models in their equilibrium structures were obtained at the highest density functional level considered (MN15+) in order to mitigate artifacts in chemical bonding due to lack of basis set saturation. The atom-centered properties were obtained from Hirshfeld population analysis (HPA), ${ }^{98}$ Weinhold natural population analysis (NPA), ${ }^{99}$ and Merz-Kollman electrostatic potential fit (ESP) ${ }^{100}$ methods. All of these methods consider molecular electron density as their starting point for analysis, as opposed to Mulliken, ${ }^{101}$ Meyer, ${ }^{102}$ or Løwdin ${ }^{103}$ population analysis methods that face challenges for non-covalent interactions encountered in the present study. Nevertheless, even despite the simplicity of the MPh adsorption models, each different population analysis method displayed its inherent weaknesses. Therefore, a comprehensive analysis considering the results of each method is required to gain a comprehensive picture of the electrostatic interactions contributing to the adsorption energetics of methane on $\mathrm{MPh}$ and its heteroatom-substituted variants. In order to address the various pitfalls of the different partitioning schemes, molecular electron density differences between the infinitely separated adsorbent and adsorbate molecules and the adsorption model were obtained from single-point energy calculations using the atomic positions of the structurally optimized adsorption model. Given the presence of unpaired electrons in the B-MPh and N-MPh adsorption models, the atomic spin density distributions were also evaluated, allowing for visualization of the extent of $\pi$ conjugation and spin polarization, and elucidating some possible features of the multi-reference electronic structure.

\subsubsection{Desorption Energetics}

The interaction energies of methane adsorption on MPh and its heteroatom-substituted variants were defined as the difference in quantum mechanical potential energy at $0 \mathrm{~K}$ (EQM, also referred to as $\mathrm{E}^{\mathrm{SCF}}$ ) between the adsorbent and adsorbate at infinite separation as compared to the adsorption model:

$$
\Delta \mathrm{E}^{\mathrm{QM}}=\mathrm{E}^{\mathrm{QM}}\left(\mathrm{CH}_{4}\right)+\mathrm{E}^{\mathrm{QM}}(\mathrm{MPh})-\mathrm{E}^{\mathrm{QM}}\left(\mathrm{MPh} \times \mathrm{CH}_{4}\right)
$$

The $\Delta$ prefix carries the sign convention of the dissociation process or, analogously, the desorption process from a molecular or material surface perspective, respectively. $\Delta \mathrm{E}^{\mathrm{QM}}$ is expected to be positive for attractive adsorption interactions with a larger value corresponding to a stronger binding of the adsorbate. The basis-set superposition error (BSSE), ${ }^{104-105}$ associated with basis set incompleteness, was corrected based on counterpoise calculations. ${ }^{106}$ The BSSE is typically more severe for highly correlated MO theories, as the size of the basis set determines the number of electronic state configurations involved in the calculation of the dynamic electron correlation. This error is to be subtracted from $\Delta \mathrm{EQM}^{\mathrm{QM}}$ due to the potential for spurious gain in energy for the adsorbent and adsorbate in the presence of each other's basis functions. The corrected value for the interaction energy is then:

$$
\Delta \mathrm{E}^{\mathrm{QM}^{*}}=\Delta \mathrm{E}^{\mathrm{QM}}-\mathrm{BSSE}
$$


A further correction must also be considered due to the possible energy difference (Ewarp) between the distorted structure of the adsorbent and adsorbate in the adsorption model relative to their corresponding free structures at infinite separation. This correction is defined as:

$\mathrm{E}^{\text {warp }}=\left(\mathrm{E}^{\mathrm{QM}}\left(\mathrm{CH}_{4}\right.\right.$ in $\left.\mathrm{MPh} \times \mathrm{CH}_{4}\right)-\mathrm{E}^{\mathrm{QM}}\left(\right.$ free $\left.\left.\mathrm{CH}_{4}\right)\right)+\left(\mathrm{E}^{\mathrm{QM}}\left(\mathrm{MPh}\right.\right.$ in $\left.\mathrm{MPh} \times \mathrm{CH}_{4}\right)-\mathrm{E}^{\mathrm{QM}}($ free $\left.\mathrm{MPh})\right)$

The magnitude of Ewarp is informative as to whether the interaction can be considered as physisorption or chemisorption. In all cases herein, this deformation energy was found to be less than $0.5 \mathrm{~kJ} \mathrm{~mol}^{-1}$ and therefore the adsorption model is well within the category of physisorption.

When comparing calculated (molecular) and experimental (macroscopic) energetics of adsorption phenomena, additional thermochemical quantities (e.g., the thermal internal energy, $U$ ) at standard temperature and pressure (298.15 K and $1 \mathrm{~atm}$ ) must be considered. These can be calculated based on contributions from molecular electronic, translational, vibrational, and rotational motions using statistical mechanical (SM) models. The enthalpy and Gibbs free energy can be calculated based on an ideal gas assumption for all species involved. This assumption is designed to permit comparison to experiments in the dilute limit according to Henry's law. Under such conditions, the work contribution to the change in enthalpy upon desorption $(\Delta \mathrm{PV})$ is attributed solely to the ideal gas molar expansion of methane (i.e., $\Delta \mathrm{PV}=\mathrm{RT}$ ):

$$
\Delta \mathrm{U}^{S M}(\mathrm{~T}, \mathrm{P})=\Delta \mathrm{U}_{\text {elec }}(\mathrm{T}, \mathrm{P})+\Delta \mathrm{U}_{\text {trans }}(\mathrm{T}, \mathrm{P})+\Delta \mathrm{U}_{\text {vib }}(\mathrm{T}, \mathrm{P})+\Delta \mathrm{U}_{\text {rot }}(\mathrm{T}, \mathrm{P})
$$

At standard pressure $\left(\mathrm{P}^{\circ}=1 \mathrm{~atm}\right)$ and arbitrary temperature:

$$
\begin{gathered}
\Delta \mathrm{U}^{\circ}(\mathrm{T})=\Delta \mathrm{E}^{\mathrm{M}^{*}}+\Delta \mathrm{U}^{S M}\left(\mathrm{~T}, \mathrm{P}^{\circ}\right) \\
\Delta \mathrm{H}^{\circ}(\mathrm{T})=\Delta \mathrm{U}^{\circ}(\mathrm{T})+\Delta \mathrm{PV}=\Delta \mathrm{U}^{\circ}(\mathrm{T})+\mathrm{RT} \\
\Delta \mathrm{G}^{\circ}(\mathrm{T})=\Delta \mathrm{H}^{\circ}(\mathrm{T})-\Delta \mathrm{TS}=\Delta \mathrm{U}^{\circ}(\mathrm{T})+\mathrm{RT}-\mathrm{T} \Delta \mathrm{S}^{S M}(\mathrm{~T})
\end{gathered}
$$

Additionally, a condensed phase model for the desorption of methane into its liquid $(\rho=0.439 \mathrm{~g}$ $\mathrm{mL}^{-1}$ at $100 \mathrm{~K}$ and $\left.1 \mathrm{~atm}\right)^{107}$ was also considered:

$$
\begin{gathered}
\Delta \mathrm{H}_{\text {cond }}^{\circ}(\mathrm{T})=\Delta \mathrm{U}^{\circ}(\mathrm{T})+\Delta \mathrm{PV} \approx \Delta \mathrm{U}^{\circ}(\mathrm{T}) \\
\Delta \mathrm{G}_{\text {cond }}^{\circ}(\mathrm{T})=\Delta \mathrm{H}^{\circ}(\mathrm{T})-\mathrm{T} \Delta \mathrm{S}_{\text {cond }}^{\circ}(\mathrm{T})
\end{gathered}
$$

where $\mathrm{V}$ is the molar volume of the liquid $\left(36.4 \mathrm{~mL} \mathrm{~mol}^{-1}\right.$ at $100 \mathrm{~K}$ and $\left.1 \mathrm{~atm}^{107}\right)$. Due to its small upper limit value $\left(\Delta \mathrm{PV} \max =3.7 \mathrm{~J} \mathrm{~mol}^{-1}\right)$, the $\Delta \mathrm{PV}$ term for methane desorption was neglected in this study, as shown in Eq.(8). However, the condensed phase entropy ( $\Delta \mathrm{S}^{\circ}$ cond) was estimated using the free volume-based translational entropy correction, ${ }^{108}$ which is significantly lower than that of the gas phase value $\left(\Delta \mathrm{S}^{\mathrm{SM}}\right)$. Hence, the condensed phase Gibbs free energy ( $\Delta \mathrm{G}^{\circ}$ cond) differs significantly from the gas phase value $\left(\Delta \mathrm{G}^{\circ}\right)$. All quantities (e.g., $\Delta \mathrm{EQM}^{*}$ ) are given in units of $\mathrm{kJ} \mathrm{mol}^{-1}$, normalized to the moles of the adsorption system (containing $n$ methane molecules) except when otherwise stated. A modest statistical analysis (average and standard deviation) of energy and entropy values was afforded by considering cases for both low $\left(\mathrm{MPh} \times \mathrm{CH}_{4}\right)$ and high $\left(\mathrm{MPh} \times 2 \mathrm{CH}_{4}\right)$ methane loading (reported per mole of adsorbate instead of per mole of adsorption models). This analysis was advantageous for assessing the computational accuracy across different levels of theory, as well as for comparison between theory and experiment. 
Table 1. Free adsorbent structures (LoT: MN15, MP2, MP4SDQ, or CCSD using the $6-311++G^{* *}$ basis set) of $\mathrm{MPh}, \mathrm{B}-\mathrm{MPh}$, and N-MPh as described by averages and standard deviations of C-C distances in $\AA$ from inner $(\alpha)$, outer $(\beta)$, and peripheral $(\gamma)$ spheres, out-of-planarity $(\delta$, in $\AA$ ) of the site of substitution, and wagging angle ( $w$, in degrees) of the methylidene group (see Table S3 for basis set effects and Table S4 for the geometry in methane adsorption model).

\begin{tabular}{llllrrr}
\hline Adsorbent & LoT & Inner, $\AA$ & Outer, $\AA$ & Peripheral, $\AA$ & $\boldsymbol{\delta}, \boldsymbol{\AA}$ & $\boldsymbol{w}^{\circ}$ \\
\hline MPh & MN15 & $1.43 \pm 0.00$ & $1.42 \pm 0.04$ & $1.39 \pm 0.04$ & 0.00 & 176 \\
& MP2 & $1.43 \pm 0.00$ & $1.42 \pm 0.03$ & $1.40 \pm 0.03$ & 0.05 & 171 \\
& MP4 ${ }^{\text {DDQ }}$ & $1.43 \pm 0.01$ & $1.42 \pm 0.04$ & $1.40 \pm 0.04$ & 0.04 & 173 \\
& CCSD & $1.43 \pm 0.01$ & $1.42 \pm 0.04$ & $1.40 \pm 0.04$ & 0.04 & 173 \\
B-MPh & & & & & & \\
& MN15 & $1.52 \pm 0.01$ & $1.42 \pm 0.04$ & $1.41 \pm 0.04$ & 0.00 & 172 \\
& MP2 & $1.54 \pm 0.00$ & $1.40 \pm 0.05$ & $1.41 \pm 0.05$ & 0.05 & 169 \\
& MP4SDQ & $1.54 \pm 0.00$ & $1.41 \pm 0.04$ & $1.42 \pm 0.04$ & 0.02 & 172 \\
& CCSD & $1.54 \pm 0.01$ & $1.42 \pm 0.05$ & $1.42 \pm 0.05$ & 0.03 & 171 \\
N-MPh & & & & & & \\
& MN15 & $1.41 \pm 0.01$ & $1.42 \pm 0.04$ & $1.39 \pm 0.03$ & 0.00 & 179 \\
& MP2 & $1.41 \pm 0.01$ & $1.41 \pm 0.01$ & $1.39 \pm 0.03$ & 0.02 & 175 \\
& MP4SDQ & $1.42 \pm 0.01$ & $1.41 \pm 0.06$ & $1.40 \pm 0.04$ & 0.11 & 169 \\
& CCSD & $1.42 \pm 0.01$ & $1.42 \pm 0.06$ & $1.40 \pm 0.04$ & 0.06 & 169 \\
\hline
\end{tabular}

\section{Results and Analysis}

\subsection{Geometric Structure}

Substitution of the central site (X1) by C, B, or N (in MPh, B-MPh, and N-MPh, respectively) does not significantly affect the overall geometry, shape, or planarity of the adsorbent MPh maquette at the MN15 level. The out-of-plane distance $(\delta)$ and methylidene wagging $(w)$ parameters in Table 1 show co-planarity for the three tricyclic conjugated systems. The largest deviations from ideal values were obtained for $\mathrm{N}-\mathrm{MPh}$, which also correspond to the most challenging structural optimizations with respect to oscillations and unexpected jumps in energy, likely due to nearby excited states that mix with the $S=1 / 2$ ground state as a function of structural distortions. The inner sphere $\mathrm{C}-\mathrm{C}$ distances around the site of substitution (X1), on the other hand, do vary significantly upon heteroatom substitution. B-MPh exhibits longer average C-C distances (1.52 $\mathrm{A})$ while N-MPh exhibits slightly shorter distances $(1.41 \AA$ ) relative to MPh (1.43 $⿱$ ). These differences correlate with the presence of an electron hole (in B-MPh) versus an extra electron (in N-MPh) in the inner sphere of the conjugated $\pi$-system. On the other hand, the effect of substitution on the $\mathrm{C}-\mathrm{C}$ distances for the outer (1.42 $\AA$ ) and peripheral (1.39-1.41 $\AA$ ) spheres are negligible, suggesting that the electron hole (B-MPh) or extra electron (N-MPh) effectively delocalize into the entire $\pi$-system in a similar way. The differences in effective nuclear charge for $\mathrm{C}, \mathrm{B}$, and $\mathrm{N}$ nevertheless create localized structural perturbations in bond lengths involving the central atom. The overall adsorbent model structure shows insignificant variations (at most $0.02 \AA$, Table 1) among the conceptually converging series of correlated MO theory (MP2, MP4SDQ, CCSD) and the DFT calculations (MN15), all using the $6-311++\mathrm{G}^{* *}$ basis set. The effect of the basis set on geometric structure was investigated by comparing the reference $6-311++G^{* *}$ basis set to three more compact basis sets (631G*, SDDAll, and ST0-3G) and a larger basis set (def2-QZVPP). It is notable that, with the exception of the STO-3G minimal basis set, the compact basis sets yielded nearly identical geometric structure to that of 6-311++G** (Table S3). Similarly, structural optimization with the significantly larger 
def2-QZVPP basis set shows only a $0.01 \AA ̊$ shortening of the inner and outer sphere C-C distances. As needed, these observations allow for the use of a mixed level of theory for geometry optimization (lower, more economical) and electronic structure/energetics analyses (higher, more accurate).

The equilibrium structure of the methane adsorption model can be described as the methane adsorbate "landing" directly above the central site of substitution (X1) for all variants of the MPh adsorbent. This is the characteristic arrangement for tetrel bonding ${ }^{109}$ with the three proximal bonds of the methane forming bent $\mathrm{C}-\mathrm{H} \cdots \pi$ interactions ${ }^{41}$ with the three ring centroids of the adsorbent (a "lander" orientation). The MN15 and all correlated MO levels yield a singular global energy minimum geometry for all of the adsorption models regardless of the $\kappa_{1}, \eta_{2}$, or $\eta_{3}$ initial orientation of the methane relative to the plane of the MPh adsorbent maquette. The inner, outer, and peripheral $\mathrm{C}-\mathrm{C}$ distances of the adsorbent remain unchanged in the adsorption model as compared to the free adsorbent molecule (by comparison of Tables 1 and S2). However, nonnegligible out-of-planarity $(\delta=0.02-0.04 \AA)$ and minor methylidene wagging $\left(\Delta w<2^{\circ}\right.$ toward more linear angle) can be observed upon adsorption, a geometric signature of the methane adsorption interaction.

The equilibrium distance between the adsorbate and adsorbent is often used as a predictor for the adsorption energy. Interestingly, despite the significant inner sphere $\mathrm{C}-\mathrm{C}$ distance variation between B-MPh and MPh, the bond length of the adsorption interaction remains similar for the B$\mathrm{MPh}$ and the unsubstituted MPh maquette. The electron enriched N-MPh maquette, on the other

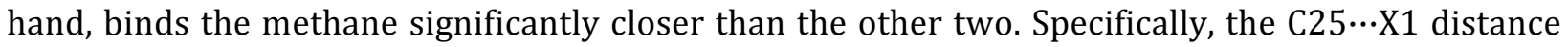
(see Table 2) is similar between B-MPh and MPh to within $0.02 \AA$, but shorter by $0.11 \AA$ for N-MPh. Another indicator for the $\mathrm{C}-\mathrm{H} \cdots \pi$ bond strength is the distance between the proximal $\mathrm{H}$ atoms on

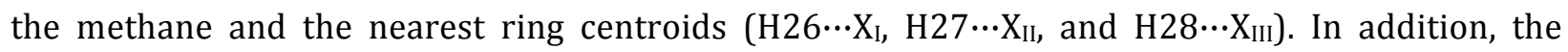
degree of rotation out of ideal eclipse orientation with respect to the ring centroids $(\omega)$ directly correlates with the equilibrium adsorption interaction distance. The N-MPh model is an outlier in both indicators, likely due to aforementioned excited state mixing with the ground state in the electron-correlated MO calculations. The geometries at the MP4SDQ and CCSD levels display considerable puckering (see the methylidene wagging parameter, $w$, in Tables 1 and S4,). To a modest degree, the methane molecule itself is a reporter for the adsorption interaction. In the adsorption model, the $\mathrm{C}-\mathrm{H}$ distances increase by $0.003 \AA$ and $0.001 \AA$ for the proximal and distal C$\mathrm{H}$ bonds, respectively, relative to their values in free methane. These can be taken as structural indicators for the presence and strength of the $\mathrm{C}-\mathrm{H} \cdots \pi$ interactions and tetrel bonding, respectively. 
Table 2. Adsorption system structures (LoT: MN15, MP2, MP4SDQ, or CCSD using the 6-311++G** basis set) of methane on MPh, B-MPh, and N-MPh. Adsorption by one $(n=1)$ and two $(n=2)$ methane molecules is described by interaction distances and twisting angles: methane to central site (C25‥X1) distance, proximal $\mathrm{H}$ to closest ring centroid $\left(\mathrm{H}_{\mathrm{p}} \cdots \mathrm{X}_{\mathrm{i}}\right)$ distance, dihedral angle formed by $\mathrm{X}_{\mathrm{i}} \cdots \mathrm{X} 1 \cdots \mathrm{C} 25-\mathrm{H}_{\mathrm{p}}(\omega)$, and proximal and distal $\mathrm{C}-\mathrm{H}$ bond lengths.

\begin{tabular}{|c|c|c|c|c|c|c|c|}
\hline Adsorbent & LoT & $\mathbf{n}$ & $\mathrm{C} 25 \cdots \mathrm{X} 1, \AA$ & $H_{p} \cdots X_{i}, \AA$ & $\omega,^{\circ}$ & $\mathrm{C}-\mathrm{H}_{\mathrm{p}},{ }^{\mathrm{a}} \AA$ & $\mathrm{C}-\mathrm{H}_{\mathrm{d}},{ }^{\mathrm{a}} \AA$ \\
\hline \multirow[t]{5}{*}{$\overline{\mathrm{MPh}}$} & MN15 & 1 & 3.27 & $2.89 \pm 0.03$ & $0 \pm 1$ & $1.092 \pm 0.000$ & 1.090 \\
\hline & MP2 & 1 & 3.27 & $2.91 \pm 0.06$ & $3 \pm 1$ & $1.092 \pm 0.000$ & 1.092 \\
\hline & MP4SDQ & 1 & 3.40 & $3.01 \pm 0.05$ & $1 \pm 0$ & $1.094 \pm 0.000$ & 1.094 \\
\hline & CCSD & 1 & 3.41 & $3.02 \pm 0.05$ & $1 \pm 1$ & $1.094 \pm 0.000$ & 1.094 \\
\hline & MN15 & 2 & $3.26 \pm 0.00$ & $2.92 \pm 0.03$ & $1 \pm 0$ & $1.092 \pm 0.000$ & $1.090 \pm 0.000$ \\
\hline \multirow[t]{5}{*}{ B-MPh } & MN15 & 1 & 3.29 & $2.92 \pm 0.04$ & $5 \pm 1$ & $1.091 \pm 0.000$ & 1.090 \\
\hline & MP2 & 1 & 3.27 & $2.91 \pm 0.06$ & $3 \pm 1$ & $1.092 \pm 0.000$ & 1.092 \\
\hline & MP4SDQ & 1 & 3.30 & $2.99 \pm 0.04$ & $3 \pm 1$ & $1.094 \pm 0.000$ & 1.094 \\
\hline & CCSD & 1 & 3.35 & $3.06 \pm 0.05$ & $3 \pm 2$ & $1.094 \pm 0.000$ & 1.094 \\
\hline & MN15 & 2 & $3.27 \pm 0.00$ & $2.94 \pm 0.04$ & $4 \pm 1$ & $1.091 \pm 0.000$ & $1.090 \pm 0.000$ \\
\hline \multirow[t]{5}{*}{$\mathrm{N}-\mathrm{MPh}$} & MN15 & 1 & 3.16 & $2.80 \pm 0.00$ & $1 \pm 1$ & $1.092 \pm 0.000$ & 1.090 \\
\hline & MP2 & 1 & 3.10 & $2.78 \pm 0.02$ & $6 \pm 1$ & $1.092 \pm 0.000$ & 1.091 \\
\hline & MP4SDQ & 1 & 3.16 & $2.85 \pm 0.07$ & $11 \pm 2$ & $1.093 \pm 0.000$ & 1.092 \\
\hline & CCSD & 1 & 3.23 & $2.88 \pm 0.07$ & $12 \pm 3$ & $1.101 \pm 0.002$ & 1.094 \\
\hline & MN15 & 2 & $3.16 \pm 0.00$ & $2.81 \pm 0.01$ & $1 \pm 1$ & $1.092 \pm 0.000$ & $1.090 \pm 0.000$ \\
\hline
\end{tabular}

aThe C-H bond lengths in free methane are $1.089 \AA$ (MN15), $1.090 \AA$ (MP2), $1.093 \AA$ (MP4SDQ), and $1.093 \AA ̊$ (CCSD).

The consequences of higher adsorbate loading were modeled by considering a methane molecule on both sides of the adsorbent $(n=2$, see Table 2). At all levels of theory, adsorption by two methane molecules leads to a symmetrical "lander" orientation of the equilibrium structure on both sides. The symmetrical interactions enforce strict planarity of the adsorbent $(\delta<0.005 \AA)$ and near planarity of the methylidene group $\left(\Delta w<2^{\circ}\right)$. As a positive foretoken for high methane uptake capacity on molecularly thin carbon surfaces such as ZTC, the distance between the adsorbent and adsorbate is only slightly affected in the double adsorption system. Thus, the two sides of the $\pi$ system of the MPh maquette have the capacity to store two adsorbent molecules. The two methane molecules are in fact closer to the adsorbent $(\Delta(\mathrm{C} 25 \cdots \mathrm{X} 1)=-0.02 \AA)$ despite that the $\mathrm{C}-\mathrm{H} \cdots \pi$ bond distances slightly increase $\left(\Delta\left(\mathrm{H}_{\mathrm{p}} \cdots \mathrm{X}_{\mathrm{i}}\right)=+0.03\right)$. This is an indication of mutual polarizability of the adsorbate. Using the "lander" analogy, the three legs of the lander spread wider as it approaches closer to the surface since the adsorption model balances the effects of tetrel bonding (related to $\mathrm{C} 25 \cdots \mathrm{X} 1$ distances) and $\mathrm{C}-\mathrm{H} \cdots \pi$ interactions $\left(\mathrm{H}_{\mathrm{p}} \cdots \mathrm{X}_{\mathrm{i}}\right.$ distances$)$.

Analysis of the conceptually converging series of correlated MO theories (MP2, MP4SDQ, and CCSD) reveals some shortcomings of the MN15 level. This is exemplified by investigating the effective length of the adsorption interaction as a sensitive metric for the strength of the $\mathrm{C}-\mathrm{H} \cdots \pi$ interaction. The distance between the methane carbon (C25) and site of substitution (X1) and the average of the three distances between the proximal $\mathrm{H}$ atoms of the methane molecule and the nearest ring

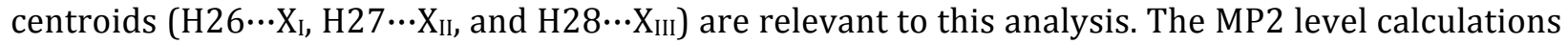
(3.27 $\AA 2.91 \AA$ ) show close agreement with those at the MN15 level (3.27, $2.89 \AA$ ), using the same 6-311++G** basis set. On the contrary, the MP4SDQ (3.40, $3.01 \AA$ ) and CCSD (3.41 $\AA$, $3.02 \AA$ ) calculations, with the same basis set but a more complete treatment of electron correlation than 
MP2, indicate that the MN15 and MP2 calculations significantly underestimate the distance of the adsorption interaction by $\sim 0.1 \AA$. The use of a larger basis set (def2-QZVPP) with the MN15 functional modestly corrects this effect of over-binding of methane (by comparison of MN15 and MN15+ in Tables 2 and S2), increasing the adsorption interaction distance by 0.01-0.02 $\AA$, regardless of the adsorbent composition. However, even at this high level of DFT (MN15+), the distance remains overestimated by $\sim 0.03 \AA$ by comparison to the correlated MO theory calculations.

Toward the future goal of applying our computational approach to larger maquettes of amorphous carbon materials where computational cost is more severe, the performance of smaller basis sets was also investigated, such as the commonly used double- $\zeta$ quality basis set $\left(6-31 \mathrm{G}^{*}\right)$. For the adsorbent alone, there are no significant differences between this smaller basis set (Table S3, MN15-) and the larger triple- and quadruple- $\zeta$ quality basis sets (Tables 1 and S3, MN15 and MN15+, respectively) in terms of molecular structure. The good geometric agreement between smaller basis sets and the more saturated ones continues for the triple- $\zeta$ quality valence shell basis set with effective core potential treatment for the 1s core electrons (Table S3, [MN15]). However, this trend no longer holds for the STO-3G minimal basis set (Table S3, \{MN15\}), as expected. The high similarity among the basis sets involving at least double- $\zeta$ quality valence shell basis functions extends to the highlighted internal coordinates obtained for the absorption models (Tables S4-S6, [MN15], MN15-, MN15, and MN15+). This suggests that adsorption geometries can already be obtained at the modest MN15/6-31G* level, or even at the valence-electron only MN15/SDDAll level, at an acceptable chemical accuracy. In situations where minimal basis sets have to be employed due to prohibitively large system sizes, one is often better off resorting to DFTB approaches that compensate for the lack of a large basis set by exploiting optimized electronic parameters. ${ }^{57}$

\subsection{Energetics}

Contrary to the molecular structure, the energetics of methane adsorption on MPh show significant variation as a function of the identity of the central site of substitution (see Table 3). By all methods and at all levels of theory, the electron enriched N-MPh adsorbent exhibits the highest change in energy upon desorption, and therefore reports the strongest adsorbate/adsorbent interaction (binding energy). The relative size of the basis set superposition error (BSSE) as compared to the differences in the desorption energies among the three adsorbents indicates the need to use an even larger basis set than $6-311++\mathrm{G}^{* *}$ for acceptable chemical accuracy. Subsequent calculations at the MN15/def2-QZVPP (MN15+) level reduced the BSSE to $\leq 0.3 \mathrm{~kJ} \mathrm{~mol}^{-1}$ per methane molecule. It is also important to gauge the energetic cost of adsorbent and adsorbate distortion due to adsorption (Ewarp), which can be used as an indicator to differentiate between physisorption and chemisorption in terms of the magnitude of the binding energy. As shown in Table 3, even the highest deformation energy ( $0.5 \mathrm{~kJ} \mathrm{~mol}^{-1}$ for the asymmetric $\mathrm{B}-\mathrm{MPh} \times \mathrm{CH}_{4}$ adsorption model) is less than $3 \%$ of the total interaction energy and below our desired chemical accuracy of $1 \mathrm{~kJ} \mathrm{~mol}^{-1}$; therefore, this effect was disregarded in all further thermochemical analyses.

The structures of the adsorbent and adsorption models (Tables 1, S3-S5) indicate that the basis set effect on geometry is negligible at all levels above the minimal basis set. In a similar comparison, the binding energies calculated at the reference level of theory (MN15/6-311++ $\mathrm{G}^{* *}$ ), shown as MN15 in Table 3, were compared to those determined using several smaller (Table S6, MN15-, [MN15], and $\{$ MN15\}) and larger basis sets (Table S6, MN15+). The considerably different BSSE in 
Table 3. Desorption energies (in $\mathrm{kJ} \mathrm{mol}^{-1}$ ) and entropies (in multiples of the universal gas constant, $\mathrm{R}=$ $8.314 \mathrm{~J} \mathrm{~mol}^{-1} \mathrm{~K}^{-1}$ ) for $\mathrm{MPh} \times \mathrm{nCH}_{4} \rightarrow \mathrm{MPh}+\mathrm{nCH}_{4}\left(\mathrm{LoT}: \mathrm{MN} 15 / 6-311++\mathrm{G}^{* *}\right)$. The interaction energy is corrected by the basis set superposition error (BSSE) from counterpoise calculation, and compared to the distortion energy ( $E^{\text {warp }}$ ), the difference in energy between the structure of the adsorbate and adsorbent in the adsorption model and at infinite separation. The standard enthalpy, Gibbs free energy, and entropy of desorption are calculated at $298 \mathrm{~K}$ using a simple statistical mechanical model assuming ideal gas behavior. Condensed phase free energy ( $\left.\Delta \mathrm{G}^{\circ}{ }_{\text {cond }}\right)$ and entropy $\left(\Delta \mathrm{G}^{\circ}{ }_{\text {cond }}\right)$ are calculated using a free volumebased translational entropy correction for liquid methane at $100 \mathrm{~K}$ and $1 \mathrm{~atm}$. A modest statistical analysis (average and standard deviation) of the thermochemical quantities is shown, normalized per mole of $\mathrm{CH}_{4}$.

\begin{tabular}{|c|c|c|c|c|c|c|c|c|c|}
\hline Adsorbent & $\mathbf{n}$ & $\begin{array}{c}\Delta E^{Q M} \\
\text { kJ mol-1 }\end{array}$ & $\begin{array}{c}\text { BSSE } \\
\text { kJ mol-1 }\end{array}$ & $\begin{array}{c}\text { Ewarp } \\
\text { kJ mol-1 }\end{array}$ & 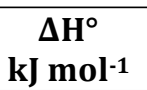 & $\begin{array}{c}\Delta \mathrm{G}^{\circ} \\
\mathrm{kJ} \mathrm{mol} \mathrm{mol}^{-1}\end{array}$ & $\begin{array}{c}\Delta \mathbf{S}^{\circ} \\
\mathbf{R}\end{array}$ & 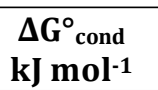 & $\begin{array}{c}\Delta \mathbf{S}_{\text {cond }} \\
\mathbf{R}\end{array}$ \\
\hline$\overline{\mathrm{MPh}}$ & 1 & 17 & 2.4 & 0.4 & 10 & -20 & 12 & 4 & 2 \\
\hline $\mathrm{B}-\mathrm{MPh}$ & 1 & 15 & 1.2 & 0.5 & 9 & -19 & 12 & 5 & 2 \\
\hline $\mathrm{N}-\mathrm{MPh}$ & 1 & 19 & 1.8 & 0.2 & 12 & -22 & 14 & 3 & 4 \\
\hline MPh & 2 & 33 & 4.6 & 0.1 & 18 & -40 & 23 & 9 & 4 \\
\hline B-MPh & 2 & 29 & 2.5 & 0.2 & 17 & -39 & 23 & 10 & 3 \\
\hline $\mathrm{N}-\mathrm{MPh}$ & 2 & 38 & 3.6 & 0.1 & 24 & -38 & 25 & 11 & 5 \\
\hline $\mathrm{MPh}$ & per $\mathrm{CH}_{4}$ & & $14.4 \pm 0.4$ & & $9.4 \pm 0.5$ & $-20.2 \pm 0.2$ & $12.0 \pm 0.3$ & $4.4 \pm 0.2$ & $2.0 \pm 0.3$ \\
\hline B-MPh & per $\mathrm{CH}_{4}$ & $\Delta \mathrm{E}^{\mathrm{QM}^{*}}=$ & $13.6 \pm 0.3$ & & $8.9 \pm 0.3$ & $-19.5 \pm 0.1$ & $11.4 \pm 0.1$ & $5.2 \pm 0.1$ & $1.5 \pm 0.1$ \\
\hline $\mathrm{N}-\mathrm{MPh}$ & per $\mathrm{CH}_{4}$ & & $17.2 \pm 0.2$ & & $12.1 \pm 0.1$ & $-20.6 \pm 2.1$ & $13.2 \pm 0.9$ & $4.0 \pm 2.1$ & $3.3 \pm 0.9$ \\
\hline
\end{tabular}

MN15- $\left(3.7 \pm 0.1 \mathrm{~kJ} \mathrm{~mol}^{-1}\right.$ per $\left.\mathrm{CH}_{4}\right)$ and $\mathrm{MN} 15+\left(0.3 \pm 0.0 \mathrm{~kJ} \mathrm{~mol}^{-1}\right.$ per $\left.\mathrm{CH}_{4}\right)$ calculations relative to the MN15 level calculation $\left(1.8 \pm 0.5 \mathrm{~kJ} \mathrm{~mol}^{-1}\right.$ per $\left.\mathrm{CH}_{4}\right)$ establishes an objective ranking of the quality of the basis sets for the given adsorption models. Despite the significant BSSE, fortuitous error cancellations lead to a remarkable similarity between the binding energies $\left(\Delta \mathrm{E}^{\mathrm{QM}}\right)$ calculated using the low quality, smaller 6-31G* basis set (Table S6, MN15-) and those calculated using the high quality, larger def2-QZVPP basis set (Table S6, MN15+). Both results are significantly different from those calculated at the reference MN15/6-311++ ${ }^{* *}$ level (Table 3, MN15). However, as the size of the basis set is reduced, both the absolute and relative values start to display very different trends, and thus caution should be exercised in their interpretation. To directly address the basis set dependence of the binding energy estimates, "Complete Basis Set" extrapolation method (Table S6, CBS) utilizing a modified QB3 scheme were carried out using the MN15/6-311++G** equilibrium structures. The trend of a stronger binding strength for methane on N-MPh over both $\mathrm{MPh}$ and B-MPh adsorbents was confirmed.

A simplistic ideal gas based statistical mechanical model was used to assess the thermochemistry of methane adsorption on MPh and its heteroatom substituted variants. The desorption enthalpies at standard conditions $\left(\Delta \mathrm{H}^{\circ}\right)$ at the reference level (Table 3, MN15) and all higher levels (Table S6, MN15+ and CBS) are endothermic (exothermic with respect to adsorption) and clearly favor adsorption on $\mathrm{N}-\mathrm{MPh}$. However, the free energies of desorption are similar for all three adsorbents and are positive, which indicates an important contribution from entropy that is inherent to theoretical calculations made in the absence of a chemical reservoir of methane. Nevertheless, there is remarkable self-consistency in how the desorption energies vary depending on the size of the basis set with that of the differences in the geometric structures of the adsorption models. Importantly, the reference $6-311++G^{* *}$ basis set (Table 2, MN15) was found to underestimate the 
Table 4. Desorption energies $\left(\Delta \mathrm{EQM}^{\mathrm{M}}\right.$ in $\left.\mathrm{kJ} \mathrm{mol}^{-1}\right)$ for $\mathrm{MPh} \times \mathrm{nCH}_{4} \rightarrow \mathrm{MPh}+\mathrm{nCH}_{4}$ from a conceptually converging series of correlated MO theories (LoT: MP2, MP3, MP4, and CCSD(T) using the 6-311++G** basis set and MN15/6-311++ $\mathrm{G}^{* *}$ equilibrium structures). A modest statistical analysis (average and standard deviation) of the thermochemical quantities is shown, normalized per mole of $\mathrm{CH}_{4}$. Significant basis set superposition errors exist at all levels, ranging from $10-14 \mathrm{~kJ} \mathrm{~mol}^{-1}\left(\mathrm{~B}-\mathrm{MPh}: 10.6 \pm 0.6 \mathrm{~kJ} \mathrm{~mol}^{-1}, \mathrm{MPh}\right.$ : $13.5 \pm 0.8 \mathrm{~kJ} \mathrm{~mol}^{-1}, \mathrm{~N}-\mathrm{MPh}: 12.7 \pm 0.7 \mathrm{~kJ} \mathrm{~mol}^{-1}$ ); thus, $\Delta \mathrm{E}^{\mathrm{QM}^{*}}$ values are not reported here.

\begin{tabular}{|c|c|c|c|c|c|}
\hline \multirow{2}{*}{ Adsorbent } & \multirow{2}{*}{$\mathbf{n}$} & \multicolumn{4}{|c|}{$\Delta \mathrm{E}^{\mathrm{QM}}\left(\mathrm{kJ} \mathrm{mol}^{-1}\right)$} \\
\hline & & MP2 & MP3 & MP4a & $\operatorname{CCSD}(\mathrm{T})^{\mathrm{b}}$ \\
\hline MPh & 1 & 24 & 17 & 22 & 20 \\
\hline B-MPh & 1 & 17 & 14 & 18 & 16 \\
\hline $\mathrm{N}-\mathrm{MPh}$ & 1 & 21 & 16 & 22 & 22 \\
\hline MPh & 2 & 45 & 32 & 42 & 38 \\
\hline B-MPh & 2 & 36 & 29 & 37 & 34 \\
\hline $\mathrm{N}-\mathrm{MPh}$ & 2 & 43 & 33 & 43 & 42 \\
\hline MPh & per $\mathrm{CH}_{4}$ & $23.0 \pm 0.6$ & $16.3 \pm 0.3$ & $21.4 \pm 0.5$ & $19.4 \pm 0.4$ \\
\hline B-MPh & per $\mathrm{CH}_{4}$ & $17.7 \pm 0.4$ & $14.4 \pm 0.5$ & $17.9 \pm 0.4$ & $17.3 \pm 0.3$ \\
\hline $\mathrm{N}-\mathrm{MPh}$ & per $\mathrm{CH}_{4}$ & $21.4 \pm 0.0$ & $16.5 \pm 0.0$ & $21.4 \pm 0.0$ & $20.6 \pm 0.1$ \\
\hline
\end{tabular}

aMP4 results are single-point energy calculations using the MP4SDQ geometry (MP4SDQ|MP4). ${ }^{b} \mathrm{CCSD}(\mathrm{T})$ results are single-point energy calculations using the CCSD geometry (CCSD|CCSD(T)).

adsorption binding distance (leading to an overestimation of the binding strength) relative to the more complete def2-QZVPP basis set (Table S5, MN15+).

The entropic penalty incurred upon bringing the adsorbent and adsorbate together in the dilute gas phase simulations at $298 \mathrm{~K}$ and 1 atm (the Henry's law limit) renders the in vacuo desorption free energy $\left(\Delta G^{\circ}\right)$ negative and adsorption non-spontaneous. However, at $100 \mathrm{~K}$ and $1 \mathrm{~atm}$ where the methane phase is liquid, the translational entropy term is drastically reduced compared to the ideal gas phase value; thus, the total entropy change ( $\Delta \mathrm{S}^{\circ}$ cond $)$ decreases by roughly an order of magnitude. By this reasoning, the adsorption process is estimated to be spontaneous at $298 \mathrm{~K}$ when using a liquid molar volume $\left(36.4 \mathrm{~mL} \mathrm{~mol}^{-1}\right)$ of methane in the translational entropy correction. The density of the free methane phase corresponding to an equilibrium condition $\left(\Delta \mathrm{G}^{\circ}=0\right)$ for $\mathrm{MPh}$ at $298 \mathrm{~K}$ is $0.439 \mathrm{~g} \mathrm{~mL}^{-1}$, which is consistent with measurements of the adsorbed phase of methane on highly porous (atomically thin, double-sided) adsorbent structures, such as zeolite-templated carbon (see Discussion). ${ }^{49}$

The optimized geometries showed significant variations between the DFT and correlated MO calculations that reveals the different treatment of intermolecular interactions. It is then critical to evaluate whether the energetic preference for methane adsorption on N-MPh determined at all respectable levels of DFT also holds at higher levels of theory (i.e., correlated MO theory), and ultimately at the mCBS-QB3 level. To this end, single-point energy calculations were carried out at the MP2, MP3, MP4, and CCSD(T) levels, starting from the equilibrium adsorption structures obtained at the MN15/6-311++G** level (Table 4). Despite the considerable size of the basis set employed, the BSSE at all levels of correlated MO theory is considerably higher (10-14 kJ mol-1 per $\mathrm{CH}_{4}$ ) than at the MN15 reference level (1.2-2.4 $\mathrm{kJ} \mathrm{mol}^{-1}$ per $\left.\mathrm{CH}_{4}\right)$, which is reduced to $\leq 0.3 \mathrm{~kJ} \mathrm{~mol}^{-1}$ per $\mathrm{CH}_{4}$ at the MN15+ level. The single-point calculations at the MP2, MP3, and MP4 levels show mixed trends for the binding energy of methane on MPh and N-MPh; however, they all consistently 
show the lowest binding energy of methane on B-MPh. The results of the highest level CCSD(T) single point calculations parallel the trends in energetics observed at the MN15 reference level. These results validate the accuracy of the level of DFT used in this work. Overall, a higher binding energy of methane is observed for N-MPh over the unsubstituted MPh adsorbent at the CCSD(T) level, while a lower binding energy of methane is always observed for B-MPh than for the unsubstituted $\mathrm{MPh}$ model. These trends are consistent with the outcome of the mCBS-QB3 calculations using the MN15/6-311++G** geometries (Tables S5-S6) for the potential energy, enthalpy, and Gibbs free energy of desorption.

To better understand the mixed trends among the binding energies in Table 4, a considerable computational effort was undertaken to investigate the effect of relaxing the DFT structures in order to perform binding energy calculations using correlated MO theory (see Table S7). Starting from the MN15/6-311++G** structures (energetics shown in Table 3), consecutive optimizations were carried out at gradually higher correlated MO levels following the conceptually converging series of MP2, MP3, MP4SDQ, and CCSD methods. Comparison of the single-point and fully relaxed correlated MO theory calculations (Table S7) indicates that the desorption energy is in fact underestimated in single-point energy calculations, but only by $\sim 1 \mathrm{~kJ} \mathrm{~mol}^{-1}$ (with some notable exceptions, especially for $\mathrm{N}-\mathrm{MPh}$ at the $\operatorname{CCSD}(\mathrm{T})$ level). Hence, full relaxation of the adsorption structures using correlated MO methods, in light of their high computational cost, cannot be justified for computational high-throughput work. Additionally, the mixed trends in binding energy are likely due to specific intricacies inherent to the electronic structure differences among the density functional and various correlated MO theory calculations, and not of structural origins.

\subsection{Electronic Structure Analysis}

Despite the overall non-polar nature of all components of the adsorption models studied in this work, electronic structure analysis reveals remarkable insights into the effects of heteroatom substitution on the binding of methane to the conjugated $\pi$-system of the MPh adsorbent. The charge distribution among the atomic constituents of the $\mathrm{MPh} \times \mathrm{nCH}_{4}$ adsorption models at the MN15+ level, as calculated by three different analysis methods, is shown in Figure 2 (see also Tables S8-S9).

Recall that the geometric structure of the adsorption models as compared to the free adsorbent molecules indicates notable perturbations around the site of substitution (X1) and within the innersphere $(\alpha)$ of carbon sites. However, the atomic charge distributions from Hirshfeld (HPA) and Merz-Kollman electrostatic potential (ESP) population analyses do not show a characteristic difference at X1, owing to the effects of electron/hole delocalization. Contrarily, the Weinhold natural orbital-based population analysis (NPA) that gives a more localized electron density description, clearly shows the presence of an electron hole (positive charge) on the boron site in the $\mathrm{B}-\mathrm{MPh}$ adsorption model and an extra electron (negative charge) on the nitrogen site in the N-MPh adsorption model.

The corresponding NPA valence electronic configurations further expose the differences between the three adsorption systems: $\mathrm{MPh} \times \mathrm{CH}_{4}\left(2 \mathrm{~s}^{0.85} 2 \mathrm{p}^{3.15}\right), \mathrm{B}-\mathrm{MPh} \times \mathrm{CH}_{4}\left(2 \mathrm{~s}^{0.57} 2 \mathrm{p}^{1.80}\right)$, and $\mathrm{N}-\mathrm{MPh} \times \mathrm{CH}_{4}$ $\left(2 \mathrm{~s}^{1.15} 2 \mathrm{p}^{4.16}\right)$ at the site of substitution. The deviations in the valence electron configuration from their formal atomic values parallel the effective nuclear charge and electronegativity differences among the $\mathrm{C}, \mathrm{B}$, and $\mathrm{N}$ central atoms. In all population analyses (though to the least extent in ESP), the undulation of the atomic charges away from the central site is visible; the lack of an electron in 


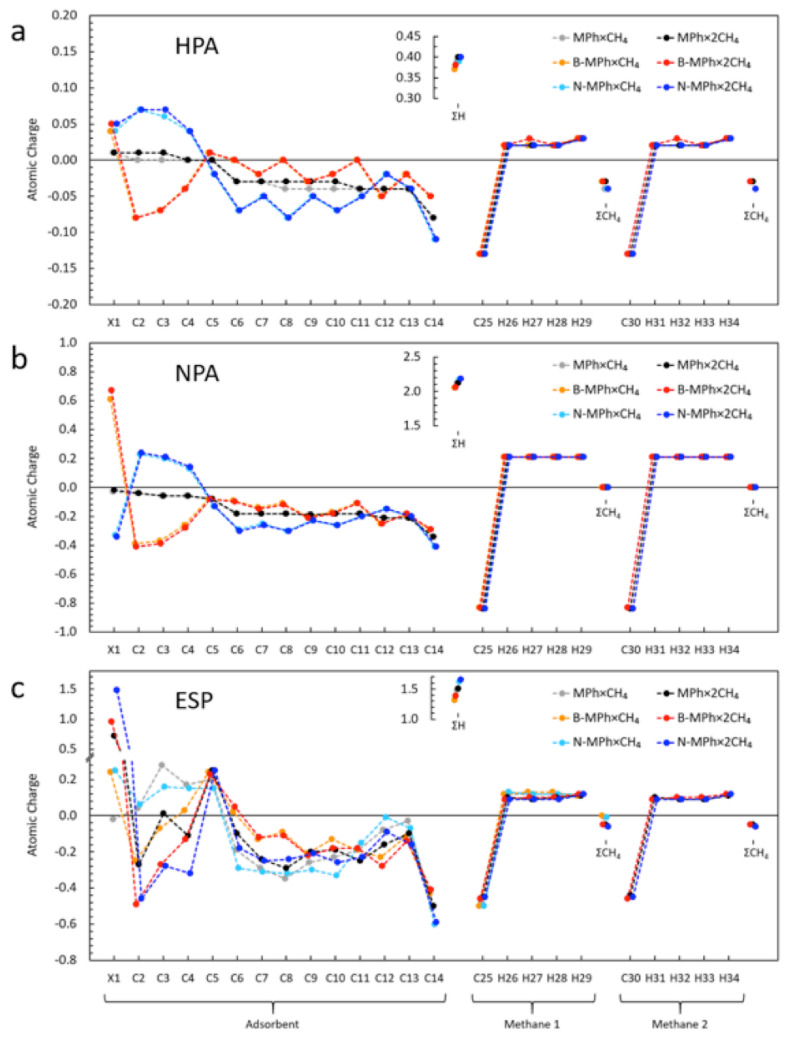

Figure 2. Atomic charge (in $\left.e^{-}\right)$distribution analysis upon single $(\mathrm{n}=1)$ and double $(\mathrm{n}=2)$ methane adsorption on MPh (grey/black), B-MPh (orange/red), and N-MPh (cyan/blue) determined by three conceptually different population analysis methods: (a) Hirshfeld (HPA), (b) Weinhold (NPA), and (c)

Merz-Kollman (ESP), at the MN15/def2-QZVPP level of theory. See Figures S1-S3 for the atomic numbering and Tables S7-S8 for the tabulated results.

$\mathrm{B}-\mathrm{MPh} \times \mathrm{nCH}_{4}$ and the extra electron in $\mathrm{N}-\mathrm{MPh} \times \mathrm{nCH}_{4}$ propagate through the inner $(\alpha)$, outer $(\beta)$, and peripheral $(\gamma)$ spheres of carbon sites in the MPh adsorbent. The differences among the three models lessen at the periphery, which lends credibility to the rationale for using the tricyclic MPh molecule as the smallest representative maquette of porous carbon surfaces (as opposed to benzene or naphthalene). The atomic charge on the methylidene carbon (C14), serving as a spectator for the triple ring system, correlates with the electronic structure differences of the $\mathrm{C}, \mathrm{B}$, and $\mathrm{N}$ central atoms; it is the most electrophilic on B-MPh and least electrophilic on N-MPh. The ESP results are the least reasonable overall, especially at the site of substitution where the B-MPh and $\mathrm{N}-\mathrm{MPh}$ adsorption models show excessively high positive charge. This limitation of ESP at the central site is expected, since the electron density contribution from X1 is obscured by the adsorbate molecule, and thus does not contribute significantly to the surface charge witnessed by the probe. All population analyses indicate a slightly acidic character of the (ten) peripheral $\mathrm{C}-\mathrm{H}$ bonds in all three adsorption models. The partial (per H atom) charges are $+0.04,+0.21$, and +0.15 , with standard deviations of \pm 0.01 , by HPA, NPA, and ESP analysis, respectively.

Lastly, the electronic structure of the methane adsorbate is remarkably similar across all adsorption models within each method of analysis. Contrary to the clarity it imparted at the site of 


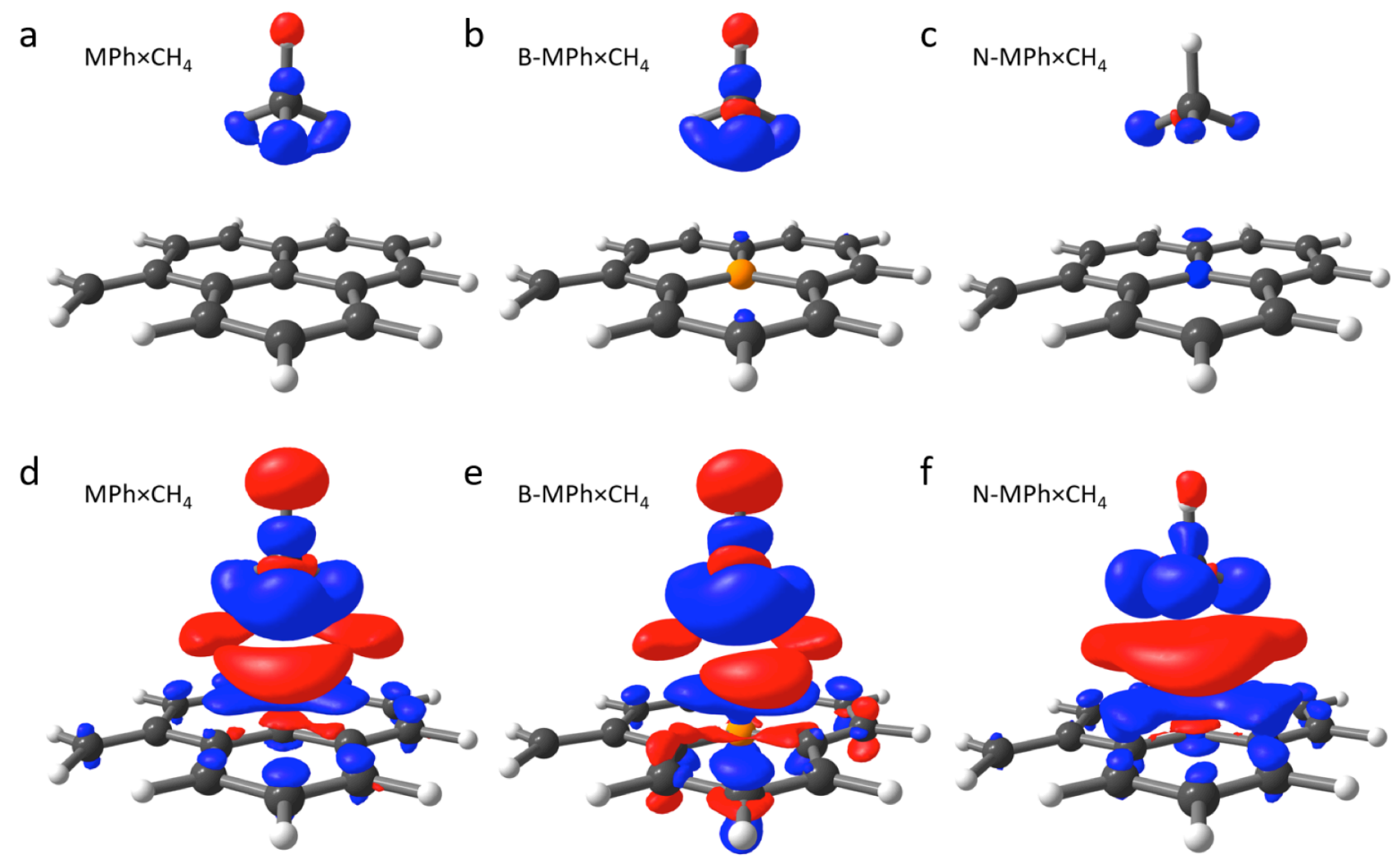

Figure 3. Electron density difference plots for methane interactions with MPh and its heteroatomsubstituted variants: (a-c) at a high contour level of $5 \times 10^{-4}\left(e^{-}\right)^{2} \AA^{-3}$ and (d-f) at a low contour level of $1.5 \times 10^{-4}\left(e^{-}\right)^{2} \AA^{-3}$ for $\mathrm{MPh} \times \mathrm{CH}_{4}(\mathrm{a}, \mathrm{d}), \mathrm{B}-\mathrm{MPh} \times \mathrm{CH}_{4}(\mathrm{~b}, \mathrm{e})$, and $\mathrm{N}-\mathrm{MPh} \times \mathrm{CH}_{4}$ (c,f). Electron density difference between the adsorption model and free adsorbent and adsorbate molecules at the MN15/def2-QZVPP level is shown (positive difference in red, negative difference in blue). See Figure $\mathbf{S 5}$ for the corresponding double $(\mathrm{n}=2)$ adsorption models.

substitution, however, as a molecular orbital-based population analysis, the NPA method only shows the internal polarization of the adsorbate as opposed to charge transfer from the adsorbent. However, both ESP and HPA analyses clearly reveal the presence of charge transfer (0.02-0.04 $e^{-}$) into the methane adsorbate. The results of the latter methods can be trusted due to their high fidelity splitting of the electron density among the atomic fragments in a chemically reasonable way.

The changes in electron density due to adsorption can be visualized by inspecting the total electron density difference plots, shown for the single $(n=1)$ adsorption models in Figure 3 (see Figure S5 for the corresponding $\mathrm{n}=2$ models). The high and low contour levels were selected to highlight electron density differences as indicators for the largest and the most well-developed electronic structure perturbations due to adsorption, respectively.

The comprehensive picture of the methane adsorption interaction on MPh can be described as alternating waves of electron density gains (red contours) and electron density losses (blue contours) propagating through the entire adsorption model. Initially (Figure 3, top panels), the C$\mathrm{H}$ bonds of the methane adsorbate show polarization by losing electron density around the proximal $\mathrm{H}$ atoms and gaining electron density at the distal $\mathrm{H}$ (for MPh and B-MPh) or methane $\mathrm{C}$ atom (for $\mathrm{N}-\mathrm{MPh}$ ). This reflects a degree of electron repulsion from the $\pi$-electron cloud of the adsorbent and effectively creates an induced dipole involving the proximal and distal $\mathrm{H}$ atoms of 


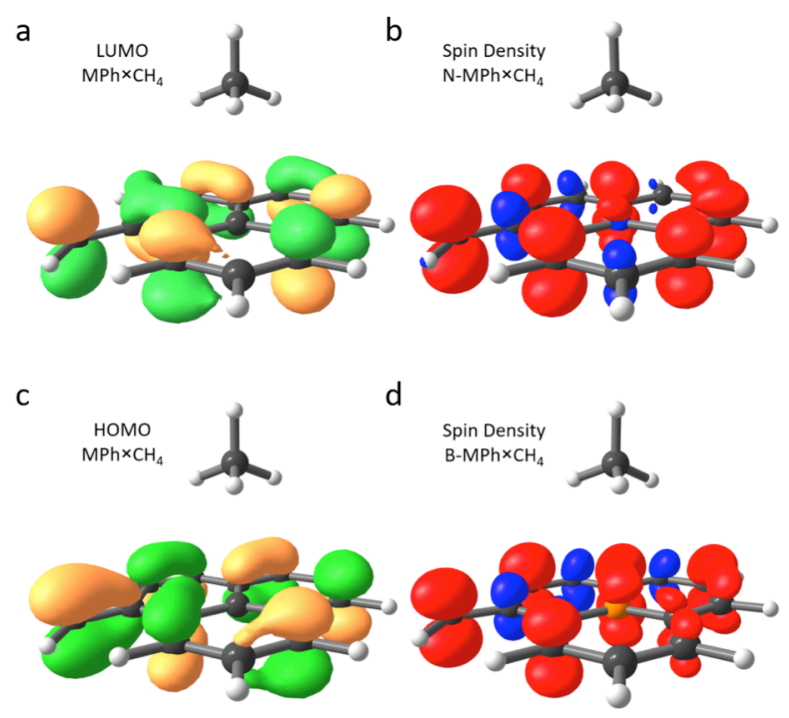

Figure 4. Comparison of the electron density of $\mathrm{MPh}$ and the spin density of B-MPh and N-MPh upon methane adsorption. (a) LUMO and (c) HOMO electron density contour plots for $\mathrm{MPh} \times \mathrm{CH}_{4}$ at a contour level of $4.5 \times 10^{-2}\left(e^{-}\right)^{2} \AA^{-3}$ and (b,d) spin density contour plots for $\mathrm{N}-\mathrm{MPh} \times \mathrm{CH}_{4}$ and $\mathrm{B}-\mathrm{MPh} \times \mathrm{CH}_{4}$ at a contour level of $3.5 \times 10^{-3}\left(e^{-}\right)^{2} \AA^{-3}$. See Figure $\mathbf{S} \mathbf{6}$ for the corresponding double $(\mathrm{n}=2)$ adsorption models.

the adsorbate. Even more fascinating is the appearance of lobes and rings above the adsorbent MPh molecule as the electron repulsion from the methane adsorbate creates ripples in the $\pi$-electron cloud. The alternating blue and red contours in Figures $\mathbf{3}$ and $\mathbf{S 3}$ are the graphical representation of a network of induced charge interactions that become components of the adsorption binding energies. The higher adsorption energy for the $\mathrm{N}-\mathrm{MPh} \times \mathrm{nCH}_{4}$ models is correlated with the greater continuity of the lobes and rings of induced charges in comparison to the B-MPh and MPh adsorption models. The B-MPh and MPh models, on the other hand, exhibit considerable node-like density features, as shown in the bottom panels of Figures $\mathbf{3}$ and $\mathbf{S} \mathbf{3}$ at the same contour levels. These electron density contour map differences further illuminate the earlier described "lander" model of methane adsorption on $\mathrm{MPh}$; the adsorbate "lander" touches down on the "soft", polarizable $\pi$-electron cloud of the adsorbent creating ripples in the electron density, like dust kicked up upon landing or circular waves spreading outward from where a droplet hit a water surface.

The presence of an electron hole and extra electron in the B-MPh and N-MPh maquettes, respectively, permits the analysis of the distribution of spin density within the adsorption models. The frontier molecular orbitals of the unsubstituted $\mathrm{MPh} \times \mathrm{CH}_{4}$ adsorption model and the spin density contour plots of the heteroatom-substituted variants are compared in Figure 4. Given that the MPh adsorbent has 14 electrons in $142 \mathrm{p}_{\mathrm{z}}$ atomic orbitals forming the conjugated $\pi$-system, the HOMO corresponds to the $\pi_{3 a}$ combination, which is the $\pi_{7}$-orbital with 3 nodal planes. Correspondingly, the LUMO is the $\pi_{3 b}$ combination, i.e., the $\pi_{8}$-orbital. In substituting the central site $(\mathrm{X} 1=\mathrm{C})$ of MPh with B, an electron hole is formally created in the HOMO (Figure 4c); likewise, an electron is formally added to the LUMO (Figure 4a) upon substitution with N. Importantly, as witnessed by comparison of the left- and right-hand sides of Figure 4, these formally electron loss/capture events, upon relaxation of the electron density, do not correspond to the electronic structure that is represented by the spin density contour plots (Figures $\mathbf{4 b}$ and $\mathbf{4 d}$ ). The spin 
density contours cannot be clearly assigned to any single $\pi$ - or $\pi^{*}$-orbital, which is an indication of the emergence of multi-reference character in the electronic structure of the adsorption system. This can also be correlated with the extent of spin polarization of the electron density owing to a different composition of the spin-up and spin-down spin orbitals as a function of the central atom electron count. The orbital mixing and the corresponding spin polarization of the electronic structure of three adsorption models are quantitatively depicted in Figure 5. 


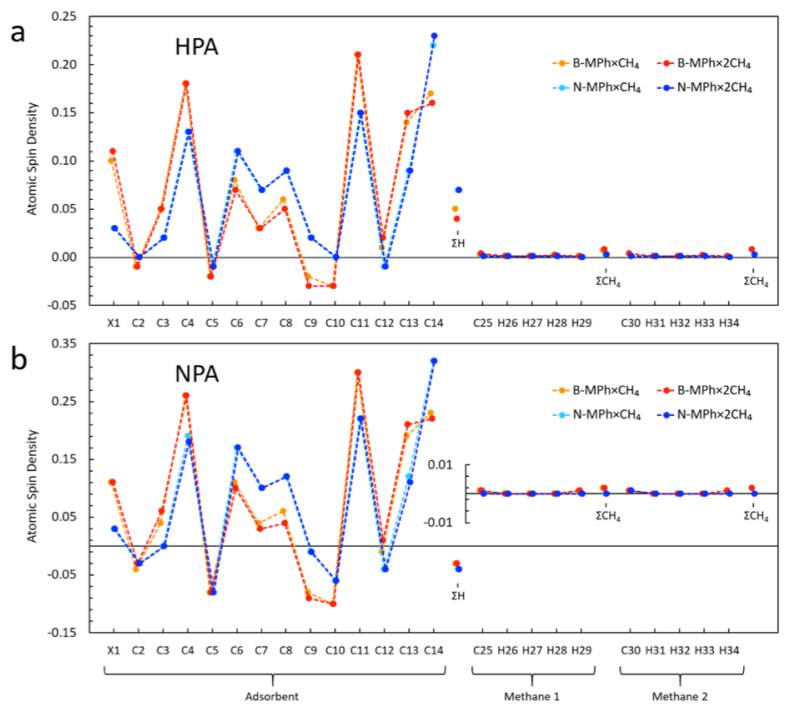

Figure 5. Atomic spin density distribution analysis upon single $(n=1)$ and double $(n=2)$ methane adsorption on B-MPh (orange/red) and N-MPh (cyan/blue) determined by two conceptually different population analysis methods: (a) Hirshfeld (HPA) and (b) Weinhold (NPA), at the MN15/def2-QZVPP level of theory. See Figures S1-S3 for the atomic numbering and Tables S10-S11 for the tabulated data.

The unpaired electron distribution among the atomic constituents of the $\mathrm{MPh} \times \mathrm{nCH}_{4}$ adsorption models at the MN15+ level, as calculated by the HPA and NPA analysis methods, is shown in Figure 5 (see also Tables S8-S9). Contrary to the variations in atomic charges that are the sum of spin-up $(\alpha)$ and spin-down $(\beta)$ one-electron densities (wherein errors accumulate), the spin densities show only negligible dependence on the population analysis method (due to error cancelation). The Weinhold analysis (NPA) displays a slightly larger spin polarization than the Hirshfeld analysis (HPA); however, the overall spin density distribution as a function of atom location in the adsorption system is identical in both cases. The different compositions of the spin-up and spindown orbitals, and thus the multi-reference nature of the wave function, are demonstrated by the presence of both positively and negatively signed atomic spin densities in an ordered and characteristic manner, independent of the identity of substitution. While the atomic charge distribution undulates (Figure 2 and Tables S8-S9) as a function of distance from the site of substitution (X1), the atomic spin densities show the opposite trend as the peripheral $(\gamma)$ atoms accumulate the largest spin density. Exploratory calculations using larger, extended maquette molecules (results not shown) confirm that the extra electron/electron hole delocalizes to the periphery of the conjugated polycyclic molecule and does not stay localized to the inner or outer sphere of the site of substitution as the origin of spin polarization. Hirshfeld analysis (HPA) shows to a greater extent than Weinhold analysis (NPA) that the methane adsorbate also undergoes a slight spin polarization: $0.008 \mathrm{e}^{-}$for $\mathrm{B}-\mathrm{MPh} \times \mathrm{nCH}_{4}$ and $0.003 \mathrm{e}^{-} \mathrm{N}-\mathrm{MPh} \times \mathrm{nCH}_{4}$ (Figure 5 and Table S11). This is a direct indication of the presence of a small, but non-negligible magnetic interaction between the adsorbate and adsorbent in addition to the above discussed induced ionic interactions due to mutual polarization of the constituents of the adsorption system.

To a modest degree, the spin polarization also appears in the expectation value of the spin operator $<\mathrm{S}^{2}>$ at the $\mathrm{MN} 15+$ level. The $<\mathrm{S}^{2}>$ values are 0.791 and 0.783 for $\mathrm{B}-\mathrm{MPh} \times \mathrm{nCH}_{4}$ and $\mathrm{N}-\mathrm{MPh} \times \mathrm{nCH}_{4}$, respectively. Upon spin annihilation by eliminating contributions from the $\mathrm{M}_{\mathrm{s}}=1 / 2$ sublevel of the 
higher $\mathrm{S}=3 / 2$ spin state, the $<\mathrm{S}^{2}>$ values for both systems are reduced to 0.751 , which is close to the ideal, non-contaminated expectation value of $S(S+1)=0.750$. The reference wave function level for correlated MO calculations (HF/6-311++ $\mathrm{G}^{* *}$ ) shows a dramatically larger deviation from the ideal value (2.486 and 2.448). This result becomes even greater (4.982 and 4.725) upon spin annihilation, indicating significant contributions of the $M_{S}=1 / 2$ sublevel of the $S=5 / 2$ and likely higher spin states. Deviations from the ideal spin expectation value can be mitigated by constructing a restricted open-shell (ROHF) $S=1 / 2$ electronic structure calculation; however, this wave function corresponds to a significantly higher energy state by +173 and $+158 \mathrm{~kJ} \mathrm{~mol}^{-1}$ for the $\mathrm{B}-\mathrm{MPh} \times \mathrm{CH}_{4}$ and $\mathrm{N}-\mathrm{MPh} \times \mathrm{CH}_{4}$ models, respectively. These large energy values are indicative of the significant static electron correlation as captured by allowing for different composition of spin-up and spin-down one-electron orbitals in the unrestricted (UHF) calculation. Analogously, the use of the spin-polarized $\mathrm{B}-\mathrm{MPh} \times \mathrm{CH}_{4}$ and $\mathrm{N}-\mathrm{MPh} \times \mathrm{CH}_{4}$ electronic structures as initial wave functions results in a spin-unrestricted, open-shell singlet electronic structure for the unsubstituted $\mathrm{MPh} \times \mathrm{CH}_{4}$ maquette at a lower energy structure $\left(-110 \mathrm{~kJ} \mathrm{~mol}^{-1}\right)$ than the closed-shell, diamagnetic state, at the restricted HF/6-311++G** level. The energy differences between the spin-polarized (UHF) and spin-restricted (ROHF) electronic structures are gradually diminished as more complete treatment of electron correlation is employed: 264-287 at MP2, 138-152 at MP3, 98-112 at MP4SDQ, 19-30 at CCSD, and finally 43-47 at $\operatorname{CCSD}(\mathrm{T})$, in $\mathrm{kJ} \mathrm{mol}^{-1}$. The complexity of the spin manifold also explains the computational challenges of obtaining equilibrium structures that were burdened by chronic oscillations in SCF cycles, jumping arbitrarily to higher energy potential energy surfaces that correspond to resonance structures with non-planar, puckered geometries. Further multi-reference CASSCF/CASMP2 calculations are warranted in order to obtain a complete, detailed picture of methane interactions with MPh-based molecular maquettes of carbon surfaces, but remain relegated to future work.

\section{Discussion}

Understanding the fundamental physical chemistry of methane adsorption on carbon adsorbent materials is essential for the rational design and optimization of porous solids for gas storage and separations. Modification of the composition (e.g., by heteroatom substitution or edge decoration) and structure (e.g., porosity, particle morphology, or degree of crystallinity) of the adsorbent material may lead to complex and unanticipated properties. To interrogate these effects, a complement of computational tools must be applied at appropriate levels of theory. Such in silico studies have the potential to establish an atomic-scale description of the adsorption mechanism; such studies can also serve to deconvolute the often wide-ranging experimental observations and permit the identification of the most dominant physical chemical features contributing therein. Systems comprising a nonpolar adsorbate (e.g., methane) and a nonpolar adsorbent surface (a carbon material) are particularly challenging to model since they require careful consideration of a network of weak interactions. In general, the most dominant contributing interaction between methane and a (poly)aromatic adsorbent is the $\mathrm{C}-\mathrm{H} \cdots \pi$ interaction, ${ }^{41}$ a specific form of $\mathrm{H}$-bonding. In addition, tetrel bonding ${ }^{109}$ of the adsorbate and the central site between adjacent aromatic rings is also of significant relevance. In this study, a minimalist $\pi$-system has been constructed around a central site of substitution in order to contain three adjoined aromatic rings that provide a moiety for the classical form of tetrel bonding between the central atom(s) of the methane adsorbate (C25/C30) and the MPh adsorbent (X1). In addition to the H-bonding interaction, the roles of 
electron-density polarization, induced charge, and London dispersion interactions between the two nonpolar constituents were also documented in our work. The treatment of these weak, long-range, and non-specific interactions requires computationally expensive methods. Less computationally expensive approaches inevitably rely on empirical potentials or semi-empirical corrections to access large enough systems that convincingly capture the structural and energetic characteristics of such subtle interactions. While there are undoubtedly success stories in chemistry and biochemistry,71 most such efforts result in chemical accuracy that is too low to estimate the absolute energetics of the weakest adsorption systems to within $1 \mathrm{~kJ} \mathrm{~mol}^{-1}$, such as those relevant to methane physisorption on carbon surfaces (see the Supporting Information for examples). In this work, a strategy inspired by Pople's Model Chemistries, ${ }^{51}$ Peterson's Complete Basis Set extrapolation method, ${ }^{110}$ and Schaefer's focal point analysis. ${ }^{111}$ has been utilized, in which a conceptually converging series of correlated MO theories along with the judicious selection of a suitable molecular maquette (MPh) offer the desired chemical accuracy.42 This accuracy is high enough to permit a direct comparison to, as well as confidently aid the interpretation of, the experimental results. A carefully evaluated series of density functional theories of increasing approximation of chemical accuracy according to Perdew's concept of Jacob's ladder ${ }^{72}$ provides an alternative, computationally affordable means to attain high chemical accuracy, which will be essential for future assessment of larger maquettes of porous carbon materials.

The strength of the adsorbent/adsorbate interaction is an important experimental property of an adsorption system that can be assessed by numerous methods. The most common experimental metric to report is the isosteric heat of adsorption (historically referred to as $\mathrm{q}_{\mathrm{st}}$ ), most often determined by the analysis of equilibrium adsorption measurements across a range of temperatures and pressures of interest.112 At low pressures (analogous to in vacuo modeling) and room temperature, the Clausius-Clapeyron equation (with its inherent ideal gas assumption) is employed. At higher pressures, the ideal gas assumption eventually becomes invalid and the more general Clapeyron equation must instead be employed.113 In both cases, the resulting "heat" is actually the difference in enthalpy upon desorption $\left(\mathrm{q}_{\mathrm{st}}=\Delta \mathrm{H}_{\text {exp }}\right)$, which differs by a quantity $\Delta \mathrm{PV}$ (roughly equivalent to RT at low pressures) from the difference in internal energy between the adsorbed phase and the methane fluid phase surrounding it. Such "experimental" quantities are typically model-dependent, and suffer from numerous common pitfalls in their analysis; hence, great caution should be employed in the comparison of quantities across different reports. ${ }^{114}$ In this work, we put forward a thermochemical method that was optimized by comparison to a detailed set of methane adsorption equilibria measured on zeolite-templated carbon. ${ }^{48-49}$ The isosteric heat of adsorption was derived experimentally by fitting measured adsorption equilibria to a thermodynamically consistent, global Langmuir-type model between 238-526 K. This method results in a physically meaningful picture of methane adsorption on atomistically thin, graphene fragment-like surfaces resembling the present MPh maquette, across a wide range of temperature and pressure (with emphasis on the results obtained at $298 \mathrm{~K}$ ), for comparison to theory.

For the most thorough comparison of computational and experimental results, thermochemical quantities have been considered in several ways by combining the quantum mechanical potential energy at $0 \mathrm{~K}\left(\Delta \mathrm{E}^{\mathrm{QM}}\right.$ or $\left.\Delta \mathrm{E}^{\mathrm{SCF}}\right)$, corrected for $\mathrm{BSSE}\left(\Delta \mathrm{E}^{\mathrm{QM}}\right)^{*}$, with various additional corrections for zero-point energy, thermal energy, and the mechanical work terms ( $\Delta \mathrm{PV}$ or RT). The details of the calculations at two different levels of theory are shown in Tables S12 and S13 and graphically illustrated in Figure 6a (corresponding to Table S13 at the MN15+ level). The best agreement between the experimental heat of adsorption ${ }^{49}$ and any of the various thermochemical quantities is 

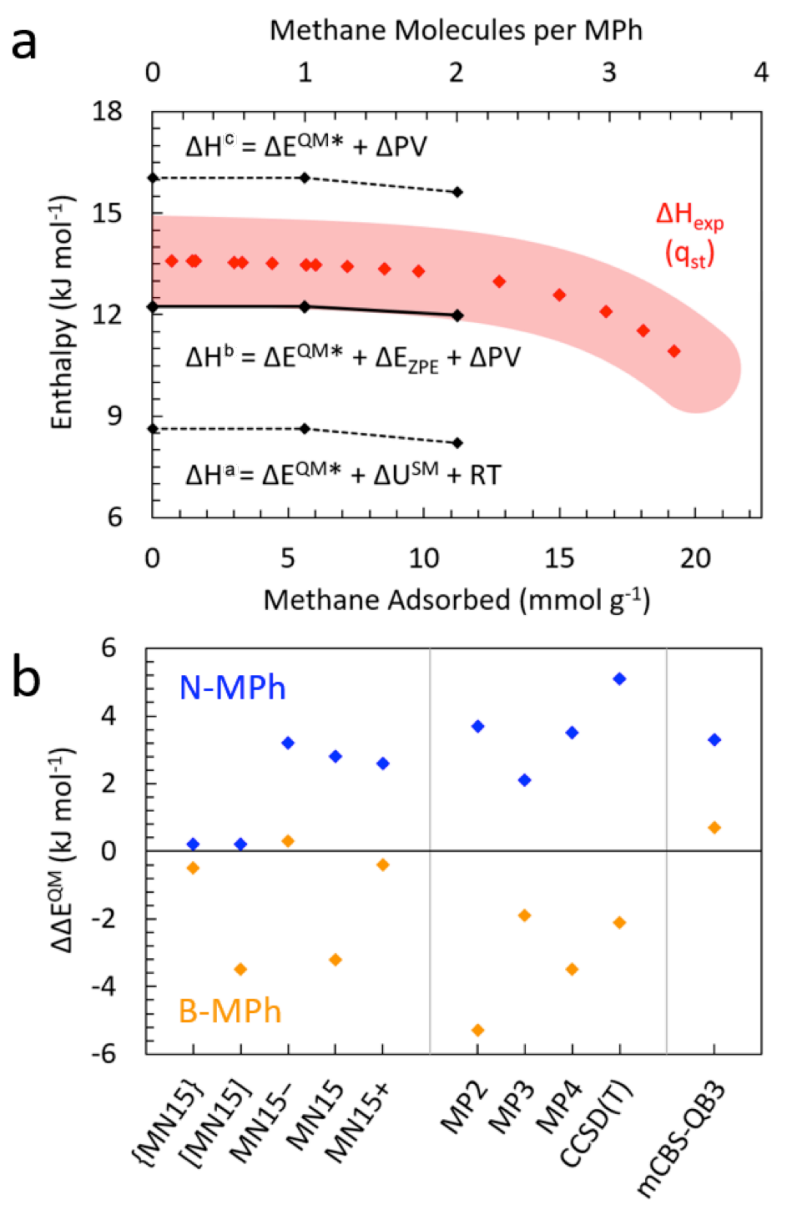

Figure 6. (a) Comparison between theoretical (dashed and solid black lines, MN15+) and experimental (red symbols with highlight as error bars) thermodynamic quantities describing methane physisorption on MPh and zeolite-templated carbon, respectively. The sign convention corresponds to desorption. (b) Level of theory dependence of the relative methane binding energies on $\mathrm{N}-\mathrm{MPh}$ (blue) and B-MPh (orange) compared to unsubstituted MPh adsorbent ( $\Delta \Delta \mathrm{E}^{\mathrm{QM}}$, as in Tables $\mathbf{4}$ and $\left.\mathbf{S 7}\right)$. obtained by considering the zero-point corrected energy of adsorption $\left(\Delta \mathrm{U}^{\mathrm{b}}=\Delta \mathrm{E}^{\mathrm{QM}} *+\Delta \mathrm{E}_{\mathrm{ZPE}}\right)$ modified by a PV or RT term. This zero-point corrected enthalpy of adsorption $\left(\Delta \mathrm{H}^{\mathrm{b}}=\Delta \mathrm{E}^{\mathrm{QM}} *+\right.$ $\Delta \mathrm{E}_{\mathrm{ZPE}}+\Delta \mathrm{PV}, 12.2 \pm 0.1 \mathrm{~kJ} \mathrm{~mol}^{-1}$ ) is consistent with the experimentally determined isosteric heat of $13.6 \pm 1 \mathrm{~kJ} \mathrm{~mol}^{-1}$ at zero loading. ${ }^{49}$ As the number of methane molecules adsorbed increases, the binding enthalpy decreases, as is also observed experimentally. Thus, analysis lends support to the use of the BSSE-corrected QM energy (at the MN15/def2-QZVPP level) and zero-point energy correction (solid black trace in Figure 6a) for the estimation of the heat of adsorption of methane on carbon surfaces determined by the isosteric method. On the other hand, we note that the commonly applied correction to the quantum mechanical potential energy due to thermal effects $\left(\Delta \mathrm{H}^{\mathrm{a}}\right.$ or $\left.\Delta \mathrm{H}^{\circ}\right)$ is not recommended for comparison of the $\mathrm{CH}_{4} / \mathrm{MPh}$ model to the $\mathrm{CH}_{4}$ /ZTC adsorption system, likely owing to the simplistic nature of the statistical mechanical model employed. By this reasoning, the best theoretical estimates $\left(\Delta \mathrm{H}^{\mathrm{b}}\right.$ from Table S13, MN15+) of the binding enthalpy of methane on $\mathrm{B}-\mathrm{MPh}$ and $\mathrm{N}-\mathrm{MPh}$ are $12.1 \pm 0.1$ and $14.3 \pm 0.1 \mathrm{~kJ}$ $\mathrm{mol}^{-1}$, respectively. Effects due to pore confinement could be the reason for the additional $\sim 1 \mathrm{~kJ} \mathrm{~mol}^{-1}$ enhancement seen in the experimental results for ZTC, effects that would logically lead to isosteric heats of adsorption of $>15 \mathrm{~kJ} \mathrm{~mol}^{-1}$ in N-doped ZTCs of high substitutional heteroatom content.

The absolute energetics of methane adsorption on porous carbon surfaces remains challenging to assess precisely even at the highest levels of theory employed herein on the small $\mathrm{MPh} \times \mathrm{CH}_{4}$ system. However, the variation in $\Delta \mathrm{E}^{\mathrm{QM}} *$ and $\Delta \mathrm{H}^{\mathrm{b}}$ (see Figure 6a and Tables S12 and S13) as a function of heteroatom substitution in the MPh maquette shows remarkable consistency at all levels of theory, lending strong credibility to the main deliverable of this study. Methane physisorption above nitrogen-based substitutional adsorption sites of $\mathrm{NC}_{3}$ type ( $\mathrm{N}$-doping in an extended $\pi$-system) is concomitant with an increase in binding strength by $\sim 3 \mathrm{~kJ} \mathrm{~mol}^{-1}$, as shown in Figure 6b. Meanwhile, physisorption above boronbased substitutional adsorption sites of $\mathrm{BC}_{3}$ type leads to a reduced binding strength by up to $5 \mathrm{~kJ}$ mol-1 $^{-1}$ relative to the pure carbon surface, with some notable exceptions at specific levels of theory. It is interesting to note that the trend for boron substitution remains far more complex than that for nitrogen, exhibiting nonobvious convergence at conceptually higher levels of theory. Overall, 
methane binding above boron is always weaker than over nitrogen, and similar or weaker than binding over carbon.

Generally, methane is not considered a significantly polarizable molecule; therefore, the estimated magnitude of interplay between the electron densities of the methane adsorbate(s) and the MPh adsorbent maquette was somewhat unexpected. Nitrogen substitution creates an electron enriched conjugated $\pi$-system in comparison to the MPh or B-MPh maquettes, which in turn enhances the adsorption via $\mathrm{C}-\mathrm{H} \cdots \pi$ interactions, tetrel bonding, and induced dipole/Coulomb interactions around the site of substitution. The additional electron in the $\pi$-system also displays greater polarizability, which helps to generate induced ionic interactions upon approach of the methane adsorbate to adsorbent surface. The emergence of these individually weak, yet cumulatively decisive interactions suggests a clear strategy for enhancing methane binding energy by nitrogen doping that can also be extended to larger, conjugated adsorbent surfaces. The best estimate of isosteric enthalpy of adsorption by $\mathrm{N}-\mathrm{MPh}$ in this work $\left(14.3 \pm 0.1 \mathrm{~kJ} \mathrm{~mol}^{-1}\right)$ approaches the ideal value for reversible adsorptive storage relevant to energy applications. ${ }^{26}, 30$ On the other hand, electron deficient (B-substituted) conjugated adsorbent surfaces exhibit a weaker or at most comparable binding of methane relative to the pure C-based adsorbent. The electron-hole created by the B-substitutions indirectly increases the effective nuclear charge of neighboring carbon atoms and thus hardens the $\pi$-cloud of the aromatic system, reducing its polarizability. Further investigations are in progress for exploring the effects of polarizable substitutions with hypervalency and low electronegativity, such as $\mathrm{P}$ and $\mathrm{S}$, substituted within the carbon surface framework. Yet further investigations into the effects of curvature ${ }^{38}$ (on larger maquettes of porous carbon surfaces) are expected to round out the energy landscape for methane interactions with real-world carbon-based adsorbent materials like ZTC.

\section{Conclusions}

Herein we report a comprehensive computational modeling approach for describing the structure of methane physisorption on porous carbon surfaces at the atomic-scale and predicting the energy of interaction using a carefully constructed molecular maquette. In contrast to an ideal graphene sheet, amorphous carbon surfaces display functional groups, exhibit edge effects, and contain defects that contribute to the emergence of localized structural moieties and properties. We propose a methylidene-augmented phenalene molecule (MPh) as a compositionally minimal model of a porous carbon surface with a central site for heteroatom (B and N) substitution. The minimal size of this maquette is essential for permitting the use of ab initio levels of theory with explicit treatment of electron correlation in order to accurately capture the complete network of "weak interactions" that include $\mathrm{C}-\mathrm{H} \cdots \pi$ bonding, tetrel bonding, induced dipole interactions, and London dispersion forces. For high-throughput computational studies, electron-correlated MO theory methods were also compared with Rung 5 density functional theory employing the MN15 functional. All levels of theory unambiguously establish the preference of methane toward adsorption at an electron-enriched ( $\mathrm{N}$-doped) substitution site. When the formally sp'-hybridized central carbon is replaced by a nitrogen in the N-MPh model, methane adsorption occurs at a shorter distance from the surface and binding energy increases. The $\mathrm{C}-\mathrm{H} \cdots \pi$ interactions characteristic of the methane "lander" geometry are supplemented by tetrel bonding formed via an effective lone pair donation to the $\mathrm{C}-\mathrm{H} \sigma^{*}$ orbital, resulting in undulating rings of induced Coulomb charges. This renders a $\sim 3 \mathrm{~kJ} \mathrm{~mol}^{-1}$ stronger interaction (correspondingly, $\Delta \mathrm{H}=14.3 \pm 0.1 \mathrm{~kJ} \mathrm{~mol}^{-1}$ ) 
than that of the unsubstituted model $\left(12.2 \pm 0.1 \mathrm{~kJ} \mathrm{~mol}^{-1}\right)$, as estimated at the MN15/def2-QZVPP level of theory. Contrarily, methane adsorption on the B-substituted adsorbent is predicted to be comparable $\left(12.1 \pm 0.1 \mathrm{~kJ} \mathrm{~mol}^{-1}\right)$ to that of the unsubstituted model at the same level of theory. These results indicate a clear advantage for electron enriched heteroatom substitutions in the design of porous carbon materials for adsorptive methane storage and delivery applications. The versatility of this approach permits future extension of this work to larger maquettes of porous carbon surfaces by considering the role of functional groups, alternative ring sizes, curvature, and other heteroatom substitutional dopants. We expect that the resulting atomic-scale insights will assist both rational materials design efforts in the laboratory and multi-scale computational modeling of next-generation adsorbent materials for energy storage applications.

\section{Acknowledgements}

R.R., E.T., and N.S. are supported by the U.S. Department of Energy's Office of Energy Efficiency and Renewable Energy (EERE) under the Hydrogen and Fuel Cell Technologies and Vehicle Technologies Offices (DE-EE0008815). S.I. acknowledges support for the analysis of theoretical results by the U.S. Department of Energy's Office of Fossil Energy (FE). N.S. acknowledges the donors of the American Chemical Society Petroleum Research Fund for partial support of this research. R.R. is thankful for the support by the MSU Undergraduate Scholars Program. We are also grateful for resources provided by the Extreme Science and Engineering Discovery Environment (XSEDE), supported by National Science Foundation grant ACI-1548562.115 Part of the computations were carried out using the Hyalite High Performance Computing System, operated and supported by the University Information Technology Research Cyberinfrastructure at Montana State University.

Supporting Information. Graphical illustrations of the nomenclature employed for adsorbent and adsorption models; potential energy surface maps for initial methane/surface interactions; electron density difference contour plots; table of literature examples of experimental and theoretical investigations related methane adsorption on carbon materials; Z-matrix definitions; complete set of geometric descriptions; detailed energetic and thermochemical analyses; tabulated electron structure data. Additional electronic supporting information including the atomic positional coordinates for all maquettes, templates for geometric and electronic structure analysis, formatted checkpoint files, and electron density and spin density cube files is available free of charge at Zenodo.org (DOI: $10.5281 /$ zenodo.4330761 or URL: https://zenodo.org/record/4330761). 


\section{References}

(1) Geim, A. K. Graphene: Status and prospects. Science 2009, 324, 1530-1534 DOI: 10.1126/science.1158877.

(2) Tang, X.; Ripepi, N.; Stadie, N. P.; Yu, L. J.; Hall, M. R. A dual-site Langmuir equation for accurate estimation of high pressure deep shale gas resources. Fuel 2016, 185, 10-17 DOI: 10.1016/j.fuel.2016.07.088.

(3) Zhang, J. F.; Clennell, M. B.; Dewhurst, D. N.; Liu, K. Y. Combined Monte Carlo and molecular dynamics simulation of methane adsorption on dry and moist coal. Fuel 2014, 122, 186-197 DOI: 10.1016/j.fuel.2014.01.006.

(4) Curtis, J. B. Fractured shale-gas systems. AAPG Bull. 2002, 86, 1921-1938 DOI: 10.1306/61eeddbe-173e-11d7-8645000102c1865d.

(5) Clarkson, C. R.; Bustin, R. M.; Levy, J. H. Application of the mono/multilayer and adsorption potential theories to coal methane adsorption isotherms at elevated temperature and pressure. Carbon 1997, 35, 1689-1705 DOI: 10.1016/s0008-6223(97)00124-3.

(6) Kulkarni, G. S.; Reddy, K.; Zhong, Z. H.; Fan, X. D. Graphene nanoelectronic heterodyne sensor for rapid and sensitive vapour detection. Nat. Commun. 2014, 5, 7 DOI: 10.1038/ncomms5376.

(7) Hadlington, S. Graphene sensor achieves ultimate sensitivity. Chem. World 2007, 4, 29-29 DOI: 10.1038/nmat1967.

(8) Schedin, F.; Geim, A. K.; Morozov, S. V.; Hill, E. W.; Blake, P.; Katsnelson, M. I.; Novoselov, K. S. Detection of individual gas molecules adsorbed on graphene. Nat. Mater. 2007, 6, 652-655 DOI: 10.1038/nmat1967.

(9) Nomura, K.; Nishihara, H.; Kobayashi, N.; Asada, T.; Kyotani, T. 4.4 V supercapacitors based on super-stable mesoporous carbon sheet made of edge-free graphene walls. Energy Environ. Sci. 2019, 12, 1542-1549 DOI: 10.1039/c8ee03184c.

(10) Lin, M. C.; Gong, M.; Lu, B. G.; Wu, Y. P.; Wang, D. Y.; Guan, M. Y.; Angell, M.; Chen, C. X.; Yang, J.; Hwang, B. J., et al. An ultrafast rechargeable aluminium-ion battery. Nature 2015, 520, 325326 DOI: $10.1038 /$ nature14340.

(11) Liu, C. G.; Yu, Z. N.; Neff, D.; Zhamu, A.; Jang, B. Z. Graphene-based supercapacitor with an ultrahigh energy density. Nano Lett. 2010, 10, 4863-4868 DOI: 10.1021/nl102661q.

(12) Stoller, M. D.; Park, S. J.; Zhu, Y. W.; An, J. H.; Ruoff, R. S. Graphene-based ultracapacitors. Nano Lett. 2008, 8, 3498-3502 DOI: 10.1021/nl802558y.

(13) Benard, P.; Chahine, R. Modeling of high-pressure adsorption isotherms above the critical temperature on microporous adsorbents: Application to methane. Lagmuir 1997, 13, 808-813 DOI: 10.1021/la960843x.

(14) Blankenship, T. S.; Blankenship, T. S., II; Balahmar, N.; Mokaya, R. Oxygen-rich microporous carbons with exceptional hydrogen storage capacity. Nat. Commun. 2017, 8 DOI: 10.1038/s41467-017-01633-x.

(15) Elizabeth Casco, M.; Martinez-Escandell, M.; Gadea-Ramos, E.; Kaneko, K.; Silvestre-Albero, J.; Rodriguez-Reinoso, F. High-pressure methane storage in porous materials: Are carbon materials in the pole position? Chem. Matter. 2015, 27, 959-964 DOI: 10.1021/cm5042524.

(16) Jorda-Beneyto, M.; Suarez-Garcia, F.; Lozano-Castello, D.; Cazorla-Amoros, D.; Linares-Solano, A. Hydrogen storage on chemically activated carbons and carbon nanomaterials at high pressures. Carbon 2007, 45, 293-303 DOI: 10.1016/j.carbon.2006.09.022.

(17) Nishihara, H.; Hou, P.-X.; Li, L.-X.; Ito, M.; Uchiyama, M.; Kaburagi, T.; Ikura, A.; Katamura, J.; Kawarada, T.; Mizuuchi, K., et al. High-pressure hydrogen storage in zeolite-templated carbon. J. Phys. Chem. C 2009, 113, 3189-3196 DOI: 10.1021/jp808890x. 
(18) Stadie, N. P.; Vajo, J. J.; Cumberland, R. W.; Wilson, A. A.; Ahn, C. C.; Fultz, B. Zeolite-templated carbon materials for high-pressure hydrogen storage. Langmuir 2012, 28, 10057-10063 DOI: 10.1021/la302050m.

(19) Zhou, Y.; Zhou, L. Fundamentals of high pressure adsorption. Langmuir 2009, 25, 13461-13466 DOI: 10.1021/la901956g.

(20) Smalley, R. E. Discovering the fullerenes. Rev. Modern Phys. 1997, 69, 723-730 DOI: 10.1103/RevModPhys.69.723.

(21) Nishihara, H.; Kyotani, T. Zeolite-templated carbons - three-dimensional microporous graphene frameworks. Chem. Commun. 2018, 54, 5648-5673 DOI: 10.1039/c8cc01932k.

(22) Cracknell, R. F.; Gordon, P.; Gubbins, K. E. Influence of pore geometry on the design of microporous materials for methane storage. J. Phys. Chem. 1993, 97, 494-499 DOI: 10.1021/j100104a036.

(23) Matranga, K. R.; Myers, A. L.; Glandt, E. D. Storage of natural-gas by adsorption on activated carbon. Chem. Engng. Sci. 1992, 47, 1569-1579 DOI: 10.1016/0009-2509(92)85005-v.

(24) Nicholson, D. Simulation studies of methane transport in model graphite micropores. Carbon 1998, 36, 1511-1523 DOI: 10.1016/s0008-6223(98)00143-2.

(25) Taylor, E. E.; Garman, K.; Stadie, N. P. Atomistic structures of zeolite-templated carbon. Chem. Mat. 2020, 32, 2742-2752 DOI: 10.1021/acs.chemmater.0c00535.

(26) Gomez-Gualdron, D. A.; Wilmer, C. E.; Farha, O. K.; Hupp, J. T.; Snurr, R. Q. Exploring the limits of methane storage and delivery in nanoporous materials. J. Phys. Chem. C 2014, 118, 6941-6951 DOI: $10.1021 /$ jp502359q.

(27) Simon, C. M.; Kim, J.; Lin, L. C.; Martin, R. L.; Haranczyk, M.; Smit, B. Optimizing nanoporous materials for gas storage. Phys. Chem. Chem. Phys. 2014, 16, 5499-5513 DOI: 10.1039/c3cp55039g.

(28) Kokcam-Demir, U.; Goldman, A.; Esrafili, L.; Gharib, M.; Morsali, A.; Weingart, O.; Janiak, C. Coordinatively unsaturated metal sites (open metal sites) in metal-organic frameworks: Design and applications. Chem. Soc. Rev. 2020, 49, 2751-2798 DOI: 10.1039/c9cs00609e.

(29) Mishra, P.; Edubilli, S.; Mandal, B.; Gumma, S. Adsorption characteristics of metal organic frameworks containing coordinatively unsaturated metal sites: Effect of metal cations and adsorbate properties. J. Phys. Chem. C 2014, 118, 6847-6855 DOI: 10.1021/jp412622b.

(30) Bhatia, S. K.; Myers, A. L. Optimum conditions for adsorptive storage. Lagmuir 2006, 22, 16881700 DOI: $10.1021 /$ la0523816.

(31) Peng, Y.; Krungleviciute, V.; Eryazici, I.; Hupp, J. T.; Farha, O. K.; Yildirim, T. Methane storage in metal-organic frameworks: Current records, surprise findings, and challenges. J. Am. Chem. Soc. 2013, 135, 11887-11894 DOI: 10.1021/ja4045289.

(32) Ashourirad, B.; Sekizkardes, A. K.; Altarawneh, S.; El-Kaderi, H. M. Exceptional gas adsorption properties by nitrogen-doped porous carbons derived from benzimidazole-linked polymers. Chem. Mat. 2015, 27, 1349-1358 DOI: 10.1021/cm504435m.

(33) Wang, X. W.; Sun, G. Z.; Routh, P.; Kim, D. H.; Huang, W.; Chen, P. Heteroatom-doped graphene materials: Syntheses, properties and applications. Chem. Soc. Rev. 2014, 43, 7067-7098 DOI: 10.1039/c4cs00141a.

(34) Chen, X.-P.; Yang, N.; N, J.-M.; Cai, M.; Ye, H.-Y.; Wong, C. K. Y.; Leung, S. Y. Y.; Ren, T.-L. Densityfunctional calculation of methane adsorption on graphenes. IEEE Electr. Dev. Lett. 2015, 36, 1366-1368 DOI: 10.1109/LED.2015.2492580.

(35) Hussain, M. A.; Vijay, D.; Sastry, G. N. Buckybowls as adsorbents for $\mathrm{CO}_{2}, \mathrm{CH}_{4}$, and $\mathrm{C}_{2} \mathrm{H}_{2}$ : Binding and structural insights from computational study. J. Comput. Chem. 2016, 37, 366-377 DOI: $10.1002 /$ jcc. 24242 . 
(36) Liu, X.-Q.; Xue, Y.; Tian, Z.-Y.; Mo, J.-J.; Qiu, N.-X.; Chu, W.; Xie, H.-P. Adsorption of $\mathrm{CH}_{4}$ on nitrogen- and boron-containing carbon models of coal predicted by density-functional theory. Appl. Surf. Sci. 2013, 285, 190-197 DOI: 10.1016/j.apsusc.2013.08.035.

(37) Burrill, D. J.; Lambrecht, D. S. Buckybowls as gas adsorbents: Binding of gaseous pollutants and their electric-field induced release. Phys. Chem. Chem. Phys. 2020, 22, 22699-22710 DOI: 10.1039/DOCP02645J.

(38) Kennedy, M. R.; Burns, L. A.; Sherrill, C. D. Buckyplates and buckybowls: Examining the effects of curvature on pi-pi interactions. J. Phys. Chem. A 2012, 116, 11920-11926 DOI: 10.1021/jp305700k.

(39) Palmer, J. C.; Brennan, J. K.; Hurley, M. M.; Balboa, A.; Gubbins, K. E. Detailed structural models for activated carbons from molecular simulation. Carbon 2009, 47, 2904-2913 DOI: 10.1016/j.carbon.2009.06.037.

(40) Sirianni, D. A.; Burns, L. A.; Sherrill, C. D. Comparison of explicitly correlated methods for computing high-accuracy benchmark energies for noncovalent interactions. J. Chem. Theory Comput. 2017, 13, 86-99 DOI: 10.1021/acs.jctc.6b00797.

(41) Morita, S.; Fujii, A.; Mikami, N.; Tsuzuki, S. Origin of the attraction in aliphatic C-H/ $\pi$ interactions: Infrared spectroscopic and theoretical characterization of gas-phase clusters of aromatics with methane. J. Phys. Chem. A 2006, 110, 10583-10590 DOI: 10.1021/jp064297k.

(42) Smith, D. G. A.; Patkowski, K. Interactions between methane and polycyclic aromatic hydrocarbons: A high accuracy benchmark study. J. Chem. Theory Comput. 2013, 9, 370-389 DOI: $10.1021 /$ ct3008809.

(43) Hu, C. G.; Liu, D.; Xiao, Y.; Dai, L. M. Functionalization of graphene materials by heteroatomdoping for energy conversion and storage. Prog. Nat. Sci. 2018, 28, 121-132 DOI: 10.1016/j.pnsc.2018.02.001.

(44) Hassani, A.; Mosavian, M. T. H.; Ahmadpour, A.; Farhadian, N. A comparative theoretical study of methane adsorption on the nitrogen, boron and lithium doped graphene sheets including density functional dispersion correction. Comp. Theo. Chem. 2016, 1084, 43-50 DOI: 10.1016/j.comptc.2016.02.019.

(45) Yepes, D.; Neese, F.; List, B.; Bistoni, G. Unveiling the delicate balance of steric and dispersion interactions in organocatalysis using high-level computational methods. J. Am. Chem. Soc. 2020, 142, 3613-3625 DOI: 10.1021/jacs.9b13725.

(46) Kim, H. S.; Kang, M. S.; Lee, S.; Lee, Y.-W.; Yoo, W. C. N-doping and ultramicroporosity-controlled crab shell derived carbons for enhanced $\mathrm{CO}_{2}$ and $\mathrm{CH}_{4}$ sorption. Micropor. Mesopor. Mat. 2018, 272, 92-100 DOI: 10.1016/j.micromeso.2018.06.021.

(47) Wang, L.; Sofer, Z.; Pumera, M. Will any crap we put into graphene increase its electrocatalytic effect? ACS Nano 2020, 14, 21-25 DOI: 10.1021/acsnano.9b00184.

(48) Stadie, N. P.; Murialdo, M.; Ahn, C. C.; Fultz, B. Anomalous isosteric enthalpy of adsorption of methane on zeolite-templated carbon. J. Am. Chem. Soc. 2013, 135, 990-993 DOI: 10.1021/ja311415m.

(49) Stadie, N. P.; Murialdo, M.; Ahn, C. C.; Fultz, B. Unusual entropy of adsorbed methane on zeolite-templated carbon. J. Phys. Chem. C 2015, 119, 26409-26421 DOI: 10.1021/acs.jpcc.5b05021.

(50) Nishihara, H.; Fujimoto, H.; Itoi, H.; Nomura, K.; Tanaka, H.; Miyahara, M. T.; Bonnaud, P. A.; Miura, R.; Suzuki, A.; Miyamoto, N., et al. Graphene-based ordered framework with a diverse range of carbon polygons formed in zeolite nanochannels. Carbon 2018, 129, 854-862 DOI: 10.1016/j.carbon.2017.12.055.

(51) Pople, J. A. Nobel lecture: Quantum chemical models. Rev. Modern Phys. 1999, 71, 1267-1274 DOI: 10.1103/RevModPhys.71.1267. 
(52) Nayyar, I.; Ginovska, B.; Karkamkar, A.; Gennett, T.; Autrey, T. Physi-sorption of $\mathrm{H}_{2}$ on pure and boron-doped graphene monolayers: A dispersion-corrected DFT study. C - J. Carbon. Res. 2020, 6, DOI: 10.3390/c6010015.

(53) Takai, K.; Suzuki, T.; Enoki, T.; Nishihara, H.; Kyotani, T. Structure and magnetic properties of curved graphene networks and the effects of bromine and potassium adsorption. Phys. Rev. $B$ 2010, 81, 12 DOI: 10.1103/PhysRevB.81.205420.

(54) Takai, K.; Suzuki, T.; Enoki, T.; Nishihara, H.; Kyotani, T. Fabrication and characterization of magnetic nanoporous zeolite templated carbon. J. Phys. Chem. Solids 2010, 71, 565-568 DOI: 10.1016/j.jpcs.2009.12.037.

(55) Ellis, E. S.; MacHale, L. T.; Szilagyi, R. K.; DuBois, J. L. How chemical environment activates anthralin and molecular oxygen for direct reaction. J. Org. Chem. 2020, 85, 1315-1321 DOI: 10.1021/acs.joc.9b03133.

(56) Szilagyi, R. K., Computational supporting information for how chemical environment activates anthralin and molecular oxygen for direct reaction. In ZENODO, 2020. DOI: 10.5281/zenodo.3771172.

(57) Nishimura, Y.; Tsuneda, T.; Sato, T.; Katouda, M.; Irle, S. Quantum chemical estimation of acetone physisorption on graphene using combined basis set and size extrapolation schemes. J. Phys. Chem. C 2017, 121, 8999-9010 DOI: 10.1021/acs.jpcc.6b13002.

(58) Fales, B. S.; Seritan, S.; Settje, N. F.; Levine, B. G.; Koch, H.; Martinez, T. J. Large-scale electron correlation calculations: Rank-reduced full configuration interaction. J. Chem. Theory Comput. 2018, 14, 4139-4150 DOI: 10.1021/acs.jctc.8b00382.

(59) Levine, D. S.; Hait, D.; Tubman, N. M.; Lehtola, S.; Whaley, K. B.; Head-Gordon, M. CASSCF with extremely large active spaces using the adaptive sampling configuration interaction method. $J$. Chem. Theory Comput. 2020, 16, 2340-2354 DOI: 10.1021/acs.jctc.9b01255.

(60) Sugisaki, K.; Nakazawa, S.; Toyota, K.; Sato, K.; Shiomi, D.; Takui, T. Quantum chemistry on quantum computers: A method for preparation of multiconfigurational wave functions on quantum computers without performing post-Hartree-Fock calculations. ACS Cental Sci. 2019, 5 , 167-175 DOI: 10.1021/acscentsci.8b00788.

(61) Chan, G. K.-L.; Sharma, S. The density matrix renormalization group in quantum chemistry. In Annual Rev. Phys. Chem., Leone, S. R.; Cremer, P. S.; Groves, J. T.; Johnson, M. A., Eds. 2011; Vol. 62, pp 465-481.

(62) Moca, C. P.; Izumida, W.; Dora, B.; Legeza, O.; Asboth, J. K.; Zarand, G. Topologically protected correlated end spin formation in carbon nanotubes. Phys. Rev. Lett. 2020, 125, DOI: 10.1103/PhysRevLett.125.056401.

(63) Elstner, M.; Seifert, G. Density functional tight binding. Philos. Trans. R. Soc. A-Math. Phys. Eng. Sci. 2014, 372, 12 DOI: 10.1098/rsta.2012.0483.

(64) Gaus, M.; Cui, Q.; Elstner, M. Density functional tight binding: Application to organic and biological molecules. Wiley Interdiscip. Rev.-Comput. Mol. Sci. 2014, 4, 49-61 DOI: 10.1002/wcms.1156.

(65) Page, A. J.; Ding, F.; Irle, S.; Morokuma, K. Insights into carbon nanotube and graphene formation mechanisms from molecular simulations: A review. Rep. Prog. Phys. 2015, 78, 38 DOI: 10.1088/0034-4885/78/3/036501.

(66) Perdew, J. P.; Burke, K.; Ernzerhof, M. Generalized gradient approximation made simple. Phys. Rev. Lett. 1996, 77, 3865-3868 DOI: 10.1103/PhysRevLett.77.3865.

(67) Perdew, J. P.; Burke, K.; Ernzerhof, M. Generalized gradient approximation made simple (vol 77, pg 3865, 1996). Phys. Rev. Lett. 1997, 78, 1396-1396 DOI: 10.1103/PhysRevLett.78.1396. 
(68) Clark, T.; Chandrasekhar, J.; Spitznagel, G. W.; Schleyer, P. V. Efficient diffuse functionaugmented basis sets for anion calculations. III. The 3-21+G basis set for first-row elements, Li-F. J. Comput. Chem. 1983, 4, 294-301 DOI: 10.1002/jcc.540040303.

(69) Frisch, M. J.; Pople, J. A.; Binkley, J. S. Self-consistent molecular-orbital methods 25. Supplementary functions for Gaussian-basis sets. J. Chem. Phys. 1984, 80, 3265-3269 DOI: 10.1063/1.447079.

(70) Krishnan, R.; Binkley, J. S.; Seeger, R.; Pople, J. A. Self-consistent molecular-orbital methods 20. Basis set for correlated wave-functions. J. Chem. Phys. 1980, 72, 650-654 DOI: 10.1063/1.438955.

(71) Christensen, A. S.; Kubar, T.; Cui, Q.; Elstner, M. Semiempirical quantum mechanical methods for noncovalent interactions for chemical and biochemical applications. Chem. Rev. 2016, 116, 5301-5337 DOI: 10.1021/acs.chemrev.5b00584.

(72) Perdew, J. P.; Schmidt, K. Jacob's ladder of density functional approximations for the exchangecorrelation energy. In Density functional theory and its application to materials, VanDoren, V.; VanAlsenoy, C.; Geerlings, P., Eds. Amer Inst Physics: Melville, 2001; Vol. 577, pp 1-20.

(73) Yu, H. Y. S.; He, X.; Li, S. H. L.; Truhlar, D. G. Mn15: A Kohn-Sham global-hybrid exchangecorrelation density functional with broad accuracy for multi-reference and single-reference systems and noncovalent interactions. Chem. Sci. 2016, 7, 5032-5051 DOI: 10.1039/c6sc00705h.

(74) Becke, A. D. Density-functional thermochemistry III. The role of exact exchange. J. Chem. Phys. 1993, 98, 5648-5652 DOI: 10.1063/1.464913.

(75) Lee, C. T.; Yang, W. T.; Parr, R. G. Development of the colle-salvetti correlation-energy formula into a functional of the electron-density. Phys. Rev. B 1988, 37, 785-789 DOI: 10.1103/PhysRevB.37.785.

(76) Ditchfield, R.; Hehre, W. J.; Pople, J. A. Self-consistent molecular-orbital methods 9. Extended Gaussian-type basis for molecular-orbital studies of organic molecules. J. Chem. Phys. 1971, 54, 724-725 DOI: 10.1063/1.1674902.

(77) Harihara, P.; Pople, J. A. Influence of polarization functions on molecular-orbital hydrogenation energies. Theor. Chim. Acta 1973, 28, 213-222 DOI: 10.1007/bf00533485.

(78) Hehre, W. J.; Ditchfield, R.; Pople, J. A. Self-consistent molecular-orbital methods 12. Further extensions of Gaussian-type basis sets for use in molecular-orbital studies of organic-molecules. J. Chem. Phys. 1972, 56, 2257-2258 DOI: 10.1063/1.1677527.

(79) Weigend, F. Accurate coulomb-fitting basis sets for $\mathrm{h}$ to rn. Phys. Chem. Chem. Phys. 2006, 8, 1057-1065 DOI: 10.1039/b515623h.

(80) Weigend, F.; Ahlrichs, R. Balanced basis sets of split valence, triple-zeta valence and quadruplezeta valence quality for $\mathrm{H}$ to Rn: Design and assessment of accuracy. Phys. Chem. Chem. Phys. 2005, 7, 3297-3305 DOI: 10.1039/b508541a.

(81) Collins, J. B.; Schleyer, P. V.; Binkley, J. S.; Pople, J. A. Self-consistent molecular-orbital methods 17. Geometries and binding-energies of 2 nd-row molecules - comparison of 3 basis sets. J. Chem. Phys. 1976, 64, 5142-5151 DOI: 10.1063/1.432189.

(82) Hehre, W. J.; Stewart, R. F.; Pople, J. A. Self-consistent molecular-orbital methods I. Use of gaussian expansions of slater-type atomic orbitals. J. Chem. Phys. 1969, 51, 2657-2658 DOI: 10.1063/1.1672392.

(83) Dunning Jr., T. H.; Hay, P. J. Gaussian basis sets for molecular calculations. In Modern theoretical chemistry, Schaefer III, H. F., Ed. Plenum: New York, 1977; Vol. 1, pp 1-28.

(84) Pople, J. A.; Nesbet, R. K. Self-consistent orbitals for radicals. J. Chem. Phys. 1954, 22, 571-572 DOI: $10.1063 / 1.1740120$.

(85) Roothaan, C. C. J. New developments in molecular orbital theory. Rev. Mod. Phys. 1951, 23, 6989 DOI: 10.1103/RevModPhys.23.69. 
(86) Frisch, M. J.; Head-Gordon, M.; Pople, J. A. A direct MP2 gradient-method. Chem. Phys. Lett. 1990, 166, 275-280 DOI: 10.1016/0009-2614(90)80029-d.

(87) Frisch, M. J.; Head-Gordon, M.; Pople, J. A. Semidirect algorithms for the MP2 energy and gradient. Chem. Phys. Lett. 1990, 166, 281-289 DOI: 10.1016/0009-2614(90)80030-h.

(88) Pople, J. A.; Binkley, J. S.; Seeger, R. Theoretical models incorporating electron correlation. Int. J. Quantum Chem. 1976, 1-19

(89) Pople, J. A.; Seeger, R.; Krishnan, R. Variational configuration interaction methods and comparison with perturbation-theory. Int. J. Quantum Chem. 1977, 149-163

(90) Krishnan, R.; Frisch, M. J.; Pople, J. A. Contribution of triple substitutions to the electron correlation-energy in 4th order perturbation-theory. J. Chem. Phys. 1980, 72, 4244-4245 DOI: 10.1063/1.439657.

(91) Krishnan, R.; Pople, J. A. Approximate $4^{\text {th }}$ order perturbation-theory of electron correlation energy. Int. J. Quantum Chem. 1978, 14, 91-100 DOI: 10.1002/qua.560140109.

(92) Čížek, J. On the use of the cluster expansion and the technique of diagrams in calculations of correlation effects in atoms and molecules. In Advances in chemical physics, LeFebvre, R.; Moser, C., Eds. John Wiley and Sons, Ltd: 1969; Vol. 14, pp 35-89.

(93) Purvis, G. D.; Bartlett, R. J. A full coupled-cluster singles and doubles model - the inclusion of disconnected triples. J. Chem. Phys. 1982, 76, 1910-1918 DOI: 10.1063/1.443164.

(94) Scuseria, G. E.; Janssen, C. L.; Schaefer, H. F. An efficient reformulation of the closed-shell coupled cluster single and double excitation (CCSD) equations. J. Chem. Phys. 1988, 89, 73827387 DOI: $10.1063 / 1.455269$.

(95) Pople, J. A.; Headgordon, M.; Raghavachari, K. Quadratic configuration-interaction - a general technique for determining electron correlation energies. J. Chem. Phys. 1987, 87, 5968-5975 DOI: $10.1063 / 1.453520$.

(96) Montgomery, J. A.; Frisch, M. J.; Ochterski, J. W.; Petersson, G. A. A complete basis set model chemistry. VI. Use of density functional geometries and frequencies. J. Chem. Phys. 1999, 110, 2822-2827 DOI: 10.1063/1.477924.

(97) Montgomery, J. A.; Frisch, M. J.; Ochterski, J. W.; Petersson, G. A. A complete basis set model chemistry. VII. Use of the minimum population localization method. J. Chem. Phys. 2000, 112, 6532-6542 DOI: 10.1063/1.481224.

(98) Hirshfeld, F. L. Bonded-atom fragments for describing molecular charge-densities. Theor. Chim. Acta 1977, 44, 129-138 DOI: 10.1007/bf00549096.

(99) Reed, A. E.; Weinstock, R. B.; Weinhold, F. Natural-population analysis. J. Chem. Phys. 1985, 83, 735-746 DOI: 10.1063/1.449486.

(100) Besler, B. H.; Merz, K. M.; Kollman, P. A. Atomic charges derived from semiempirical methods. J. Comput. Chem. 1990, 11, 431-439 DOI: 10.1002/jcc.540110404.

(101) Mulliken, R. S. Electronic population analysis on LCAO-MO molecular wave functions. J. Chem. Phys. 1955, 23, 1833-1840 DOI: 10.1063/1.1740588.

(102) Mayer, I. Bond order and valence indices: A personal account. J. Comput. Chem. 2007, 28, 204221 DOI: 10.1002/jcc.20494.

(103) Lowdin, P. O. Band theory, valence bond, and tight-binding calculations. J. Appl. Phys. 1962, 33, 251-252 DOI: 10.1063/1.1777106.

(104) Boys, S. F.; Bernardi, F. Calculation of small molecular interactions by differences of separate total energies. Some procedures with reduced errors. Mol. Phys. 1970, 19, 553-554 DOI: 10.1080/00268977000101561.

(105) Simon, S.; Duran, M.; Dannenberg, J. J. How does basis set superposition error change the potential surfaces for hydrogen bonded dimers? J. Chem. Phys. 1996, 105, 11024-11031 DOI: 10.1063/1.472902. 
(106) Burns, L. A.; Marshall, M. S.; Sherrill, C. D. Comparing counterpoise-corrected, uncorrected, and averaged binding energies for benchmarking noncovalent interactions. J. Chem. Theory Comput. 2014, 10, 49-57 DOI: 10.1021/ct400149j.

(107) Lemmon, E. W.; Huber, M. L.; McLinden, M. O., NIST standard reference database 23: Reference fluid thermodynamic and transport properties-REFPROP, Version 8.0. NIST: Nat'I Std. Ref. Data Series (NIST NSRDS), 2007.

(108) Mammen, M.; Shakhnovich, E. I.; Whitesides, G. M. Using a convenient, quantitative model for torsional entropy to establish qualitative trends for molecular processes that restrict conformational freedom. J. Org. Chem. 1998, 63, 3168-3175 DOI: 10.1021/jo970943n.

(109) Scheiner, S. Ability of IR and NMR spectral data to distinguish between a tetrel bond and a hydrogen bond. J. Phys. Chem. A 2018, 122, 7852-7862 DOI: 10.1021/acs.jpca.8b07631.

(110) Feller, D.; Peterson, K. A.; Dixon, D. A. A survey of factors contributing to accurate theoretical predictions of atomization energies and molecular structures. J. Chem. Phys. 2008, 129, 32 DOI: 10.1063/1.3008061.

(111) Schuurman, M. S.; Muir, S. R.; Allen, W. D.; Schaefer, H. F. Toward subchemical accuracy in computational thermochemistry: Focal point analysis of the heat of formation of NCO and H,N,C,O isomers. J. Chem. Phys. 2004, 120, 11586-11599 DOI: 10.1063/1.1707013.

(112) Myers, A. L. Thermodynamics of adsorption in porous materials. AICHE J. 2002, 48, 145-160 DOI: 10.1002/aic.690480115.

(113) Stadie, N. P. Synthesis and thermodynamic studies of physisorptive energy storage materials. California Institute of Technology, Passadena, CA, 2013.

(114) Sircar, S.; Mohr, R.; Ristic, C.; Rao, M. B. Isosteric heat of adsorption: Theory and experiment. J. Phys. Chem. B 1999, 103, 6539-6546 DOI: 10.1021/jp9903817.

(115) Towns, J.; Cockerill, T.; Dahan, M.; Foster, I.; Gaither, K.; Grimshaw, A.; Hazlewood, V.; Lathrop, S.; Lifka, D.; Peterson, G. D., et al. XSEDE: Accelerating scientific discovery. Comput. Sci. Eng. 2014, 16, 62-74 DOI: 10.1109/mcse.2014.80. 


\section{SUPPORTING INFORMATION}

\section{Methane Adsorption on Heteroatom-Modified Maquettes of Porous Carbon Surfaces}

Rylan Rowsey, ${ }^{1}$ Erin E. Taylor, ${ }^{1}$ Stephan Irle, ${ }^{2}$ Nicholas P. Stadie, ${ }^{*}$ and Robert K. Szilagyi ${ }^{*}$

1Department of Chemistry \& Biochemistry, Montana State University, Bozeman, Montana, 59717, United States

${ }^{2}$ Computational Sciences \& Engineering Division, Oak Ridge National Laboratory, Oak Ridge, Tennessee, 37831, United States

*szilagyi@montana.edu and nstadie@montana.edu

Additional electronic supporting information including the atomic positional coordinates for all maquettes, templates for geometric and electronic structure analysis, formatted checkpoint files, and electron density and spin density cube files is available free of charge at Zenodo.org (DOI: 10.5281/zenodo.4330761 or URL: https://zenodo.org/record/4330761) 


\section{Table of Contents:}

Figure S1. Graphical illustrations of the nomenclature employed for adsorbent reference orientation and atom numbering. The central position 1 is the site of substitution (X1 position, $\mathrm{X}=\mathrm{C}, \mathrm{B}$, or $\mathrm{N}$ ). Relative to X1, the nearest neighbors ( $\alpha$ positions) are numbered $2-4$, the second-nearest neighbors ( $\beta$ positions) are numbered 5-10, and the third-nearest neighbors ( $\gamma$ positions) are numbered 11-13. The methylidene group carbon is numbered 14 . While this is different from the IUPAC numbering convention, it is suited for clarity within the present work. The rings of the MPh models are labeled with roman numerals. Ring I contains the dangling methylidene group, which breaks the symmetry of the model. Rings II and III are adjacent and opposite to ring I, respectively.

Figure S2. Graphical illustrations of the nomenclature employed for representative internal coordinates of the adsorbent. The "inner sphere" coordinates are defined by three $\mathrm{C}-\mathrm{C}$ distances between the site of substitution (X1) and each of the $\alpha \mathrm{C}$ atoms. The "outer sphere" is defined by six $\mathrm{C}-\mathrm{C}$ distances between adjacent $\alpha \mathrm{C}$ and $\beta \mathrm{C}$ atoms. The "peripheral sphere" is defined by six plus one $\mathrm{C}-$ $\mathrm{C}$ distances between adjacent $\beta \mathrm{C}$ and $\gamma \mathrm{C}$ atoms, and the methylidene $\gamma^{\prime} \mathrm{C}$ atom. The planarity of the molecule is described by the distance $(\delta)$ between the site of substitution (X1) and the plane formed by the ring centroids ( $\mathrm{X}_{\mathrm{I}}, \mathrm{X}_{\mathrm{II}}$, and $\left.\mathrm{X}_{\mathrm{III}}\right)$. Finally, the out-of-plane wagging character of the methylidene group is defined by the angle $(\mathrm{w})$ between the $\gamma^{\prime} \mathrm{C} \cdots i p s o-\beta C \cdots p a r a-\alpha \mathrm{C}$ of ring I. Notably, the inplane bending of the MPh structure is typically negligible owing to the extensive $\pi$-conjugation of all carbon/heteroatom sites.

Figure S3. Graphical illustrations of the nomenclature employed for adsorption model geometry, atom numbering, and internal coordinates. The bond length of the adsorption interaction is defined by the distance between the methane carbon (C25) and site of substitution (X1), as well as the three distances between the proximal $\mathrm{H}$ atoms of the methane molecule and the nearest ring centroids $\left(\mathrm{H} 26 \cdots \mathrm{X}_{\mathrm{I}}, \mathrm{H} 27 \cdots \mathrm{X}_{\mathrm{II}}\right.$, and $\left.\mathrm{H} 28 \cdots \mathrm{X}_{\mathrm{III}}\right)$. The distortion imposed by the adsorption interaction is defined by four $\mathrm{C}-\mathrm{H}$ distances within the methane (adsorbate) molecule, and the dihedral angles $\left(\omega_{\mathrm{I}}, \omega_{\mathrm{II}}\right.$, and $\left.\omega_{\mathrm{III}}\right)$ between the methane $\mathrm{C}-\mathrm{H}$ bonds and the closest ring centroid: $\mathrm{C} 25-\mathrm{H}(26,27,28) \cdots \mathrm{X} 1 \cdots \gamma \mathrm{C}(11,12,13)$. The $\mathrm{C}-\mathrm{H}$ distances are further classified as proximal (C25-H26, C25-H27, and C25$\mathrm{H} 28)$ or distal (C25-H29) relative to the adsorbent surface.

Figure S4. (a) Potential energy surface maps for methane interactions with MPh and its heteroatom-substituted variants (B-MPh and $\mathrm{N}-\mathrm{MPh}$ ) in $\kappa^{1}$ approach geometry at the PBE/6-311++G** level. (b) The PBE optimized adsorption models $\mathrm{MPh} \times \mathrm{CH}_{4}, \mathrm{~B}-\mathrm{MPh} \times \mathrm{CH}_{4}$, and $\mathrm{N}-\mathrm{MPh} \times \mathrm{CH}_{4}$ in their starting geometries used for structural optimizations. (c) Potential energy difference maps between the PBE/6-311++G** and the MN15/6-311++G** levels of theory. 
Figure S5. Electron density difference plots for methane interactions with $\mathrm{MPh}$ and its heteroatom-substituted variants: (a-c) at a high contour level of $5 \times 10^{-4}\left(e^{-}\right)^{2} \AA^{-3}$ and (d-f) at a low contour level of $1.5 \times 10^{-4}\left(e^{-}\right)^{2} \AA^{-3}$ for $\mathrm{MPh} \times 2 \mathrm{CH}_{4}(\mathrm{a}, \mathrm{d}), \mathrm{B}-$ $\mathrm{MPh} \times 2 \mathrm{CH}_{4}(\mathrm{~b}, \mathrm{e})$, and $\mathrm{N}-\mathrm{MPh} \times 2 \mathrm{CH}_{4}(\mathrm{c}, \mathrm{f})$. Electron density difference between the double adsorption model and the separate adsorbent and adsorbates at the MN15/def2-QZVPP level is shown (positive difference in red, negative difference in blue). See Figure 3 for the corresponding single $(n=1)$ adsorption models.

Figure S6. Comparison of the electron density of MPh and the spin density of B-MPh and $\mathrm{N}-\mathrm{MPh}$ upon methane adsorption. (a) LUMO and (c) HOMO electron density contour plots for $\mathrm{MPh} \times 2 \mathrm{CH}_{4}$ at a contour level of $4.5 \times 10^{-2}\left(e^{-}\right)^{2} \AA^{-3}$ and (b,d) spin density contour plots for $\mathrm{N}-\mathrm{MPh} \times 2 \mathrm{CH}_{4}$ and $\mathrm{B}-\mathrm{MPh} \times 2 \mathrm{CH}_{4}$ at a contour level of $3.5 \times 10^{-3}\left(e^{-}\right)^{2} \AA^{-3}$. See Figure 4 for the corresponding single $(\mathrm{n}=1)$ adsorption models.

Table S1: Overview of literature examples of experimental (top) and theoretical (bottom) investigations of methane adsorption on carbon surfaces. The sign convention corresponds to energy of dissociation/desorption. All experimental and theoretical values refer to isosteric heat of desorption $\left(\mathrm{q}_{\mathrm{st}}\right)$ from gas adsorption measurements and calculated desorption energy $\left(\Delta_{\mathrm{des}} \mathrm{E}\right)$ from quantum potential energy differences, respectively.

Table S2. Graphical illustration and Z-matrix definitions for $\kappa^{1}, \mu_{2}, \mu_{3}$, and $\eta^{2}$ approaches of $\mathrm{CH}_{4}$ to the $\mathrm{X} 1$ position of MPh and its heteroatom substituted variants.

Table S3. Free adsorbent structures (LoT: MN15 using the STO-3G \{MN15\}, SDDAll [MN15], 6-31G* (MN15-), or def2-QZVPP (MN15+) basis sets) of MPh, B-MPh, and N-MPh as described by averages and standard deviations of inner, outer, and peripheral sphere $\mathrm{C}-\mathrm{C}$ distances in $\AA$, out-of-planarity $(\delta$, in $\AA$ ) of the site of substitution, and wagging angle ( $w$, in degrees) of the methylidene group (see Table S4 for the geometry upon methane adsorption)

Table S4. Adsorbent structures upon adsorption (LoT: MN15, MP2, MP4SDQ, or CCSD using the 6-311++G** basis set, or MN15 using the ST0-3G \{MN15\}, SDDAll [MN15], 631G* (MN15-), or def2-QZVPP (MN15+) basis sets) of methane on MPh, B-MPh, and $\mathrm{N}-\mathrm{MPh}$, as described by averages and standard deviations of inner, outer, and peripheral sphere $\mathrm{C}$-C distances in $\AA$, out-of-planarity $(\delta$, in $\AA$ ) of the site of substitution, and wagging angle ( $w$, in degrees) of the methylidene group (see Tables $\mathbf{1}$ and $\mathbf{S} 3$ for the free adsorbent structures). 
Table S5. Adsorption model structures (LoT: MN15 using the STO-3G $\quad$ MN15\}, SDDAll [MN15], 6-31G* (MN15-), or def2-QZVPP (MN15+) basis sets) of methane on $\mathrm{MPh}, \mathrm{B}-\mathrm{MPh}$, and N-MPh. Adsorption by one $(\mathrm{n}=1)$ and two $(\mathrm{n}=2)$ methane molecules is described by interaction distances and twisting angles: methane to central site $(\mathrm{C} 25 \cdots \mathrm{X} 1)$ distance, proximal $\mathrm{H}$ to closest ring centroid $\left(\mathrm{H}_{\mathrm{p}} \cdots \mathrm{X}_{\mathrm{i}}\right)$ distance, dihedral angle formed by $\mathrm{X}_{\mathrm{i}} \cdots \mathrm{X} 1 \cdots \mathrm{C} 25-\mathrm{H}_{\mathrm{p}}(\omega)$, and proximal and distal $\mathrm{C}-\mathrm{H}$ bond lengths.

Table S6. Desorption energies $\left(\Delta_{\text {des, }} \mathrm{kJ} \mathrm{mol}^{-1}\right)$ for $\mathrm{MPh} \times \mathrm{nCH}_{4} \rightarrow \mathrm{MPh}+\mathrm{nCH}_{4}$ (LoT: MN15 using the ST0-3G $\{$ MN15\}, SDDAll [MN15], 6-31G* (MN15-), or def2-QZVPP (MN15+) basis sets). CBS refers to the modified complete basis set extrapolation method employing the CBS-QB3 formalism, but utilizing the MN15/6-311++G** geometry. The standard enthalpy, Gibbs free energy, and entropy of desorption are calculated at $298 \mathrm{~K}$ using a simple statistical mechanical model assuming ideal gas behavior. A modest statistical analysis (average and standard deviation) of the thermochemical quantities is shown, normalized per mole of $\mathrm{CH}_{4}$.

Table S7. Energy stabilization $(\Delta \Delta \mathrm{EQM})$ and desorption $\left(\rightarrow \mathrm{MPh}+\mathrm{CH}_{4}\right)$ energy differences (in $\mathrm{kJ} \mathrm{mol}^{-1}$ ) due to optimizing the MN16/6-311++ $\mathrm{G}^{* *}$ equilibrium structures of the adsorbent, adsorbate, and the adsorption model using a conceptually converging series of correlated MO theories (LoT: MP2, MP3, MP4, CCSD, or $\operatorname{CCSD}(\mathrm{T})$ using the $6-311++\mathrm{G}^{* *}$ basis set).

Table S8. Atomic charge (electron) distribution analysis upon single $(n=1)$ and double (n = 2) methane adsorption on MPh, B-MPh, and N-MPh determined by three conceptually different population analysis methods: Hirshfeld (HPA), Weinhold (NPA), and Merz-Kollman (ESP) at the MN15/def2-QZVPP level of theory. See Figure 2 for a graphical plot and Figure $\mathbf{S 1}$ for the numbering of atom positions.

Table S9. Atomic charge (electron) distribution analysis upon single ( $\mathrm{n}=1)$ and double (n = 2) methane adsorption on MPh, B-MPh, and N-MPh determined by three conceptually different population analysis methods: Hirshfeld (HPA), Weinhold (NPA), and Merz-Kollman (ESP) at the MN15/def2-QZVPP level of theory. See Figure $\mathbf{2}$ for a graphical plot and Figure $\mathbf{S 1}$ for the numbering of atom positions (numbering of the second adsorbate is logical).

Table S10. Atomic spin densities of the adsorbent molecule for single (n=1) and double (n = 2) methane adsorption on B-MPh and N-MPh from Hirshfeld population analysis (HPA) and Weinhold natural population analysis (NPA) at the MN15/def2-QZVPP level of theory. See Figure S1 for the numbering of atom positions.

Table S11. Atomic spin densities of the adsorbate molecule(s) for single ( $n=1)$ and double $(\mathrm{n}=2)$ methane adsorption on B-MPh and N-MPh from Hirshfeld population analysis (HPA) and Weinhold natural population analysis (NPA) at the MN15/def2-QZVPP level of theory. See Figure S1 for the numbering of atom positions (numbering of the second adsorbate is logical). 
Table S12. Thermochemical quantities (in $\mathrm{kJ} \mathrm{mol}^{-1}$ ) for comparison to experimental measurements of physisorptive binding of methane on porous carbon surfaces at $298 \mathrm{~K}$. LoT: MN15/6-311++G**. MPh $\times \mathrm{CH}_{4}$ corresponds to $5.6 \mathrm{mmol} \mathrm{g}^{-1}$ of absolute uptake and $\mathrm{MPh} \times 2 \mathrm{CH}_{4}$ corresponds to $11.2 \mathrm{mmol} \mathrm{g}^{-1}$, where uptake is defined as the true or "absolute" quantity. At room temperature $(298 \mathrm{~K})$, this corresponds to the following equilibrium pressures for adsorption on ZTC: 9.5 and 26.8 bar (or 9.3 and $26.4 \mathrm{~atm}$ ), respectively. The enthalpy of desorption $\left(\Delta_{\text {des }} \mathrm{H}\right)$ at these conditions is measured to be 13.5 and $13.1 \mathrm{~kJ} \mathrm{~mol}^{-1}$, respectively (Stadie et al., 2015 - Reference 49).

Table S13. Thermochemical quantities (in $\mathrm{kJ} \mathrm{mol}^{-1}$ ) for comparison to experimental measurements of physisorptive binding of methane on porous carbon surfaces at $298 \mathrm{~K}$. LoT: MN15/def2-QZVPP. $\mathrm{MPh} \times \mathrm{CH}_{4}$ corresponds to $5.6 \mathrm{mmol} \mathrm{g}^{-1}$ of absolute uptake and $\mathrm{MPh} \times 2 \mathrm{CH}_{4}$ corresponds to $11.2 \mathrm{mmol} \mathrm{g}^{-1}$, where uptake is defined as the true or "absolute" quantity. At room temperature $(298 \mathrm{~K})$, this corresponds to the following equilibrium pressures for adsorption on ZTC: 9.5 and 26.8 bar (or 9.3 and $26.4 \mathrm{~atm}$ ), respectively. The enthalpy of desorption $\left(\Delta_{\text {des }} \mathrm{H}\right)$ at these conditions is measured to be 13.5 and $13.1 \mathrm{~kJ} \mathrm{~mol}^{-1}$, respectively (Stadie et al., 2015 - Reference 49).. 


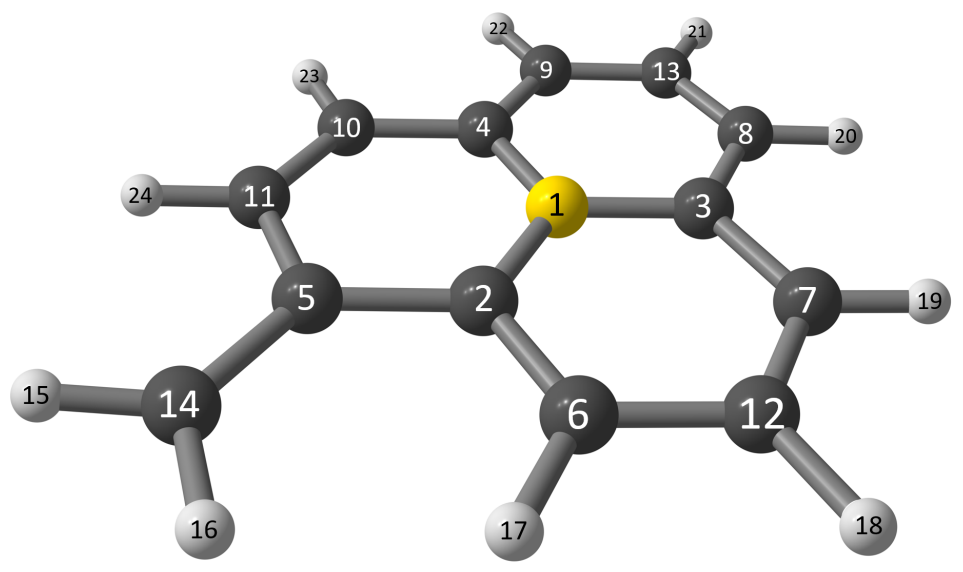

Figure S1. Graphical illustrations of the nomenclature employed for adsorbent reference orientation and atom numbering. The central position 1 is the site of substitution $(\mathrm{X} 1$ position, $\mathrm{X}=$

$\mathrm{C}, \mathrm{B}$, or $\mathrm{N}$ ). Relative to $\mathrm{X} 1$, the nearest neighbors ( $\alpha$ positions) are numbered $2-4$, the secondnearest neighbors ( $\beta$ positions) are numbered 5-10, and the third-nearest neighbors ( $\gamma$ positions) are numbered 11-13. The methylidene group carbon is numbered 14 . While this is different from the IUPAC numbering convention, it is suited for clarity within the present work. The rings of the $\mathrm{MPh}$ models are labeled with roman numerals. Ring I contains the dangling methylidene group, which breaks the symmetry of the model. Rings II and III are adjacent and opposite to ring I, respectively.

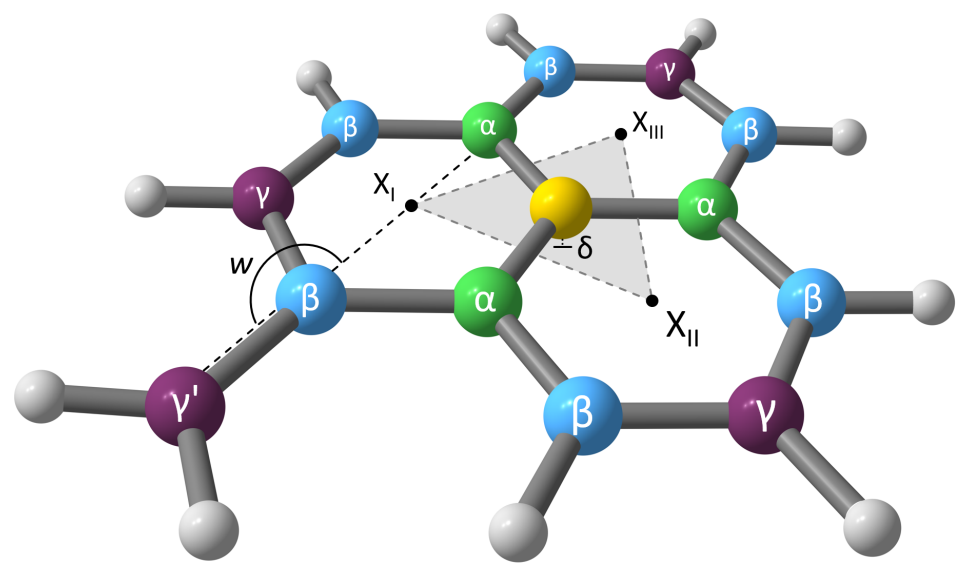

Figure S2. Graphical illustrations of the nomenclature employed for representative internal coordinates of the adsorbent. The "inner sphere" coordinates are defined by three $\mathrm{C}-\mathrm{C}$ distances between the site of substitution (X1) and each of the $\alpha \mathrm{C}$ atoms. The "outer sphere" is defined by six $\mathrm{C}-\mathrm{C}$ distances between adjacent $\alpha \mathrm{C}$ and $\beta \mathrm{C}$ atoms. The "peripheral sphere" is defined by six plus one $\mathrm{C}-\mathrm{C}$ distances between adjacent $\beta \mathrm{C}$ and $\gamma \mathrm{C}$ atoms, and the methylidene $\gamma^{\prime} \mathrm{C}$ atom. The planarity of the molecule is described by the distance $(\delta)$ between the site of substitution (X1) and the plane formed by the ring centroids $\left(\mathrm{X}_{\mathrm{I}}, \mathrm{X}_{\mathrm{II}}\right.$, and $\mathrm{X}_{\mathrm{III}}$ ). Finally, the out-of-plane wagging character of the methylidene group is defined by the angle $(\mathrm{w})$ between the $\gamma^{\prime} \mathrm{C} \cdots$ ipso- $\beta \mathrm{C} \cdots$ para- $\alpha \mathrm{C}$ of ring I. Notably, the in-plane bending of the MPh structure is typically negligible owing to the extensive $\pi$ conjugation of all carbon/heteroatom sites. 


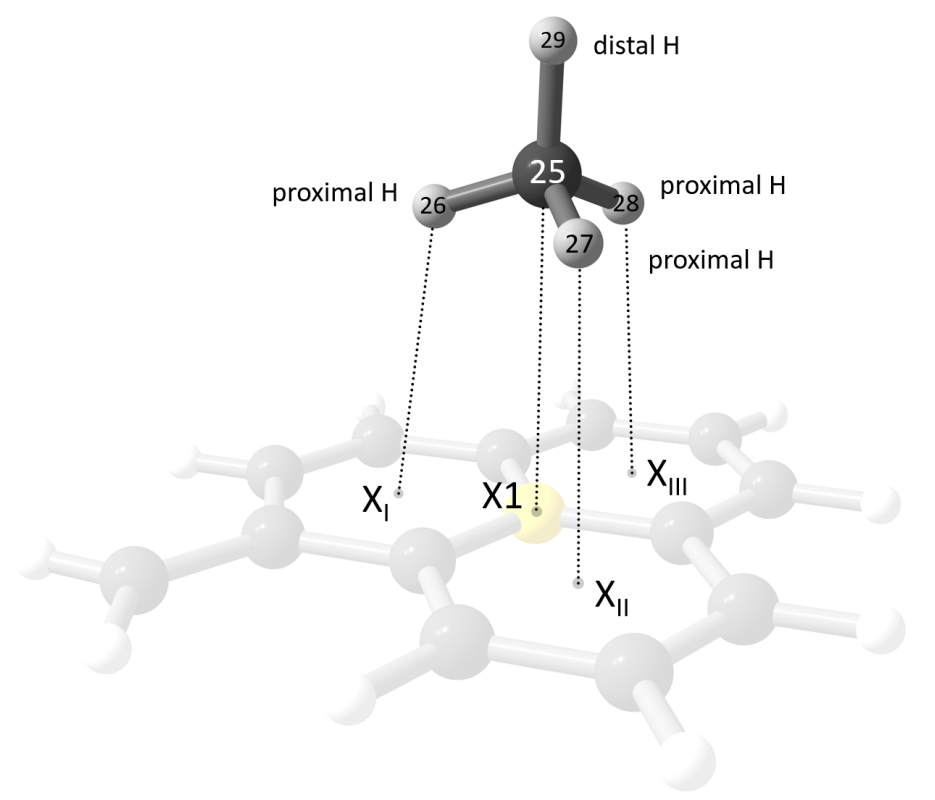

Figure S3. Graphical illustrations of the nomenclature employed for adsorption model geometry, atom numbering, and internal coordinates. The bond length of the adsorption interaction is defined by the distance between the methane carbon (C25) and site of substitution (X1), as well as the three distances between the proximal $\mathrm{H}$ atoms of the methane molecule and the nearest ring centroids $\left(\mathrm{H} 26 \cdots \mathrm{X}_{\mathrm{I}}, \mathrm{H} 27 \cdots \mathrm{X}_{\mathrm{II}}\right.$, and $\left.\mathrm{H} 28 \cdots \mathrm{X}_{\mathrm{III}}\right)$. The distortion imposed by the adsorption interaction is defined by four $\mathrm{C}-\mathrm{H}$ distances within the methane (adsorbate) molecule, and the dihedral angles $\left(\omega_{\mathrm{I}}, \omega_{\mathrm{II}}\right.$, and $\left.\omega_{\text {III }}\right)$ between the methane $\mathrm{C}-\mathrm{H}$ bonds and the closest ring centroid: $\mathrm{C} 25-$

$\mathrm{H}(26,27,28) \cdots \mathrm{X} 1 \cdots \gamma \mathrm{C}(11,12,13)$. The $\mathrm{C}-\mathrm{H}$ distances are further classified as proximal $(\mathrm{C} 25-\mathrm{H} 26$, $\mathrm{C} 25-\mathrm{H} 27$, and $\mathrm{C} 25-\mathrm{H} 28)$ or distal $(\mathrm{C} 25-\mathrm{H} 29)$ relative to the adsorbent surface. 
a
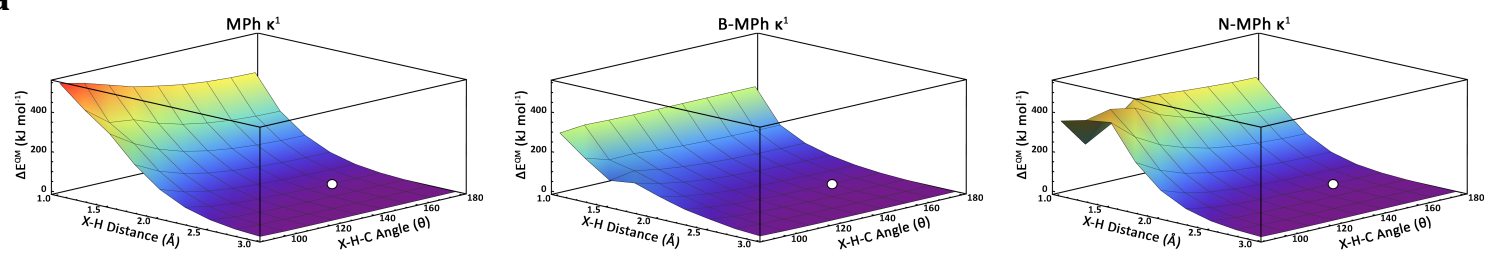

b

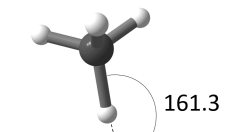

161.3
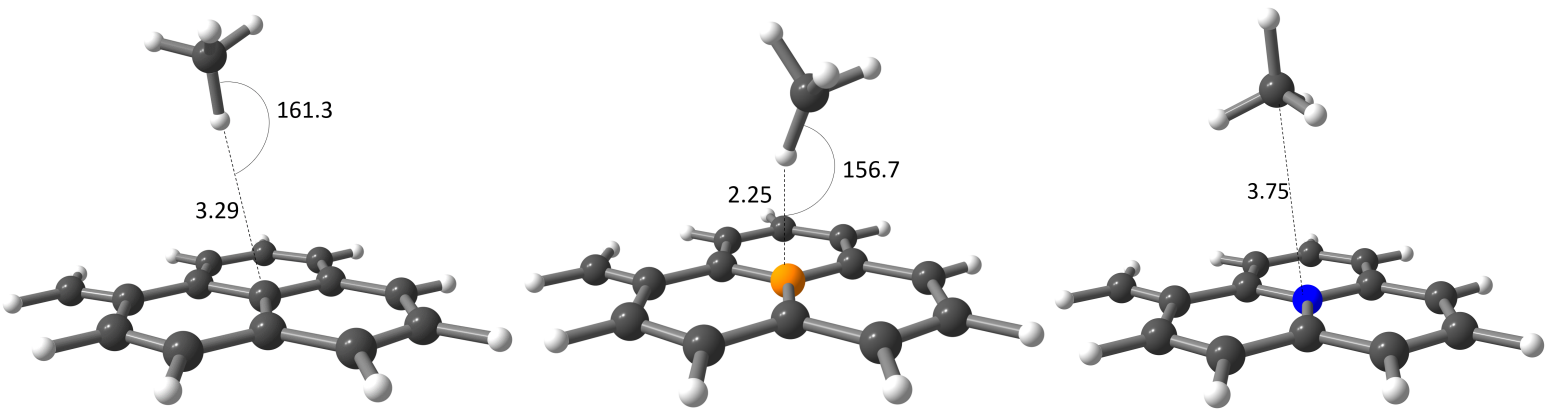

C
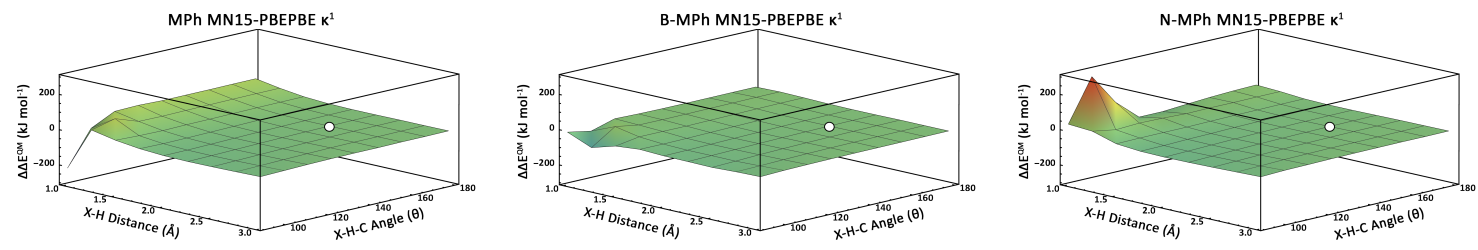

Figure S4. (a) Potential energy surface maps for methane interactions with MPh and its heteroatom-substituted variants (B-MPh and N-MPh) in $\kappa^{1}$ approach geometry at the PBE/6$311++\mathrm{G}^{* *}$ level. (b) The PBE optimized adsorption models $\mathrm{MPh} \times \mathrm{CH}_{4}, \mathrm{~B}-\mathrm{MPh} \times \mathrm{CH}_{4}$, and $\mathrm{N}-\mathrm{MPh} \times \mathrm{CH}_{4}$ in their starting geometries used for structural optimizations. (c) Potential energy difference maps between the PBE/6-311++G** and the MN15/6-311++G** levels of theory. 

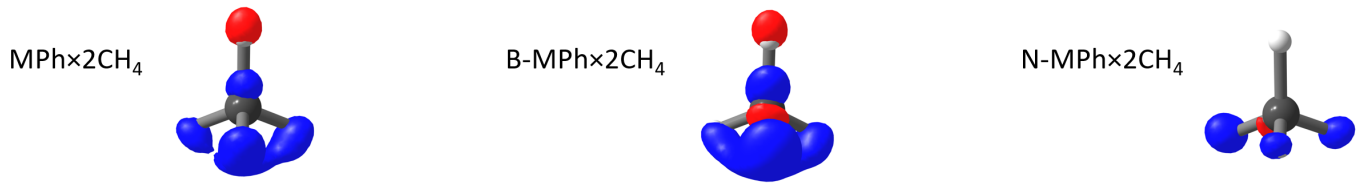

a
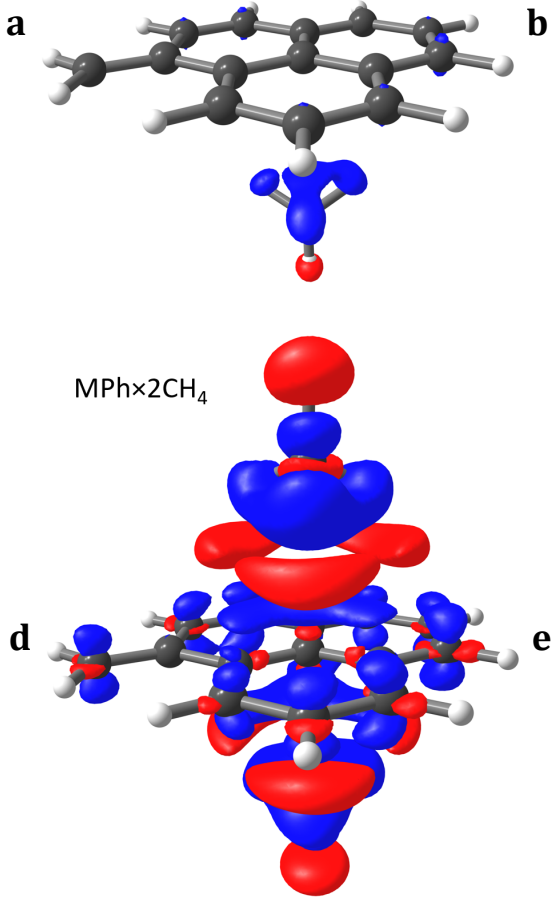

b
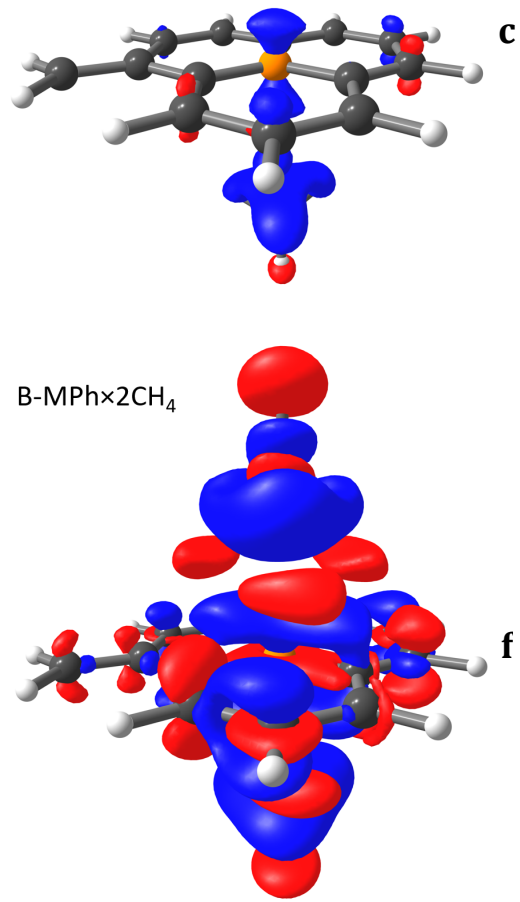
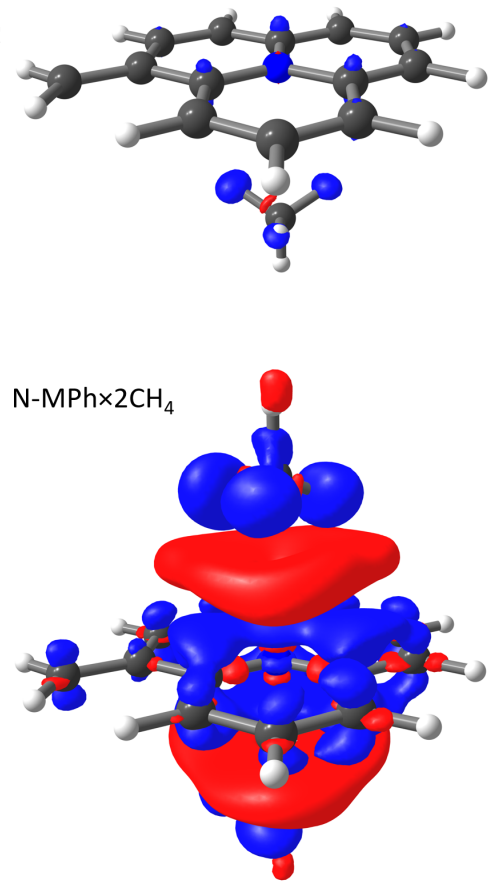

Figure S5. Electron density difference plots for methane interactions with $\mathrm{MPh}$ and its heteroatomsubstituted variants: (a-c) at a high contour level of $5 \times 10^{-4}\left(e^{-}\right)^{2} \AA^{-3}$ and (d-f) at a low contour level of $1.5 \times 10^{-4}\left(e^{-}\right)^{2} \AA^{-3}$ for $\mathrm{MPh} \times 2 \mathrm{CH}_{4}(\mathrm{a}, \mathrm{d}), \mathrm{B}-\mathrm{MPh} \times 2 \mathrm{CH}_{4}(\mathrm{~b}, \mathrm{e})$, and $\mathrm{N}-\mathrm{MPh} \times 2 \mathrm{CH}_{4}$ (c,f). Electron density difference between the double adsorption model and the separate adsorbent and adsorbates at the MN15/def2-QZVPP level is shown (positive difference in red, negative difference in blue). See

Figure 3 for the corresponding single $(n=1)$ adsorption models. 

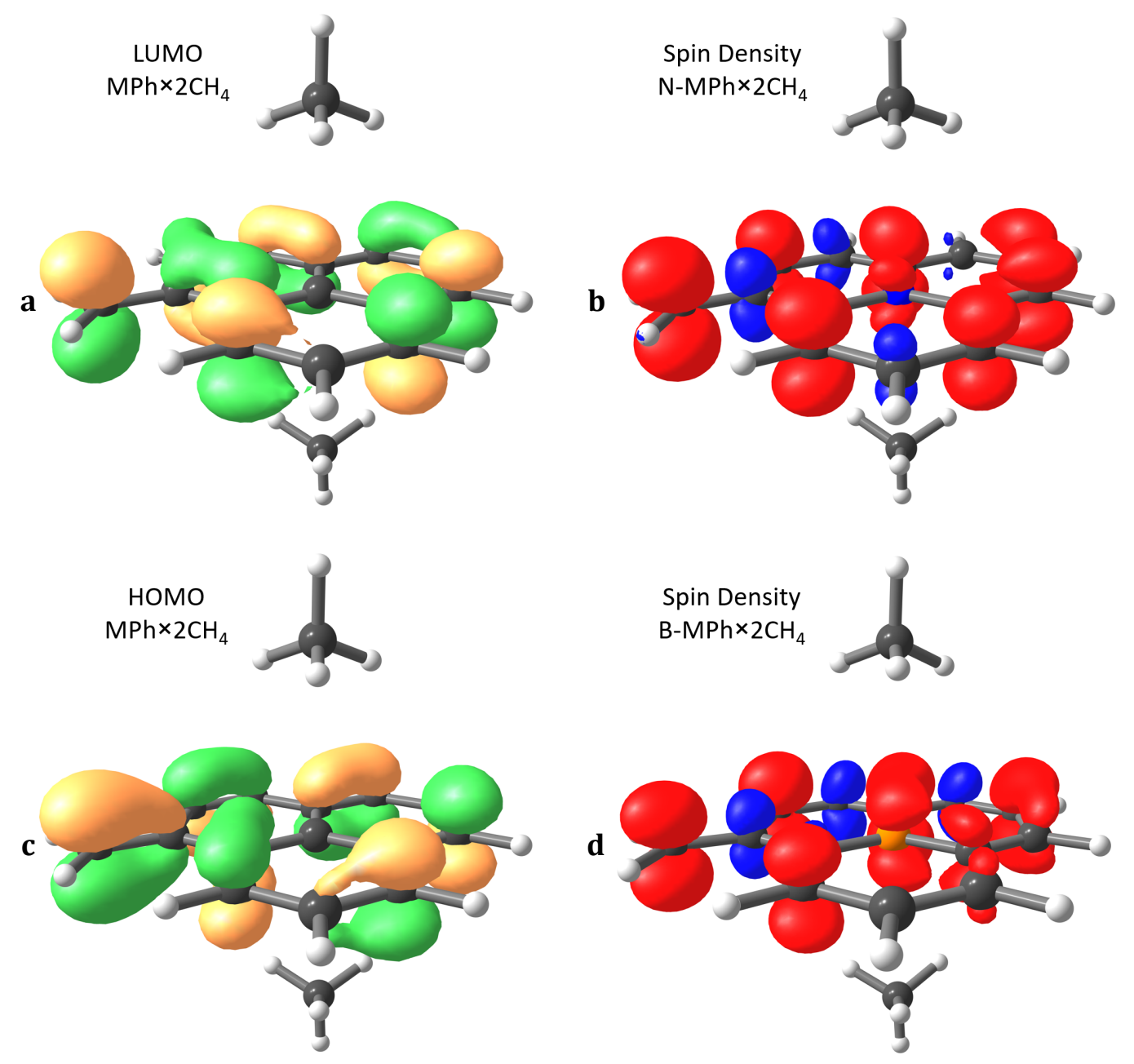

Figure S6. Comparison of the electron density of MPh and the spin density of B-MPh and N-MPh upon methane adsorption. (a) LUMO and (c) HOMO electron density contour plots for $\mathrm{MPh} \times 2 \mathrm{CH}_{4}$ at a contour level of $4.5 \times 10^{-2}\left(e^{-}\right)^{2} \AA^{-3}$ and (b,d) spin density contour plots for $\mathrm{N}-\mathrm{MPh} \times 2 \mathrm{CH}_{4}$ and B$\mathrm{MPh} \times 2 \mathrm{CH}_{4}$ at a contour level of $3.5 \times 10^{-3}\left(e^{-}\right)^{2} \AA^{-3}$. See Figure 4 for the corresponding single $(\mathrm{n}=1)$ adsorption models. 
Table S1: Overview of literature examples of experimental (top) and theoretical (bottom) investigations of methane adsorption on carbon surfaces. The sign convention corresponds to energy of dissociation/desorption. All experimental and theoretical values refer to isosteric heat of desorption ( $\mathrm{q}_{\mathrm{s}}$ ) from gas adsorption measurements and calculated desorption energy $\left(\Delta_{\text {des }} E\right)$ from quantum potential energy differences, respectively.

\section{Experimental Studies:}

Author(s) Year

DOI

Adsorbent

Method

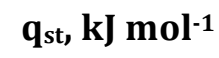

\section{Chahine}

1997 10.1021/la960843x

CNS-201
AS activated carbon

Gas adsorption

activated carbon
activated carbon

$1998 \underline{10.1021 / \text { la970119u }}$

KOH-activated anthracite-based

Lozano-

2002 10.1016/S0008-6223(02)00194-X

activated carbon

MOF5 and ZIF8

2007 10.1021/jp074889i

$2013 \quad 10.1021 / \mathrm{ja} 311415 \mathrm{~m}$

2013 10.1021/es4000643

2015 10.1021/acs.jpcc.5b05021

MOFs

microporous carbons

ZTC, MSC-30, CNS-201

ordered mesoporous carbon

soft templated ordered mesoporous carbon (sOMC)

ZTC, MSC-30, CNS-201

Gas adsorption

Gas adsorption

Gas adsorption

Gas adsorption

microporous carbons

Gas adsorption

Stadie

2018 10.1016/j.micromeso.2018.06.021

$\mathrm{N}$-doped nitrogen-doped crab shell-derived carbon nanofibers

Gas adsorption

14.35

$\sim 12.2$

$13.5 \ldots 19.5$

15.4

$\sim 14,15,19$

Theoretical Studies:

\section{Author(s) Year}

DOI

Adsorbent

Theory

GCMC, isosteric

GCMC, isosteric

GCMC, isosteric

$1993 \frac{10.1021 / \mathrm{j} 100104 \mathrm{a} 036}{10.1021 / \mathrm{a} 0523816}$ microporous carbon

porous carbon

carbon slit pore

carbon slit pore
carbon slit pore

GCMC, isosteric

coal-based activated carbon

hybrid reverse MC-derived amorphous microporous carbon

2009 10.1016/j.carbon.2009.06.037

Palmer

$201210.1021 /$ ct3008809

$\begin{array}{lll}\text { Smith } & 2012 & 10.1021 / \text { ct3008809 } \\ \text { Lui } & 2013 & 10.1016 / \text { j.apsusc.2013.08.035 }\end{array}$

Chen

2015 10.1109/LED.2015.2492580

polyaromatic hydrocarbons

open surface

graphene

$\operatorname{CCSD}(\mathrm{T})+\mathrm{MP} 2$

DFT (LDA CA-PZ)

DFT (LDA GGA)

buckybowls multilayer graphene open surface

DFT (M05-2X)

coronene open surface

buckybowls

open surface

Burrill $\quad 2020 \quad 10.1039 / D 0 C P 02645 I$

Denis $\quad 2008 \quad 10.1016 / j . c h e m p h y s .2008 .07 .024$

$\mathrm{N}$-doped nanotube segments

B-doped graphene

$\mathrm{N}$-doped graphene

$\mathrm{N}$-doped graphene

B-doped monolayer and multilayer graphene

$\mathrm{N}$-doped monolayer and multilayer graphene

B-doped graphene

DFT (M05-2X)

DFT $(\omega \mathrm{B} 97 \mathrm{M}-\mathrm{V} / \mathrm{pc}-2)$

$18.9 \ldots 20.7$

\section{Wang}

2015 10.1002/pssb.201451632

Chen

2015 10.1109/LED.2015.2492580

Hassani

2016 10.1016/j.comptc.2016.02.019

$\mathrm{N}$-doped graphene curved surface

open surface

open surface

open surface

open surface

open surface

open surface

open surface

\section{DFT (LDA)}

DFT (LDA CA-PZ)

DFT (LDA CA-PZ)

DFT (PBE)

DFT (LDA GGA)

DFT (LDA GGA)

DFT D3

DFT D3
$\Delta_{\text {des }} \mathrm{E}, \mathbf{k J} \mathbf{~ m o l}^{-1}$

$\sim 12^{\text {a }}$

$\sim 12^{\mathrm{a}}$

16

$\sim 19$ a

$\sim 14 \ldots \sim 20$

$9.8 \ldots 14.9$

43.4

$4.6 \ldots 20.3$

$4.6 \ldots 20.3$

$7.23 \ldots 23.3$

$10.3 \ldots 31.0$

$6.2 \ldots 14.8$

$2.9 \ldots 17.3$

$10.6 \ldots 206.5$

49.2

41.5

$7.5 \ldots 17.5$

$5.4 \ldots 13.4$ 
Table S2. Graphical illustration and Z-matrix definitions for $\kappa^{1}, \mu_{2}, \mu_{3}$, and $\eta^{2}$ approaches of $\mathrm{CH}_{4}$ to the X1 position of MPh and its heteroatom substituted variants.

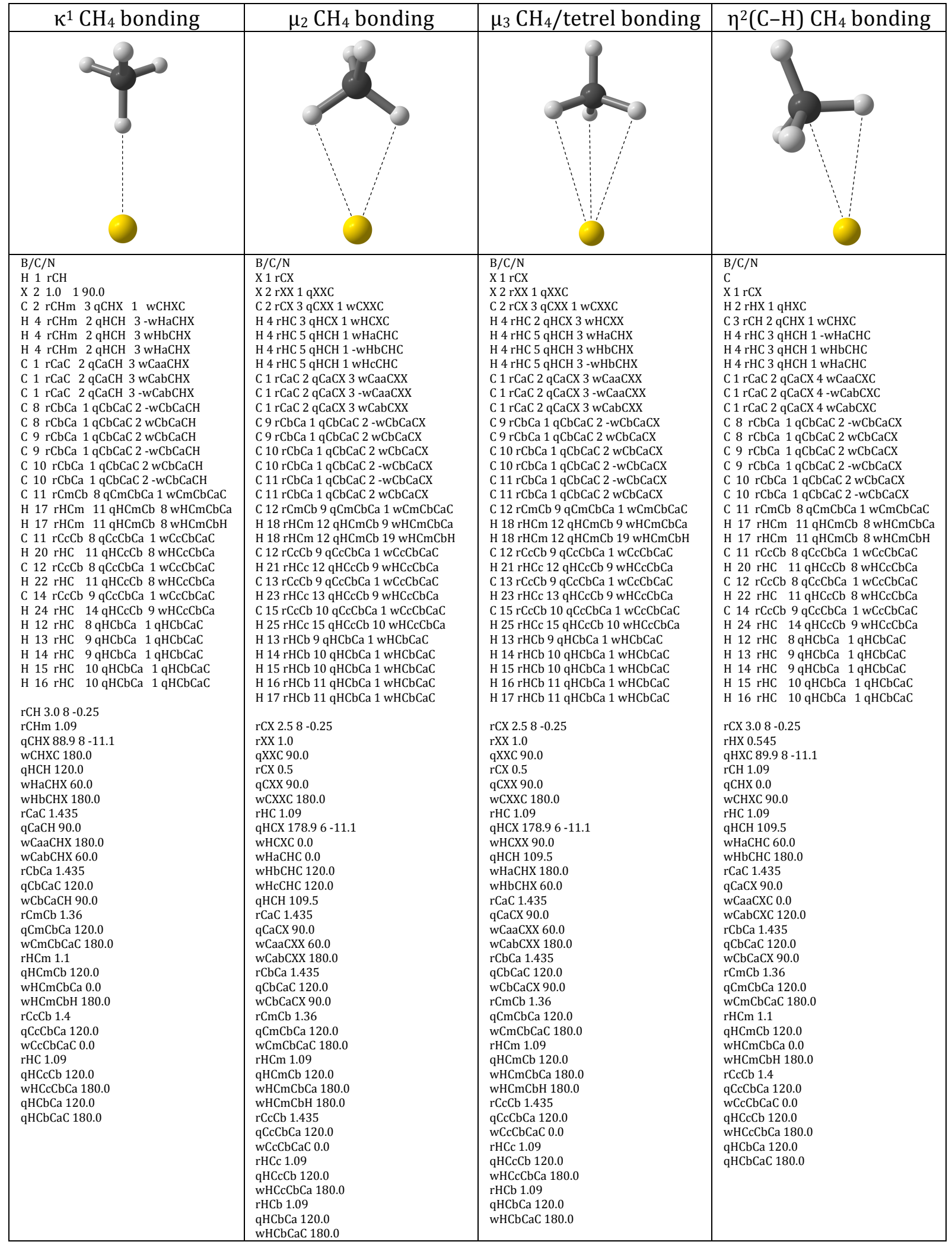


Table S3. Free adsorbent structures (LoT: MN15 using the ST0-3G \{MN15\}, SDDAll [MN15], 6-31G* (MN15-), or def2-QZVPP (MN15+) basis sets) of MPh, B-MPh, and N-MPh as described by averages and standard deviations of inner, outer, and peripheral sphere $\mathrm{C}-\mathrm{C}$ distances in $\AA$, out-of-planarity $(\delta$, in $\AA$ ) of the site of substitution, and wagging angle $(w$, in degrees) of the methylidene group (see Table S4 for the geometry upon methane adsorption).

\begin{tabular}{|c|c|c|c|c|c|c|}
\hline Adsorbent & LoT & Inner, $\AA$ & Outer, ̊̊ & Peripheral, $\AA$ & $\delta, \AA$ & $w,^{\circ}$ \\
\hline \multirow[t]{4}{*}{ MPh } & $\{$ MN15\} & $1.44 \pm 0.01$ & $1.43 \pm 0.05$ & $1.41 \pm 0.05$ & 0.00 & 177 \\
\hline & [MN15] & $1.43 \pm 0.00$ & $1.42 \pm 0.04$ & $1.40 \pm 0.04$ & 0.00 & 177 \\
\hline & MN15- & $1.43 \pm 0.00$ & $1.42 \pm 0.04$ & $1.40 \pm 0.04$ & 0.00 & 176 \\
\hline & MN15+ & $1.42 \pm 0.00$ & $1.41 \pm 0.04$ & $1.39 \pm 0.04$ & 0.00 & 176 \\
\hline \multirow[t]{4}{*}{ B-MPh } & $\{\mathrm{MN} 15\}$ & $1.52 \pm 0.01$ & $1.44 \pm 0.05$ & $1.42 \pm 0.05$ & 0.00 & 174 \\
\hline & [MN15] & $1.52 \pm 0.01$ & $1.42 \pm 0.04$ & $1.41 \pm 0.04$ & 0.00 & 173 \\
\hline & MN15- & $1.52 \pm 0.01$ & $1.42 \pm 0.04$ & $1.41 \pm 0.04$ & 0.00 & 172 \\
\hline & MN15+ & $1.51 \pm 0.01$ & $1.41 \pm 0.04$ & $1.41 \pm 0.04$ & 0.00 & 172 \\
\hline \multirow[t]{4}{*}{ N-MPh } & $\{\mathrm{MN} 15\}$ & $1.44 \pm 0.01$ & $1.44 \pm 0.05$ & $1.41 \pm 0.04$ & 0.00 & 179 \\
\hline & [MN15] & $1.41 \pm 0.01$ & $1.42 \pm 0.04$ & $1.39 \pm 0.03$ & 0.00 & 179 \\
\hline & MN15- & $1.41 \pm 0.01$ & $1.42 \pm 0.04$ & $1.39 \pm 0.03$ & 0.01 & 179 \\
\hline & MN15+ & $1.40 \pm 0.01$ & $1.41 \pm 0.04$ & $1.39 \pm 0.03$ & 0.00 & 179 \\
\hline
\end{tabular}


Table S4. Adsorbent structures upon adsorption (LoT: MN15, MP2, MP4SDQ, or CCSD using the 6$311++G^{* *}$ basis set, or MN15 using the STO-3G \{MN15\}, SDDAll [MN15], 6-31G* (MN15-), or def2QZVPP (MN15+) basis sets) of methane on MPh, B-MPh, and N-MPh, as described by averages and standard deviations of inner, outer, and peripheral sphere $\mathrm{C}-\mathrm{C}$ distances in $\AA$, out-of-planarity $(\delta$, in $\AA$ ) of the site of substitution, and wagging angle ( $w$, in degrees) of the methylidene group (see

Tables $\mathbf{1}$ and $\mathbf{S 3}$ for the free adsorbent structures).

\begin{tabular}{|c|c|c|c|c|c|c|c|}
\hline Adsorbent & LoT & $\mathbf{n}$ & Inner, Å & Outer, Å & Peripheral, Å & $\delta, \AA$ & $w,^{\circ}$ \\
\hline \multirow[t]{13}{*}{$\overline{\mathrm{MPh}}$} & $\{\mathrm{MN} 15\}$ & 1 & $1.44 \pm 0.01$ & $1.43 \pm 0.05$ & $1.41 \pm 0.05$ & 0.01 & 177 \\
\hline & [MN15] & 1 & $1.43 \pm 0.00$ & $1.42 \pm 0.04$ & $1.40 \pm 0.04$ & 0.03 & 176 \\
\hline & MN15- & 1 & $1.43 \pm 0.00$ & $1.42 \pm 0.04$ & $1.40 \pm 0.04$ & 0.03 & 175 \\
\hline & MN15 & 1 & $1.43 \pm 0.00$ & $1.42 \pm 0.04$ & $1.40 \pm 0.04$ & 0.03 & 175 \\
\hline & MN15+ & 1 & $1.42 \pm 0.00$ & $1.41 \pm 0.04$ & $1.39 \pm 0.04$ & 0.03 & 176 \\
\hline & MP2 & 1 & $1.54 \pm 0.00$ & $1.40 \pm 0.05$ & $1.41 \pm 0.05$ & 0.03 & 171 \\
\hline & MP4SDQ & 1 & $1.43 \pm 0.01$ & $1.42 \pm 0.04$ & $1.40 \pm 0.04$ & 0.05 & 173 \\
\hline & CCSD & 1 & $1.43 \pm 0.01$ & $1.42 \pm 0.04$ & $1.40 \pm 0.04$ & 0.04 & 173 \\
\hline & $\{\mathrm{MN} 15\}$ & 2 & $1.44 \pm 0.01$ & $1.43 \pm 0.05$ & $1.41 \pm 0.05$ & 0.00 & 177 \\
\hline & [MN15] & 2 & $1.43 \pm 0.00$ & $1.42 \pm 0.04$ & $1.40 \pm 0.04$ & 0.00 & 177 \\
\hline & MN15- & 2 & $1.43 \pm 0.00$ & $1.42 \pm 0.04$ & $1.40 \pm 0.04$ & 0.00 & 176 \\
\hline & MN15 & 2 & $1.43 \pm 0.00$ & $1.42 \pm 0.04$ & $1.39 \pm 0.04$ & 0.00 & 176 \\
\hline & MN15+ & 2 & $1.42 \pm 0.00$ & $1.41 \pm 0.04$ & $1.39 \pm 0.04$ & 0.00 & 176 \\
\hline \multirow[t]{13}{*}{ B-MPh } & $\{\mathrm{MN} 15\}$ & 1 & $1.52 \pm 0.01$ & $1.44 \pm 0.05$ & $1.43 \pm 0.05$ & 0.00 & 174 \\
\hline & [MN15] & 1 & $1.52 \pm 0.01$ & $1.42 \pm 0.04$ & $1.41 \pm 0.04$ & 0.02 & 173 \\
\hline & MN15- & 1 & $1.52 \pm 0.01$ & $1.42 \pm 0.04$ & $1.41 \pm 0.04$ & 0.04 & 172 \\
\hline & MN15 & 1 & $1.52 \pm 0.01$ & $1.42 \pm 0.04$ & $1.41 \pm 0.04$ & 0.04 & 172 \\
\hline & MN15+ & 1 & $1.52 \pm 0.01$ & $1.41 \pm 0.04$ & $1.41 \pm 0.04$ & 0.04 & 172 \\
\hline & MP2 & 1 & $1.54 \pm 0.00$ & $1.40 \pm 0.05$ & $1.41 \pm 0.05$ & 0.03 & 171 \\
\hline & MP4SDQ & 1 & $1.54 \pm 0.00$ & $1.41 \pm 0.04$ & $1.42 \pm 0.04$ & 0.02 & 173 \\
\hline & CCSD & 1 & $1.54 \pm 0.01$ & $1.42 \pm 0.05$ & $1.42 \pm 0.05$ & 0.04 & 171 \\
\hline & $\{\mathrm{MN} 15\}$ & 2 & $1.52 \pm 0.01$ & $1.43 \pm 0.05$ & $1.43 \pm 0.05$ & 0.00 & 174 \\
\hline & [MN15] & 2 & $1.52 \pm 0.01$ & $1.42 \pm 0.04$ & $1.41 \pm 0.04$ & 0.00 & 173 \\
\hline & MN15- & 2 & $1.52 \pm 0.01$ & $1.42 \pm 0.04$ & $1.41 \pm 0.04$ & 0.00 & 172 \\
\hline & MN15 & 2 & $1.52 \pm 0.01$ & $1.42 \pm 0.04$ & $1.41 \pm 0.04$ & 0.00 & 172 \\
\hline & MN15+ & 2 & $1.52 \pm 0.01$ & $1.41 \pm 0.04$ & $1.41 \pm 0.04$ & 0.00 & 172 \\
\hline \multirow[t]{13}{*}{$\mathrm{N}-\mathrm{MPh}$} & $\{\mathrm{MN} 15\}$ & 1 & $1.44 \pm 0.01$ & $1.44 \pm 0.05$ & $1.41 \pm 0.04$ & 0.01 & 179 \\
\hline & [MN15] & 1 & $1.41 \pm 0.01$ & $1.42 \pm 0.04$ & $1.39 \pm 0.03$ & 0.03 & 178 \\
\hline & MN15- & 1 & $1.41 \pm 0.01$ & $1.42 \pm 0.04$ & $1.39 \pm 0.03$ & 0.03 & 175 \\
\hline & MN15 & 1 & $1.41 \pm 0.01$ & $1.42 \pm 0.04$ & $1.39 \pm 0.03$ & 0.02 & 177 \\
\hline & MN15+ & 1 & $1.40 \pm 0.01$ & $1.41 \pm 0.04$ & $1.39 \pm 0.03$ & 0.02 & 178 \\
\hline & MP2 & 1 & $1.41 \pm 0.01$ & $1.41 \pm 0.01$ & $1.39 \pm 0.03$ & 0.01 & 175 \\
\hline & MP4SDQ & 1 & $1.41 \pm 0.01$ & $1.42 \pm 0.02$ & $1.39 \pm 0.03$ & 0.01 & 176 \\
\hline & CCSD & 1 & $1.42 \pm 0.01$ & $1.42 \pm 0.07$ & $1.41 \pm 0.05$ & 0.07 & 169 \\
\hline & $\{\mathrm{MN} 15\}$ & 2 & $1.44 \pm 0.0$ & $1.44 \pm 0.05$ & $1.41 \pm 0.04$ & 0.00 & 179 \\
\hline & [MN15] & 2 & $1.41 \pm 0.0$ & $1.42 \pm 0.04$ & $1.39 \pm 0.03$ & 0.00 & 179 \\
\hline & MN15- & 2 & $1.41 \pm 0.01$ & $1.42 \pm 0.04$ & $1.39 \pm 0.03$ & 0.00 & 179 \\
\hline & MN15 & 2 & $1.41 \pm 0.01$ & $1.42 \pm 0.04$ & $1.39 \pm 0.03$ & 0.00 & 179 \\
\hline & MN15+ & 2 & $1.40 \pm 0.01$ & $1.41 \pm 0.04$ & $1.39 \pm 0.03$ & 0.00 & 179 \\
\hline
\end{tabular}


Table S5. Adsorption model structures (LoT: MN15 using the STO-3G \{MN15\}, SDDAll [MN15], 631G* (MN15-), or def2-QZVPP (MN15+) basis sets) of methane on MPh, B-MPh, and N-MPh.

Adsorption by one $(\mathrm{n}=1)$ and two $(\mathrm{n}=2)$ methane molecules is described by interaction distances

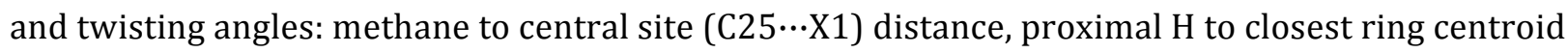
$\left(\mathrm{H}_{\mathrm{p}} \cdots \mathrm{X}_{\mathrm{i}}\right)$ distance, dihedral angle formed by $\mathrm{X}_{\mathrm{i}} \cdots \mathrm{X} 1 \cdots \mathrm{C} 25-\mathrm{H}_{\mathrm{p}}(\omega)$, and proximal and distal $\mathrm{C}-\mathrm{H}$ bond lengths.

\begin{tabular}{|c|c|c|c|c|c|c|c|}
\hline Adsorbent & LoT & $\mathbf{n}$ & $\mathrm{C} 25 \cdots \mathrm{X} 1, \AA$ & $H_{p} \cdots X_{i}, \AA$ & $\omega,^{\circ}$ & $\mathrm{C}-\mathrm{H}_{\mathrm{p}},{ }^{\mathrm{a}} \AA$ & $\mathrm{C}-\mathrm{H}_{\mathrm{d}},{ }^{\mathrm{a}} \AA$ \\
\hline \multirow{8}{*}{$\mathrm{MPh}$} & $\{\mathrm{MN} 15\}$ & 1 & 3.44 & $3.09 \pm 0.20$ & $2 \pm 1$ & $1.096 \pm 0.000$ & 1.096 \\
\hline & [MN15] & 1 & 3.29 & $2.92 \pm 0.03$ & $0 \pm 1$ & $1.091 \pm 0.000$ & 1.090 \\
\hline & MN15- & 1 & 3.28 & $2.90 \pm 0.04$ & $1 \pm 1$ & $1.094 \pm 0.000$ & 1.093 \\
\hline & MN15+ & 1 & 3.28 & $2.91 \pm 0.04$ & $0 \pm 0$ & $1.089 \pm 0.000$ & 1.087 \\
\hline & $\{\mathrm{MN} 15\}$ & 2 & $3.56 \pm 0.01$ & $3.23 \pm 0.38$ & $10 \pm 4$ & $1.096 \pm 0.000$ & $1.096 \pm 0.000$ \\
\hline & [MN15] & 2 & $3.29 \pm 0.00$ & $2.95 \pm 0.02$ & $1 \pm 0$ & $1.091 \pm 0.000$ & $1.090 \pm 0.000$ \\
\hline & MN15- & 2 & $3.27 \pm 0.00$ & $2.93 \pm 0.03$ & $1 \pm 1$ & $1.094 \pm 0.000$ & $1.093 \pm 0.000$ \\
\hline & MN15+ & 2 & $3.27 \pm 0.00$ & $2.93 \pm 0.03$ & $1 \pm 0$ & $1.089 \pm 0.000$ & $1.087 \pm 0.000$ \\
\hline \multirow{8}{*}{ B-MPh } & $\{\mathrm{MN} 15\}$ & 1 & 3.45 & $3.11 \pm 0.28$ & $2 \pm 1$ & $1.096 \pm 0.000$ & 1.096 \\
\hline & [MN15] & 1 & 3.28 & $2.91 \pm 0.04$ & $4 \pm 1$ & $1.091 \pm 0.000$ & 1.090 \\
\hline & MN15- & 1 & 3.29 & $2.91 \pm 0.05$ & $3 \pm 1$ & $1.094 \pm 0.000$ & 1.093 \\
\hline & MN15+ & 1 & 3.30 & $2.93 \pm 0.05$ & $5 \pm 1$ & $1.088 \pm 0.000$ & 1.087 \\
\hline & $\{\mathrm{MN} 15\}$ & 2 & $3.44 \pm 0.01$ & $3.10 \pm 0.23$ & $6 \pm 2$ & $1.096 \pm 0.000$ & $1.096 \pm 0.000$ \\
\hline & [MN15] & 2 & $3.26 \pm 0.00$ & $2.92 \pm 0.04$ & $4 \pm 1$ & $1.091 \pm 0.000$ & $1.090 \pm 0.000$ \\
\hline & MN15- & 2 & $3.27 \pm 0.00$ & $2.93 \pm 0.05$ & $2 \pm 1$ & $1.094 \pm 0.000$ & $1.093 \pm 0.000$ \\
\hline & MN15+ & 2 & $3.29 \pm 0.00$ & $2.95 \pm 0.04$ & $4 \pm 1$ & $1.088 \pm 0.000$ & $1.087 \pm 0.000$ \\
\hline \multirow[t]{8}{*}{$\mathrm{N}-\mathrm{MPh}$} & $\{\mathrm{MN} 15\}$ & 1 & 3.28 & $2.93 \pm 0.01$ & $0 \pm 0$ & $1.096 \pm 0.000$ & 1.096 \\
\hline & [MN15] & 1 & 3.17 & $2.82 \pm 0.01$ & $7 \pm 11$ & $1.091 \pm 0.000$ & 1.089 \\
\hline & MN15- & 1 & 3.17 & $2.80 \pm 0.01$ & $1 \pm 1$ & $1.095 \pm 0.000$ & 1.093 \\
\hline & MN15+ & 1 & 3.17 & $2.81 \pm 0.00$ & $1 \pm 1$ & $1.089 \pm 0.000$ & 1.087 \\
\hline & $\{\mathrm{MN} 15\}$ & 2 & $3.28 \pm 0.00$ & $2.94 \pm 0.01$ & $1 \pm 0$ & $1.096 \pm 0.000$ & $1.096 \pm 0.000$ \\
\hline & [MN15] & 2 & $3.17 \pm 0.00$ & $2.83 \pm 0.01$ & $1 \pm 1$ & $1.091 \pm 0.000$ & $1.089 \pm 0.000$ \\
\hline & MN15- & 2 & $3.16 \pm 0$ & $2.82 \pm 0.01$ & $1 \pm 1$ & $1.095 \pm 0.000$ & $1.093 \pm 0.000$ \\
\hline & MN15+ & 2 & $3.16 \pm 0.00$ & $2.82 \pm 0.01$ & $1 \pm 1$ & $1.089 \pm 0.000$ & $1.087 \pm 0.000$ \\
\hline
\end{tabular}

aThe C-H bond lengths in free methane are, at $\{$ MN15\}: $1.095 \AA$, [MN15]: $1.089 \AA$, MN15-: $1.092 \AA$; and MN15+: $1.086 \AA$. 
Table S6. Desorption energies $\left(\Delta_{\mathrm{des}}, \mathrm{kJ} \mathrm{mol}^{-1}\right)$ for $\mathrm{MPh} \times \mathrm{nCH}_{4} \rightarrow \mathrm{MPh}+\mathrm{nCH}_{4}$ (LoT: MN15 using the STO-3G \{MN15\}, SDDAll [MN15], 631G* (MN15-), or def2-QZVPP (MN15+) basis sets). CBS refers to the modified complete basis set extrapolation method employing the CBS-QB3 formalism, but utilizing the MN15/6-311++G** geometry. The standard enthalpy, Gibbs free energy, and entropy of desorption are calculated at $298 \mathrm{~K}$ using a simple statistical mechanical model assuming ideal gas behavior. A modest statistical analysis (average and standard deviation) of the thermochemical quantities is shown, normalized per mole of $\mathrm{CH}_{4}$.

\begin{tabular}{|c|c|c|c|c|c|c|c|c|c|c|}
\hline \multirow{2}{*}{ Adsorbent } & \multirow{2}{*}{$\mathbf{n}$} & \multicolumn{5}{|c|}{$\Delta_{\text {des }} \mathrm{U}^{\mathrm{QM}}\left(\mathrm{kJ} \mathrm{mol}^{-1}\right)$} & \multicolumn{4}{|c|}{ BSSE (kJ mol-1) } \\
\hline & & $\{$ MN15\} & [MN15] & MN15- & MN15+ & mCBS-QB3 & $\{$ MN15\} & [MN15] & MN15- & MN15+ \\
\hline$\overline{\mathrm{MPh}}$ & 1 & 3 & 16 & 13 & 14 & 9 & 2.5 & 2.8 & 3.7 & 0.3 \\
\hline B-MPh & 1 & 2 & 13 & 14 & 13 & 10 & 1.9 & 2.2 & 4.4 & 0.2 \\
\hline N-MPh & 1 & 3 & 17 & 16 & 16 & 12 & 2.3 & 2.6 & 3.9 & 0.3 \\
\hline $\mathrm{MPh}$ & 2 & 5 & 33 & 26 & 27 & 18 & 5.0 & 5.7 & 7.2 & 0.6 \\
\hline $\mathrm{B}-\mathrm{MPh}$ & 2 & 4 & 25 & 26 & 26 & 18 & 4.2 & 4.3 & 8.3 & 0.5 \\
\hline $\mathrm{N}-\mathrm{MPh}$ & 2 & 5 & 33 & 32 & 32 & 24 & 4.6 & 5.1 & 7.4 & 0.6 \\
\hline MPh & per $\mathrm{CH}_{4}$ & $2.5 \pm 0.0$ & $16.3 \pm 0.0$ & $13.0 \pm 0.2$ & $13.6 \pm 0.3$ & $8.9 \pm 0.1$ & & & & \\
\hline $\mathrm{B}-\mathrm{MPh}$ & per $\mathrm{CH}_{4}$ & $2.0 \pm 0.1$ & $12.8 \pm 0.3$ & $13.3 \pm 0.2$ & $13.2 \pm 0.3$ & $9.6 \pm 0.6$ & & & & \\
\hline $\mathrm{N}-\mathrm{MPh}$ & per $\mathrm{CH}_{4}$ & $2.7 \pm 0.0$ & $16.5 \pm 0.2$ & $16.2 \pm 0.4$ & $16.2 \pm 0.2$ & $12.2 \pm 0.0$ & & & & \\
\hline
\end{tabular}

\begin{tabular}{|c|c|c|c|c|c|c|c|c|c|c|c|}
\hline \multirow{2}{*}{ Adsorbent } & \multirow{2}{*}{$\mathbf{n}$} & \multicolumn{5}{|c|}{$\Delta_{\mathrm{des}} \mathrm{H}^{\circ}\left(\mathrm{kJ} \mathrm{\textrm {mol } ^ { - 1 } )}\right.$} & \multicolumn{5}{|c|}{$\Delta_{\mathrm{des}} \mathrm{G}^{\circ}\left(\mathrm{kJ} \mathrm{\textrm {mol } ^ { - 1 } )}\right.$} \\
\hline & & $\{$ MN15\} & [MN15] & MN15- & MN15+ & mCBS-QB3 & $\{$ MN15\} & [MN15] & MN15- & MN15+ & mCBS-QB3 \\
\hline$\overline{\mathrm{MPh}}$ & 1 & -3 & 11 & 8 & 9 & 7 & -28 & -23 & -28 & -26 & -19 \\
\hline $\mathrm{B}-\mathrm{MPh}$ & 1 & -3 & 8 & 9 & 9 & 9 & -31 & -27 & -26 & -25 & -19 \\
\hline $\mathrm{N}-\mathrm{MPh}$ & 1 & -3 & 12 & 9 & 11 & 9 & -40 & -26 & -23 & -25 & -12 \\
\hline $\mathrm{MPh}$ & 2 & -3 & 23 & 16 & 16 & 14 & -62 & -46 & -54 & -51 & -35 \\
\hline $\mathrm{B}-\mathrm{MPh}$ & 2 & -6 & 15 & 17 & 17 & 16 & -56 & -53 & -51 & -50 & -41 \\
\hline $\mathrm{N}-\mathrm{MPh}$ & 2 & -7 & 23 & 21 & 22 & 22 & -80 & -51 & -53 & -50 & -35 \\
\hline $\mathrm{MPh}$ & per $\mathrm{CH}_{4}$ & $-1.9 \pm 0.9$ & $11.5 \pm 0.0$ & $7.9 \pm 0.2$ & $8.7 \pm 0.3$ & $7.2 \pm 0.0$ & $-29.3 \pm 2.3$ & $-23.1 \pm 0.2$ & $-27.3 \pm 0.6$ & $-13.1 \pm 0.6$ & $-18.2 \pm 1.0$ \\
\hline B-MPh & per $\mathrm{CH}_{4}$ & $-3.2 \pm 0.2$ & $7.8 \pm 0.2$ & $8.4 \pm 0.2$ & $8.4 \pm 0.3$ & $8.4 \pm 0.6$ & $-29.8 \pm 2.2$ & $-26.8 \pm 0.4$ & $-26.0 \pm 0.4$ & $-12.6 \pm 0.3$ & $-19.9 \pm 1.2$ \\
\hline N-MPh & per $\mathrm{CH}_{4}$ & $-3.4 \pm 0.1$ & $11.4 \pm 0.2$ & $9.6 \pm 1.5$ & $11.2 \pm 0.2$ & $9.9 \pm 1.6$ & $-40.0 \pm 0.1$ & $-25.7 \pm 0.3$ & $-24.9 \pm 2.3$ & $-12.7 \pm 0.3$ & $-14.5 \pm 4.2$ \\
\hline
\end{tabular}


Table S7. Energy stabilization $(\Delta \Delta \mathrm{EQM})$ and desorption $\left(\rightarrow \mathrm{MPh}+\mathrm{CH}_{4}\right)$ energy differences (in kJ mol1) due to optimizing the $M N 16 / 6-311++\mathrm{G}^{* *}$ equilibrium structures of the adsorbent, adsorbate, and the adsorption model using a conceptually converging series of correlated MO theories (LoT: MP2, MP3, MP4, CCSD, or CCSD(T) using the $6-311++\mathrm{G}^{* *}$ basis set).

\begin{tabular}{lrrrrr}
\hline \multicolumn{1}{c}{$\Delta \Delta \mathbf{\Delta E \mathbf { Q M }}$} & MP2 & MP3 & MP4a & CCSD & CCSD(T) $^{\mathbf{b}}$ \\
\hline $\mathrm{MPh}$ & -10 & -5 & -10 & -6 & -9 \\
$\mathrm{~B}-\mathrm{MPh}$ & -10 & -8 & -9 & -7 & -7 \\
$\mathrm{~N}-\mathrm{MPh}$ & -13 & -9 & -15 & -11 & -10 \\
& & & & & \\
$\mathrm{CH}_{4}$ & $<.1$ & $<0.1$ & $<0.1$ & $<0.1$ & $<0.1$ \\
& & & & & \\
$\mathrm{MPh} \times \mathrm{CH}_{4}$ & -9 & -5 & -8 & -5 & -8 \\
$\mathrm{~B}-\mathrm{MPh} \times \mathrm{CH}_{4}$ & -9 & -8 & -9 & -7 & -6 \\
$\mathrm{~N}-\mathrm{MPh} \times \mathrm{CH}_{4}$ & -10 & -10 & -9 & -8 & -12 \\
& & & & & -1 \\
$\rightarrow \mathrm{MPh}+\mathrm{CH}_{4}$ & -1 & 0 & -2 & -1 & -1 \\
$\rightarrow \mathrm{B}-\mathrm{MPh}+\mathrm{CH}_{4}$ & -1 & 0 & 0 & 0 & +2 \\
$\rightarrow \mathrm{N}-\mathrm{MPh}+\mathrm{CH}_{4}$ & -3 & +2 & -6 & -3 &
\end{tabular}

aMP4 results are single-point energy calculations using the MP4SDQ geometry (i.e., MP4|MP4SDQ). ${ }^{b} \mathrm{CCSD}(\mathrm{T})$ results are single-point energy calculations using the CCSD geometry (i.e., CCSD(T)|CCSD) 
Table S8. Atomic charge (electron) distribution analysis upon single $(\mathrm{n}=1)$ and double $(\mathrm{n}=2)$ methane adsorption on $\mathrm{MPh}$, B-MPh, and N-MPh determined by three conceptually different population analysis methods: Hirshfeld (HPA), Weinhold (NPA), and Merz-Kollman (ESP) at the MN15/def2-QZVPP level of theory. See Figure 2 for a graphical plot and Figure $\mathbf{S 1}$ for the numbering of atom positions.

\begin{tabular}{|c|c|c|c|c|c|c|c|c|c|c|c|c|c|c|c|c|}
\hline \multirow[b]{2}{*}{$\mathbf{X}$} & \multirow{2}{*}{$\mathbf{n}$} & \multirow{2}{*}{ X1 } & \multicolumn{3}{|c|}{$\boldsymbol{\alpha}$} & \multicolumn{6}{|c|}{$\boldsymbol{\beta}$} & \multicolumn{3}{|c|}{$\gamma$} & \multirow{2}{*}{$\begin{array}{c}=\mathrm{CH}_{2} \\
\mathrm{C} 14\end{array}$} & \multirow{2}{*}{$\boldsymbol{\Sigma} \mathbf{H}$} \\
\hline & & & $\mathrm{C} 2$ & C3 & C4 & C5 & C6 & C7 & C8 & C9 & C10 & C11 & C12 & C13 & & \\
\hline \multicolumn{17}{|c|}{ Hirshfeld Population Analysis (HPA) } \\
\hline $\mathrm{C}$ & 1 & 0.01 & 0.00 & 0.00 & 0.00 & 0.00 & -0.03 & -0.03 & -0.04 & -0.04 & -0.04 & -0.04 & -0.04 & -0.04 & -0.08 & 0.39 \\
\hline B & 1 & 0.04 & -0.08 & -0.07 & -0.04 & 0.01 & 0.00 & -0.02 & 0.00 & -0.03 & -0.02 & 0.00 & -0.05 & -0.02 & -0.05 & 0.37 \\
\hline $\mathrm{N}$ & 1 & 0.04 & 0.07 & 0.06 & 0.04 & -0.02 & -0.07 & -0.05 & -0.08 & -0.05 & -0.07 & -0.05 & -0.02 & -0.04 & -0.11 & 0.39 \\
\hline $\mathrm{C}$ & 2 & 0.01 & 0.01 & 0.01 & 0.00 & 0.00 & -0.03 & -0.03 & -0.03 & -0.03 & -0.03 & -0.04 & -0.04 & -0.04 & -0.08 & 0.40 \\
\hline B & 2 & 0.05 & -0.08 & -0.07 & -0.04 & 0.01 & 0.00 & -0.02 & 0.00 & -0.03 & -0.02 & 0.00 & -0.05 & -0.02 & -0.05 & 0.38 \\
\hline $\mathrm{N}$ & 2 & 0.05 & 0.07 & 0.07 & 0.04 & -0.02 & -0.07 & -0.05 & -0.08 & -0.05 & -0.07 & -0.05 & -0.02 & -0.04 & -0.11 & 0.40 \\
\hline \multicolumn{17}{|c|}{ Weinhold Natural Population Analysis (NPA) } \\
\hline $\mathrm{C}$ & 1 & -0.03 & -0.04 & -0.06 & -0.06 & -0.08 & -0.18 & -0.18 & -0.18 & -0.19 & -0.18 & -0.18 & -0.21 & -0.21 & -0.34 & 2.12 \\
\hline B & 1 & 0.61 & -0.39 & -0.37 & -0.26 & -0.08 & -0.09 & -0.14 & -0.11 & -0.20 & -0.17 & -0.11 & -0.25 & -0.19 & -0.29 & 2.05 \\
\hline $\mathrm{N}$ & 1 & -0.33 & 0.23 & 0.20 & 0.13 & -0.13 & -0.29 & -0.25 & -0.30 & -0.23 & -0.26 & -0.20 & -0.15 & -0.20 & -0.41 & 2.17 \\
\hline $\mathrm{C}$ & 2 & -0.02 & -0.04 & -0.06 & -0.06 & -0.08 & -0.18 & -0.18 & -0.18 & -0.19 & -0.18 & -0.18 & -0.21 & -0.21 & -0.34 & 2.12 \\
\hline B & 2 & 0.67 & -0.41 & -0.39 & -0.28 & -0.08 & -0.10 & -0.15 & -0.12 & -0.21 & -0.18 & -0.11 & -0.25 & -0.18 & -0.29 & 2.06 \\
\hline $\mathrm{N}$ & 2 & -0.34 & 0.24 & 0.21 & 0.14 & -0.13 & -0.30 & -0.26 & -0.30 & -0.23 & -0.26 & -0.20 & -0.15 & -0.20 & -0.41 & 2.18 \\
\hline \multicolumn{17}{|c|}{ Merz-Kollman Electrostatic Potential Fit (ESP) } \\
\hline $\mathrm{C}$ & 1 & -0.02 & 0.04 & 0.28 & 0.17 & 0.20 & -0.19 & -0.29 & -0.35 & -0.26 & -0.23 & -0.19 & -0.08 & -0.03 & -0.51 & 1.48 \\
\hline B & 1 & 0.24 & -0.25 & -0.07 & 0.03 & 0.24 & 0.02 & -0.13 & -0.09 & -0.21 & -0.13 & -0.19 & -0.23 & -0.12 & -0.43 & 1.32 \\
\hline $\mathrm{N}$ & 1 & 0.25 & 0.06 & 0.16 & 0.15 & 0.15 & -0.29 & -0.31 & -0.32 & -0.30 & -0.33 & -0.15 & -0.01 & -0.07 & -0.60 & 1.62 \\
\hline $\mathrm{C}$ & 2 & 0.72 & -0.27 & 0.01 & -0.11 & 0.25 & -0.10 & -0.24 & -0.29 & -0.20 & -0.19 & -0.25 & -0.16 & -0.10 & -0.50 & 1.51 \\
\hline B & 2 & 0.96 & -0.49 & -0.27 & -0.13 & 0.23 & 0.05 & -0.12 & -0.11 & -0.22 & -0.18 & -0.18 & -0.28 & -0.14 & -0.41 & 1.39 \\
\hline $\mathrm{N}$ & 2 & 1.48 & -0.46 & -0.28 & -0.32 & 0.25 & -0.18 & -0.25 & -0.24 & -0.21 & -0.26 & -0.23 & -0.09 & -0.16 & -0.59 & 1.66 \\
\hline
\end{tabular}


Table S9. Atomic charge (electron) distribution analysis upon single $(\mathrm{n}=1)$ and double $(\mathrm{n}=2)$ methane adsorption on $\mathrm{MPh}$, B-MPh, and N-MPh determined by three conceptually different population analysis methods: Hirshfeld (HPA), Weinhold (NPA), and Merz-Kollman (ESP) at the MN15/def2-QZVPP level of theory. See Figure 2 for a graphical plot and Figure $\mathbf{S 1}$ for the numbering of atom positions (numbering of the second adsorbate is logical).

\begin{tabular}{|c|c|c|c|c|c|c|c|c|c|c|c|c|c|}
\hline $\mathbf{X}$ & $\mathbf{n}$ & C25 & & proximal & & distal & $\Sigma \mathrm{CH}_{4}$ & C30 & & proximal & & distal & $\Sigma \mathrm{CH}_{4}$ \\
\hline & & & H26 & & H28 & & & & H31 & & H33 & & \\
\hline \multicolumn{14}{|c|}{ Hirshfeld Population Analysis (HPA) } \\
\hline $\mathrm{C}$ & 1 & -0.13 & 0.02 & 0.02 & 0.02 & 0.03 & -0.04 & & & & & & \\
\hline B & 1 & -0.13 & 0.02 & 0.02 & 0.02 & 0.03 & -0.03 & & & & & & \\
\hline $\mathrm{N}$ & 1 & -0.13 & 0.02 & 0.02 & 0.02 & 0.03 & -0.04 & & & & & & \\
\hline $\mathrm{C}$ & 2 & -0.13 & 0.02 & 0.02 & 0.02 & 0.03 & -0.03 & -0.13 & 0.02 & 0.02 & 0.02 & 0.03 & -0.03 \\
\hline B & 2 & -0.13 & 0.02 & 0.03 & 0.02 & 0.03 & -0.03 & -0.13 & 0.02 & 0.03 & 0.02 & 0.03 & -0.03 \\
\hline $\mathrm{N}$ & 2 & -0.13 & 0.02 & 0.02 & 0.02 & 0.03 & -0.04 & -0.13 & 0.02 & 0.02 & 0.02 & 0.03 & -0.04 \\
\hline \multicolumn{14}{|c|}{ Weinhold Natural Population Analysis (NPA) } \\
\hline $\mathrm{C}$ & 1 & -0.84 & 0.21 & 0.21 & 0.21 & 0.21 & 0.00 & & & & & & \\
\hline $\mathrm{B}$ & 1 & -0.83 & 0.21 & 0.21 & 0.21 & 0.21 & 0.00 & & & & & & \\
\hline $\mathrm{N}$ & 1 & -0.84 & 0.21 & 0.21 & 0.21 & 0.21 & 0.00 & & & & & & \\
\hline $\mathrm{C}$ & 2 & -0.84 & 0.21 & 0.21 & 0.21 & 0.21 & 0.00 & -0.84 & 0.21 & 0.21 & 0.21 & 0.21 & 0.00 \\
\hline $\mathrm{B}$ & 2 & -0.83 & 0.21 & 0.21 & 0.21 & 0.21 & 0.00 & -0.83 & 0.21 & 0.21 & 0.21 & 0.21 & 0.00 \\
\hline $\mathrm{N}$ & 2 & -0.84 & 0.21 & 0.21 & 0.21 & 0.21 & 0.00 & -0.84 & 0.21 & 0.21 & 0.21 & 0.21 & 0.00 \\
\hline \multicolumn{14}{|c|}{ Merz-Kollman Electrostatic Potential Fit (ESP) } \\
\hline $\mathrm{C}$ & 1 & -0.48 & 0.12 & 0.12 & 0.12 & 0.11 & -0.01 & & & & & & \\
\hline B & 1 & -0.50 & 0.12 & 0.13 & 0.13 & 0.11 & 0.00 & & & & & & \\
\hline $\mathrm{N}$ & 1 & -0.50 & 0.13 & 0.12 & 0.12 & 0.12 & -0.01 & & & & & & \\
\hline $\mathrm{C}$ & 2 & -0.45 & 0.10 & 0.09 & 0.10 & 0.11 & -0.05 & -0.44 & 0.10 & 0.09 & 0.09 & 0.11 & -0.05 \\
\hline B & 2 & -0.46 & 0.09 & 0.10 & 0.10 & 0.12 & -0.05 & -0.46 & 0.09 & 0.10 & 0.10 & 0.12 & -0.05 \\
\hline $\mathrm{N}$ & 2 & -0.45 & 0.09 & 0.09 & 0.09 & 0.12 & -0.06 & -0.45 & 0.09 & 0.09 & 0.09 & 0.12 & -0.06 \\
\hline
\end{tabular}


Table S10. Atomic spin densities of the adsorbent molecule for single $(n=1)$ and double $(n=2)$ methane adsorption on B-MPh and NMPh from Hirshfeld population analysis (HPA) and Weinhold natural population analysis (NPA) at the MN15/def2-QZVPP level of theory. See Figure $\mathbf{S 1}$ for the numbering of atom positions.

\begin{tabular}{|c|c|c|c|c|c|c|c|c|c|c|c|c|c|c|c|c|}
\hline \multirow{2}{*}{$\mathbf{X}$} & \multirow{2}{*}{$\mathbf{n}$} & \multirow{2}{*}{ X1 } & \multicolumn{3}{|c|}{$\alpha$} & \multirow[b]{2}{*}{ C5 } & \multirow[b]{2}{*}{ C6 } & \multicolumn{2}{|c|}{$\boldsymbol{\beta}$} & \multirow[b]{2}{*}{ C9 } & \multirow[b]{2}{*}{ C10 } & \multirow[b]{2}{*}{ C11 } & \multirow{2}{*}{$\begin{array}{c}\gamma \\
\mathrm{C} 12 \\
\end{array}$} & \multirow[b]{2}{*}{ C13 } & \multirow{2}{*}{$\begin{array}{c}=\mathrm{CH}_{2} \\
\mathrm{C} 14\end{array}$} & \multirow{2}{*}{$\Sigma \mathbf{H}$} \\
\hline & & & $\mathrm{C} 2$ & C3 & $\mathrm{C} 4$ & & & C7 & C8 & & & & & & & \\
\hline \multicolumn{17}{|c|}{ Hirshfeld Population Analysis (HPA) } \\
\hline $\mathrm{B}$ & 1 & 0.10 & -0.01 & 0.05 & 0.18 & -0.02 & 0.08 & 0.03 & 0.06 & -0.02 & -0.03 & 0.21 & 0.01 & 0.14 & 0.17 & 0.05 \\
\hline $\mathrm{N}$ & 1 & 0.03 & 0.00 & 0.02 & 0.13 & -0.01 & 0.11 & 0.07 & 0.09 & 0.02 & 0.00 & 0.15 & -0.01 & 0.09 & 0.22 & 0.07 \\
\hline B & 2 & 0.11 & -0.01 & 0.05 & 0.18 & -0.02 & 0.07 & 0.03 & 0.05 & -0.03 & -0.03 & 0.21 & 0.02 & 0.15 & 0.16 & 0.04 \\
\hline $\mathrm{N}$ & 2 & 0.03 & 0.00 & 0.02 & 0.13 & -0.01 & 0.11 & 0.07 & 0.09 & 0.02 & 0.00 & 0.15 & -0.01 & 0.09 & 0.23 & 0.07 \\
\hline \multicolumn{17}{|c|}{ Weinhold Natural Population Analysis (NPA) } \\
\hline B & 1 & 0.11 & -0.04 & 0.04 & 0.26 & -0.08 & 0.11 & 0.04 & 0.06 & -0.08 & -0.10 & 0.30 & -0.01 & 0.19 & 0.23 & -0.03 \\
\hline $\mathrm{N}$ & 1 & 0.03 & -0.03 & 0.00 & 0.19 & -0.08 & 0.17 & 0.10 & 0.12 & -0.01 & -0.06 & 0.22 & -0.04 & 0.12 & 0.32 & -0.04 \\
\hline B & 2 & 0.11 & -0.03 & 0.06 & 0.26 & -0.08 & 0.10 & 0.03 & 0.04 & -0.09 & -0.10 & 0.30 & 0.01 & 0.21 & 0.22 & -0.03 \\
\hline $\mathrm{N}$ & 2 & 0.03 & -0.03 & 0.00 & 0.18 & -0.08 & 0.17 & 0.10 & 0.12 & -0.01 & -0.06 & 0.22 & -0.04 & 0.11 & 0.32 & -0.04 \\
\hline
\end{tabular}

Table S11. Atomic spin densities of the adsorbate molecule $(s)$ for single $(n=1)$ and double $(n=2)$ methane adsorption on B-MPh and NMPh from Hirshfeld population analysis (HPA) and Weinhold natural population analysis (NPA) at the MN15/def2-QZVPP level of theory. See Figure $\mathbf{S 1}$ for the numbering of atom positions (numbering of the second adsorbate is logical).

\begin{tabular}{|c|c|c|c|c|c|c|c|c|c|c|c|c|c|}
\hline \multirow{2}{*}{$\mathbf{X}$} & \multirow{2}{*}{$\mathbf{n}$} & \multirow{2}{*}{ C25 } & \multicolumn{3}{|c|}{ proximal } & \multirow{2}{*}{$\begin{array}{c}\text { distal } \\
\text { H29 }\end{array}$} & \multirow{2}{*}{$\Sigma \mathrm{CH}_{4}$} & \multirow{2}{*}{ C30 } & \multicolumn{3}{|c|}{ proximal } & \multirow{2}{*}{$\begin{array}{c}\text { distal } \\
\text { H34 }\end{array}$} & \multirow{2}{*}{$\Sigma \mathbf{C H}_{4}$} \\
\hline & & & H26 & H27 & H28 & & & & H31 & H32 & H33 & & \\
\hline \multicolumn{14}{|c|}{ Hirshfeld Population Analysis (HPA) } \\
\hline $\mathrm{B}$ & 1 & 0.003 & 0.001 & 0.001 & 0.002 & 0.001 & 0.007 & & & & & & \\
\hline $\mathrm{N}$ & 1 & 0.001 & 0.001 & 0.001 & 0.001 & 0.000 & 0.003 & & & & & & \\
\hline B & 2 & 0.004 & 0.001 & 0.001 & 0.002 & 0.001 & 0.008 & 0.004 & 0.001 & 0.001 & 0.002 & 0.001 & 0.008 \\
\hline $\mathrm{N}$ & 2 & 0.001 & 0.001 & 0.001 & 0.001 & 0.000 & 0.003 & 0.001 & 0.001 & 0.001 & 0.001 & 0.000 & 0.003 \\
\hline \multicolumn{14}{|c|}{ Weinhold Natural Population Analysis (NPA) } \\
\hline B & 1 & 0.001 & 0.000 & 0.000 & 0.000 & 0.001 & 0.002 & & & & & & \\
\hline $\mathrm{N}$ & 1 & 0.001 & 0.000 & 0.000 & 0.000 & 0.000 & 0.000 & & & & & & \\
\hline B & 2 & 0.001 & 0.000 & 0.000 & 0.000 & 0.001 & 0.002 & 0.001 & 0.000 & 0.0 & 0.000 & & 0.002 \\
\hline $\mathrm{N}$ & 2 & 0.000 & 0.000 & 0.000 & 0.000 & 0.000 & 0.000 & 0.001 & 0.000 & 0.000 & 0.000 & 0.000 & 0.000 \\
\hline
\end{tabular}


Table S12. Thermochemical quantities (in $\mathrm{kJ} \mathrm{mol}^{-1}$ ) for comparison to experimental measurements of physisorptive binding of methane on porous carbon surfaces at $298 \mathrm{~K}$. LoT: MN15/6-311++G**. $\mathrm{MPh} \times \mathrm{CH}_{4}$ corresponds to $5.6 \mathrm{mmol} \mathrm{g}^{-1}$ of absolute uptake and $\mathrm{MPh} \times 2 \mathrm{CH}_{4}$ corresponds to $11.2 \mathrm{mmol}$ $\mathrm{g}^{-1}$, where uptake is defined as the true or "absolute" quantity. At room temperature (298 K), this corresponds to the following equilibrium pressures for adsorption on ZTC: 9.5 and 26.8 bar (or 9.3 and $26.4 \mathrm{~atm})$, respectively. The enthalpy of desorption $(\Delta \mathrm{H})$ at these conditions is measured to be 13.5 and $13.1 \mathrm{~kJ} \mathrm{~mol}^{-1}$, respectively (Stadie et al., 2015 - Reference 49).

\begin{tabular}{|c|c|c|c|c|c|c|c|c|c|}
\hline System & $\begin{array}{c}\mathbf{P} \\
\text { atm }\end{array}$ & $\begin{array}{l}\Delta_{\text {des }} \mathrm{EQM}^{*} \\
\mathrm{~kJ} \mathrm{~mol}^{-1}\end{array}$ & $\begin{array}{l}\Delta_{\mathrm{des}} \mathrm{E}_{\mathrm{ZPE}} \\
\mathbf{k J} \mathrm{mol}^{-1}\end{array}$ & 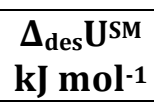 & $\begin{array}{c}\Delta_{\text {des }} \mathrm{Ua}^{\mathrm{a}} \\
\mathbf{k J} \mathrm{mol}^{-1}\end{array}$ & $\begin{array}{c}\Delta_{\text {des }} \mathrm{Ub}^{\mathrm{b}} \\
\mathbf{k J} \mathrm{mol}^{-1}\end{array}$ & $\begin{array}{c}\Delta_{\text {des }} \mathrm{Ha}^{\mathrm{a}} \\
\mathrm{kJ} \mathrm{mol}^{-1}\end{array}$ & $\begin{array}{c}\Delta_{\text {des }^{b}} \\
\text { kJ mol-1 }\end{array}$ & $\begin{array}{c}\Delta_{\text {desHc }} \\
\text { kJ mol-1 }\end{array}$ \\
\hline $\mathrm{MPh} \times \mathrm{CH}_{4}$ & 1 & 14.8 & -4.0 & -7.4 & 7.4 & 10.8 & 9.8 & 13.2 & 17.2 \\
\hline $\mathrm{B}-\mathrm{MPh} \times \mathrm{CH}_{4}$ & 1 & 13.9 & -3.5 & -7.2 & 6.6 & 10.4 & 9.1 & 12.9 & 16.4 \\
\hline $\mathrm{N}-\mathrm{MPh} \times \mathrm{CH}_{4}$ & 1 & 17.4 & -4.6 & -7.6 & 9.8 & 12.9 & 12.3 & 15.3 & 19.9 \\
\hline $\mathrm{MPh} \times \mathrm{CH}_{4}$ & 9.3 & 14.8 & -4.0 & -7.4 & 7.4 & 10.8 & 9.8 & 13.2 & 17.2 \\
\hline $\mathrm{B}-\mathrm{MPh} \times \mathrm{CH}_{4}$ & 9.3 & 13.9 & -3.5 & -7.2 & 6.6 & 10.4 & 9.1 & 12.9 & 16.4 \\
\hline $\mathrm{N}-\mathrm{MPh} \times \mathrm{CH}_{4}$ & 9.3 & 17.4 & -4.6 & -7.6 & 9.8 & 12.9 & 12.3 & 15.3 & 19.9 \\
\hline $\mathrm{MPh} \times 2 \mathrm{CH}_{4}$ & 26.4 & 14.1 & -4.1 & -7.6 & 6.6 & 10.1 & 9.1 & 12.5 & 16.6 \\
\hline $\mathrm{B}-\mathrm{MPh} \times 2 \mathrm{CH}_{4}$ & 26.4 & 13.4 & -3.5 & -7.3 & 6.1 & 9.9 & 8.6 & 12.4 & 15.9 \\
\hline $\mathrm{N}-\mathrm{MPh} \times 2 \mathrm{CH}_{4}$ & 26.4 & 17.0 & -4.4 & -7.6 & 9.4 & 12.6 & 11.9 & 15.1 & 19.5 \\
\hline
\end{tabular}

a defined as $\Delta \mathrm{U}^{\mathrm{a}}=\Delta \mathrm{EQM}^{*}+\Delta \mathrm{U}^{\mathrm{SM}}$ and $\Delta \mathrm{H}^{\mathrm{a}}=\Delta \mathrm{EQM}^{*}+\Delta \mathrm{U}^{S M}+\mathrm{RT}$ referred to as $\Delta \mathrm{U}^{\circ}$ and $\Delta \mathrm{H}^{\circ}$ at $\mathrm{P}=1$ atm; b defined as $\Delta \mathrm{U}^{\mathrm{b}}=\Delta \mathrm{EQM}^{*}+\Delta \mathrm{E}_{\mathrm{ZPE}}$ and $\Delta \mathrm{H}^{\mathrm{b}}=\Delta \mathrm{E}^{\mathrm{QM}}+\Delta \mathrm{E}_{\mathrm{ZPE}}+\Delta \mathrm{PV}$; defined as $\Delta \mathrm{H}^{\mathrm{c}}=\Delta \mathrm{E}^{\mathrm{QM}} * \Delta \mathrm{PV}$

Table S13. Thermochemical quantities (in $\mathrm{kJ} \mathrm{mol}^{-1}$ ) for comparison to experimental measurements of physisorptive binding of methane on porous carbon surfaces at $298 \mathrm{~K}$. LoT: MN15/def2-QZVPP. $\mathrm{MPh} \times \mathrm{CH}_{4}$ corresponds to $5.6 \mathrm{mmol} \mathrm{g}^{-1}$ of absolute uptake and $\mathrm{MPh} \times 2 \mathrm{CH}_{4}$ corresponds to $11.2 \mathrm{mmol}$ $\mathrm{g}^{-1}$, where uptake is defined as the true or "absolute" quantity. At room temperature $(298 \mathrm{~K})$, this corresponds to the following equilibrium pressures for adsorption on ZTC: 9.5 and 26.8 bar (or 9.3 and $26.4 \mathrm{~atm})$, respectively. The enthalpy of desorption $\left(\Delta_{\mathrm{des}} \mathrm{H}\right)$ at these conditions is measured to be 13.5 and $13.1 \mathrm{~kJ} \mathrm{~mol}^{-1}$, respectively (Stadie et al., 2015 - Reference 49).

\begin{tabular}{|c|c|c|c|c|c|c|c|c|c|}
\hline System & $\begin{array}{c}\mathbf{P} \\
\text { atm }\end{array}$ & $\begin{array}{l}\Delta_{\text {des }} \mathrm{E}^{\mathrm{QM} *} \\
\mathrm{~kJ} \mathrm{~mol}^{-1}\end{array}$ & $\begin{array}{l}\Delta_{\text {des }} E_{\mathrm{ZPE}} \\
\mathrm{kJ} \mathrm{mol}^{-1}\end{array}$ & $\begin{array}{c}\Delta_{\text {des }} \mathrm{USM}^{\mathrm{SM}} \\
\mathrm{kJ} \mathrm{mol}^{-1}\end{array}$ & $\begin{array}{c}\Delta_{\text {des }} \mathbf{U}^{\mathbf{a}} \\
\mathbf{k J ~ m o l}^{-1}\end{array}$ & $\begin{array}{c}\Delta_{\text {des }} \mathbf{U}^{\mathrm{b}} \\
\mathbf{k J ~ m o l}^{-1}\end{array}$ & $\begin{array}{c}\Delta_{\text {des }} \mathrm{H}^{\mathbf{a}} \\
\mathrm{kJ} \mathrm{mol}^{-1}\end{array}$ & $\begin{array}{c}\Delta_{\text {des }} \mathbf{H}^{\mathbf{b}} \\
\mathrm{kJ} \mathrm{mol}^{-1}\end{array}$ & $\begin{array}{c}\Delta_{\text {des }} \mathrm{H}^{\mathrm{c}} \\
\mathrm{kJ} \mathrm{mol}^{-1}\end{array}$ \\
\hline $\mathrm{MPh} \times \mathrm{CH}_{4}$ & 1 & 13.6 & -3.8 & -7.4 & 6.1 & 9.8 & 8.6 & 12.2 & 16.0 \\
\hline $\mathrm{B}-\mathrm{MPh} \times \mathrm{CH}_{4}$ & 1 & 13.1 & -3.4 & -7.3 & 5.8 & 9.7 & 8.3 & 12.2 & 15.6 \\
\hline $\mathrm{N}-\mathrm{MPh} \times \mathrm{CH}_{4}$ & 1 & 16.1 & -4.2 & -7.5 & 8.6 & 11.9 & 11.0 & 14.4 & 18.6 \\
\hline $\mathrm{MPh} \times \mathrm{CH}_{4}$ & 9.3 & 13.6 & -3.8 & -7.4 & 6.1 & 9.8 & 8.6 & 12.2 & 16.0 \\
\hline $\mathrm{B}-\mathrm{MPh} \times \mathrm{CH}_{4}$ & 9.3 & 13.1 & -3.4 & -7.3 & 5.8 & 9.7 & 8.3 & 12.2 & 15.6 \\
\hline $\mathrm{N}-\mathrm{MPh} \times \mathrm{CH}_{4}$ & 9.3 & 16.1 & -4.2 & -7.5 & 8.6 & 11.9 & 11.0 & 14.4 & 18.6 \\
\hline $\mathrm{MPh} \times 2 \mathrm{CH}_{4}$ & 26.4 & 13.1 & -3.6 & -7.4 & 5.7 & 9.5 & 8.2 & 12.0 & 15.6 \\
\hline $\mathrm{B}-\mathrm{MPh} \times 2 \mathrm{CH}_{4}$ & 26.4 & 12.8 & -3.3 & -7.3 & 5.5 & 9.5 & 8.0 & 12.0 & 15.2 \\
\hline $\mathrm{N}-\mathrm{MPh} \times 2 \mathrm{CH}_{4}$ & 26.4 & 15.8 & -4.1 & -7.5 & 8.3 & 11.7 & 10.8 & 14.2 & 18.3 \\
\hline
\end{tabular}

a defined as $\Delta \mathrm{U}^{\mathrm{a}}=\Delta \mathrm{E}^{\mathrm{QM}^{*}}+\Delta \mathrm{U}^{\mathrm{SM}}$ and $\Delta \mathrm{H}^{\mathrm{a}}=\Delta \mathrm{E}^{*} \mathrm{M}^{*}+\Delta \mathrm{U}^{S M}+\mathrm{RT}$ referred to as $\Delta \mathrm{U}^{\circ}$ and $\Delta \mathrm{H}^{\circ}$ at $\mathrm{P}=1$

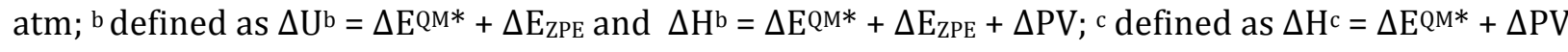

